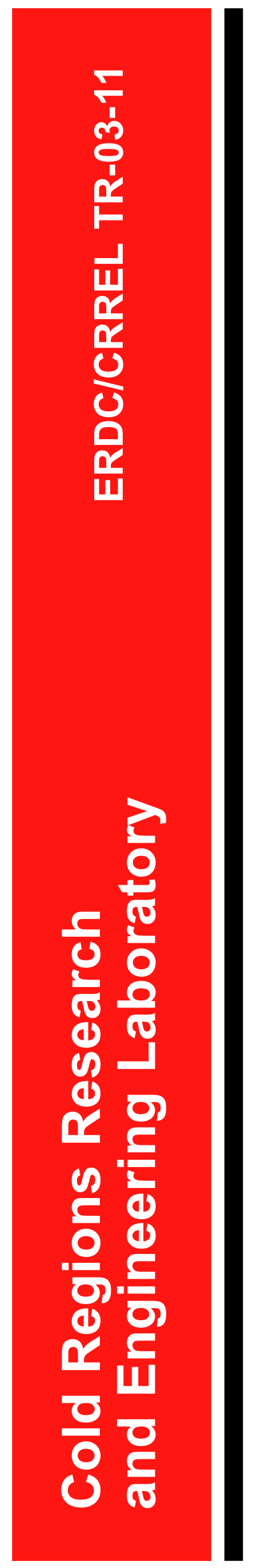

\title{
Remote Assessment of Army Tactical River Crossing Sites Using LIDAR Imagery
}

Barry A. Coutermarsh

July 2003 
ERDC/CRREL TR-03-11

July 2003

\section{Remote Assessment of Army Tactictal River Crossing Sites Using LIDAR Imagery}

Barry A. Coutermarsh

Cold Regions Research and Engineering Laboratory

72 Lyme Road

Hanover, New Hampshire 03755

Approved for public release; distribution is unlimited. 


\section{ABSTRACT}

Tactical river crossings present impediments to Army units on the move because they require specialized procedures and equipment as well as more detailed planning and control than normal operations. A crossing site's suitability is highly dependant on riverbank geography. Commanders with accurate riverbank data can increase the speed of crossing operations, both by quickly and accurately determining appropriate sites and by minimizing the amount and type of equipment carried forward to effect the crossings. A previous study examined how conventional terrain analysis would be used to determine suitable crossing sites. In that study, there was a $16 \%$ acceptable site selection rate for remotely determined crossing sites. The most common problem, which was not detectable using conventional techniques, was that bank slope was too steep for vehicles to traverse. This study looks at using a Light Distance and Ranging (LIDAR) digital elevation model (DEM) to improve acceptable site selection rate. LIDAR data were collected at the sites identified in the previous study and inspected to see if the DEM would provide the information and resolution necessary to improve crossing site identification. The DEM was compared to selected onsite surveys and visual information collected previously to identify discrepancies. The LIDAR DEM analysis looked at 18 potential sites and resulted in an $88 \%$ acceptable site selection rate.

DISCLAIMER: The contents of this report are not to be used for advertising, publication, or promotional purposes. Citation of trade names does not constitute an official endorsement or approval of the use of such commercial products. All product names and trademarks cited are the property of their respective owners. The findings of this report are not to be construed as an official Department of the Army position unless so designated by other authorized documents. 


\section{CONTENTS}

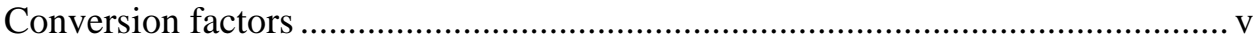

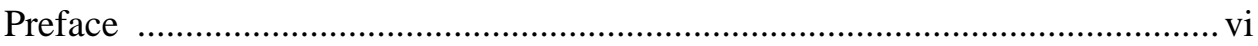

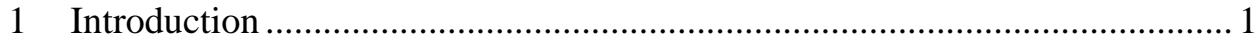

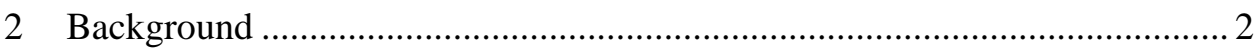

General bridging/fording site assessment requirements.............................. 2

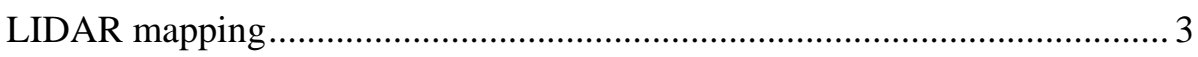

Data post processing................................................................................ 4

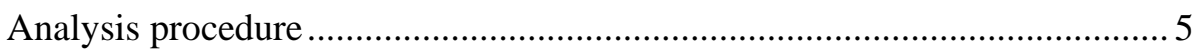

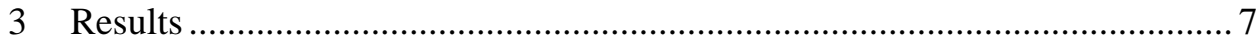

Crossing site examples ......................................................................... 7

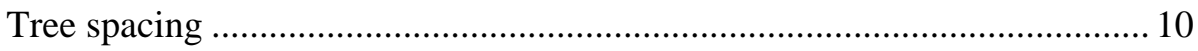

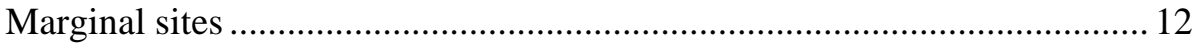

Vegetation height errors ...................................................................... 14

Road/trail recognition........................................................................ 17

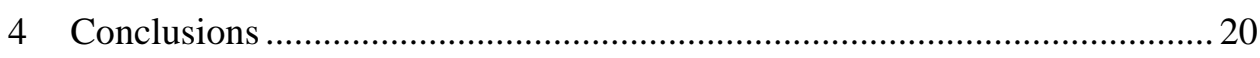

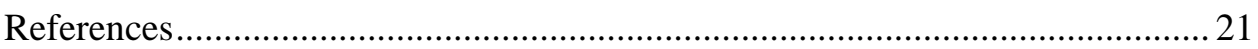

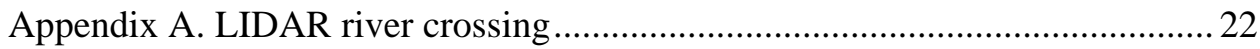

\section{ILLUSTRATIONS}

Figure 1. Example of a data scan line with a nutating mirror LIDAR ................. 3

Figure 2. Site 1 LIDAR DEM looking north .................................................. 8

Figure 3. Ground survey and LIDAR DEM comparison, Transect 1 .................. 9

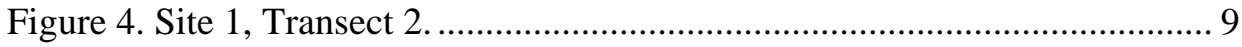

Figure 5. Site 1, Transect 3......................................................................... 10

Figure 6. LIDAR DEM of Site 3 looking at brush and trees on the west bank. 11

Figure 7. Site 2 LIDAR DEM looking north................................................ 12

Figure 8. Ground survey and LIDAR DEM comparison, Site 2...................... 12

Figure 9. Site 2 bank slopes taken from the LIDAR data................................ 13

Figure 10. Site 20 LIDAR DEM looking south............................................... 14

Figure 11. Site 20 LIDAR and ground survey comparison profile from west

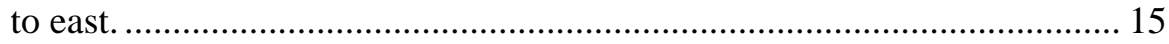


Figure 12. Site 9 LIDAR DEM looking north. .............................................. 16

Figure 13. Profile of west bank....................................................................... 16

Figure 14. Site 4 east bank comparing ALSM data with approximated

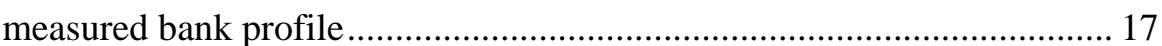

Figure 15. Site 5 east bank DEM showing road leading into the river .............. 18

Figure 16. Cross section of road at Site 5..................................................... 18

Figure 17. Trails and cleared areas in trees adjacent to Site 16....................... 19 


\section{CONVERSION FACTORS, NON-SI TO SI UNITS OF MEASUREMENT}

Non-SI units of measurement used in this report can be converted to SI units as follows:

\begin{tabular}{|l|l|l|}
\hline Multiply & By & To obtain \\
\hline degrees (angle) & 0.01745329 & radians \\
\hline feet & 0.3048 & meters \\
\hline inches & 0.0254 & meters \\
\hline
\end{tabular}




\section{PREFACE}

This report was prepared by Barry A. Coutermarsh, Research Engineer, Applied and Military Research Branch, U.S. Army Engineer Research and Development Center, Cold Regions Research and Engineering Laboratory (CRREL), Hanover, New Hampshire.

The Light Detection and Ranging (LIDAR) data analysis described here was performed under DA Project 4A762784AT42.

The Commander and Executive Director of the Engineer Research and Development Center is Colonel James R. Rowan, EN. The Director is Dr. James R. Houston. 


\title{
Remote Assessment of Army Tactical River Crossing Sites Using LIDAR Imagery
}

\author{
BARRY A. COUTERMARSH
}

\section{INTRODUCTION}

The U.S. Army's emerging doctrine of fast, highly mobile units places an emphasis on unrestricted travel over the modern battlefield. The successful application of this concept will require commanders to have accurate and detailed information about the terrain they have to move over. A linear feature, such as a river, can be a significant obstacle to movement in both time and distance. It can force units to detour to suitable crossing sites and then return to their original line of march, thereby losing time with both the detour and crossing. The crossing operation itself requires specialized equipment and places exaggerated constraints on vehicle mobility, most notably as a result of bank slope and traction loss in potentially wet soils.

In order for terrain information to be valuable for unrestricted maneuver, it should be of a resolution sufficient to the mobility requirements at hand. For example, terrain data of a general nature, such as the information that can be derived from a 20-foot contour interval map, might be adequate for most of the non-constrained maneuvering likely to be encountered by units traveling crosscountry. These maps show existing road networks, general slope, and vegetative conditions. Units can frequently bypass relatively small obstacles and impassable areas. However, a linear feature obstruction, by its very nature, prevents an easy bypass. In this case, travel must be constrained to areas of the obstacle that have a geometry that will allow passage by the least capable vehicle in the unit.

This study was performed to determine whether a Light Detection and Ranging (LIDAR) imagery Digital Elevation Model (DEM) could provide the riverbank geometry at a resolution adequate to make vehicle mobility go/no-go decisions. 


\section{BACKGROUND}

The conventional techniques described in TR-03-8 (Coutermarsh and Dwinal 2003) can identify potential sites relative to the availability of staging areas, road networks, travel lanes, and general topography and vegetation. As TR-03-8 pointed out, these techniques do a good job as far as finding potential features that can be identified in a two-dimensional plane, e.g., an open space adequate to hold a certain number of vehicles for use as a crossing staging area. The most prevalent problem with the potential crossing sites in that study was riverbank slope, which created the necessity for determining the third dimension of height. On-site reconnaissance is now required to characterize specific terrain and vegetation near a river where a greater spatial resolution is necessary to determine vehicle mobility possibilities.

The study described in TR-03-8 found that after an on-site inspection only about $16 \%$ of the potential crossing sites were acceptable, meaning that $84 \%$ of the time that a potential site is identified, on-site reconnaissance would find it unacceptable. A reconnaissance is both dangerous and time-consuming and hinders a unit's rapid movement. If there was a remote technique that could determine terrain characteristics at a resolution sufficient for mobility determinations, then river crossing site selections, and thus the entire crossing operation, would be safer and quicker. We investigated the use of LIDAR as a tool to accomplish this mapping.

\section{General bridging/fording site assessment requirements}

A unit's general vehicle mobility concerns could be characterized as slope, vegetation, ground bearing capacity, surface conditions, road and trail presence, and significant linear feature obstacles. It is not necessary for the terrain data resolution to be at the individual vehicle mobility constraint level because units are not necessarily restricted to a tight one-vehicle-wide corridor, and there is room to maneuver around many obstacles that might be encountered. When units encounter a significant linear feature (such as a river) across their intended route, the terrain resolution requirements at that feature increase to the individual vehicle mobility constraints. This is because movement is now restricted to specific river crossing sites that are suitable for a bridge or where water depth will allow fording and vehicles are not free to maneuver at will.

In our previous study, we used the vehicle mobility constraints for a HighMobility Multipurpose Wheeled Vehicle (HMMWV) and an M 2/3 Infantry Fighting Vehicle to assess the suitability of the selected crossing sites. We found 
that bank slope and/or height were the most often encountered problems at the crossing sites selected, which for our study were a $60 \%\left(27^{\circ}\right)$ slope and a vertical step capability of $0.56 \mathrm{~m}$ (1.83 ft). These constraints defined our minimum terrain resolution requirements to be able to remotely determine suitable crossing sites.

\section{LIDAR mapping}

The University of Florida's (UFL) Geosensing Division performed the LIDAR mapping in this study, which they call Airborne Laser Swath Mapping (ALSM). ALSM as defined by UFL is the technique of using a scanning laser ranging unit to collect $\mathrm{x}, \mathrm{y}$, and $\mathrm{z}$ coordinates of the earth's topography. The technique is also called Laser Detection and Ranging (LADAR). Although it is not the intent of this report to explain the theory of LIDAR, a brief background of the UFL system is helpful in understanding the spacing and grouping of the collected terrain data points and how that can affect the collection strategy and post-processing visualization of the data.

The UFL system is flown in a small fixed-wing aircraft between about 1000 and 6500 feet above ground level (AGL) with the laser light projected to the ground through a mirror that nutates perpendicular to the track of the aircraft. This results in a sawtooth point collection pattern as shown in Figure 1.

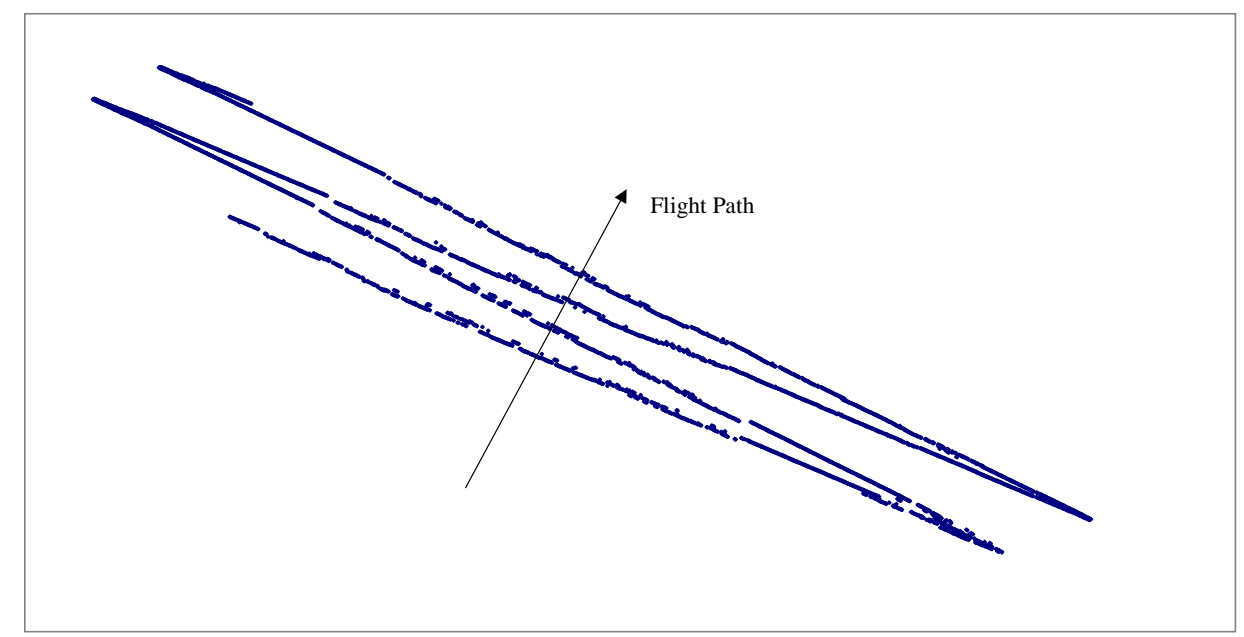

Figure 1. Example of a data scan line with a nutating mirror LIDAR. Each line consists of individual laser points that have an $x, y$, and $z$ coordinate, as well as a light intensity value. 
The size of the point striking the ground is determined by the laser characteristics and flight elevation. The distance between data points along and between the scan lines depends upon the pulse repetition rate of the laser, and the plane's forward speed and elevation above the ground. The laser used in this study had a 33-kHz scan rate, a 0.30-mrad beam divergence, 1047-nm wavelength, automatic roll compensation, first and last returns for each pulse, and intensity for each pulse. It had a variable scan angle from 0 to 0.68 of the altitude.

The laser's position in space is known at every instant using a kinematic Global Positioning System (GPS) and thus every point's location can be referenced to a known datum of the user's choosing. The point spacing is relatively dense in the axis of the mirror nutation but the forward motion of the plane causes gaps between the scan lines as the mirror traverses from one end of its travel to the other. As Figure 1 shows, the sawtooth pattern can affect how data should be collected to capture certain features.

For example, in our work we found several river sections that had very steep, nearly vertical banks. If the nutation axis is parallel to a steep riverbank, as it would be if the plane's flight path were perpendicular to the river, it is more likely the vertical surface could fall in the gaps of the sawtooth pattern shown in Figure 1. The data would then miss a break in the slope of the terrain and subsequent data interpolation between the LIDAR points would smooth the terrain and show it as a sloped surface rather than vertical. The magnitude of the error would depend upon where the terrain break was located in the pattern, the point spacing, and the interpolation algorithm. Several passes orthogonal to each other may be desirable to achieve dense, evenly distributed, point spacing where achieving a high terrain resolution is necessary.

\section{Data post processing}

The output files from the LIDAR data consisted of nine columns of data as follows: 1) The time in GPS seconds of the week, 2) easting of the first return, 3) northing of the first return, 4) ellipsoid height of the first return, 5) easting of the second return, 6) northing of the second return, 7) ellipsoid height of the second return, 8) intensity of the first return, and 9) intensity of the second return. The Vertical Datum for the ellipsoid heights was GRS80 and all units were in meters.

We used the commercial data visualization software, TECPLOT, to visualize the LIDAR data. This software is not designed specifically for LIDAR data but it has good capabilities for handling these types of data. Specifically it is not limited in the number of data points it can accept; it provides algorithms to convert point data into 2-D contour plots and 3-D elevation plots (DEMs), and the DEM can be colored according to elevation. The data can be rotated to look 
at the terrain from any angle and portions of interest can be magnified. Elevations and locations can be determined at any point in the image with the cursor. Vertical cross sections can be produced from sections of the elevation plots to determine slope and to compare with on-site surveyed slopes.

We did no sophisticated filtering or analysis of the LIDAR returns and there are advanced techniques that apparently can extract more information from the LIDAR than what we did. For example, it is possible to define the ground surface beneath a tall grass cover, as long as the vegetation is thin enough that some of the LIDAR points can penetrate to the ground. Some of this information is contained in the second return of the pulse. For example, if a pulse has two returns, it is sometimes assumed the second return is the ground surface. By looking at enough returns in any specific area the accuracy of this assumption can frequently be determined. This technique may prove useful where tall grass along the riverbanks makes the riverbanks appear higher than they are. The same technique can be used to map the ground surface beneath a tree canopy, thereby proving useful in some of our areas where trees lined the river and there was a question as to the amount of space between trunks for vehicles to move through. Our data also included light intensity values that we did not use in this study and which can be used to infer material properties. This technique might be able to discern marsh areas versus solid ground.

\section{Analysis procedure}

There are two fundamental questions when using LIDAR data for tactical river crossing assessment: 1) Can the technique accurately model the ground surface with the necessary resolution for vehicle movement? 2) Does it provide the type of information necessary for this application even if it has the necessary resolution? To answer these questions we had LIDAR DEMs made of 18 of the potential river crossing sites identified in TR-03-8 (Coutermarsh and Dwinal 2003). At 12 of these sites, we performed a conventional transit and tape ground survey to compare to the LIDAR results to help determine the resolution accuracy. At each crossing site we used the DEM to develop riverbank profiles at several locations, determined the slope from these profiles, and compared it with our photographs and ground survey of the site. If the slope was under our $27^{\circ}$ maximum and the vegetation looked widely spaced or small enough to allow our baseline vehicles to pass, then the site was considered acceptable. The selections were compared with our earlier work from TR-03-8 to determine if in fact the site was useable or not and why. We looked at the height and spacing of vegetation in the DEM to infer the possibility of vehicles passing between or through it. The DEMs were colored according to elevation to make the interpretation easier. 
At selected sites a ground survey was performed using a conventional transit and tape method. Transect reference points were established using a Wide Area Augmentation System (WAAS) GPS system. These points were used to locate the ground survey transect in the LIDAR DEM. The WAAS system is not as accurate as a DGPS system or as accurate as the kinematic GPS used in the survey, so there is some error in the horizontal positioning of our survey transects. If this appeared to be a problem the transect was adjusted where a known reference feature such as the water surface was available. 


\section{$3 \quad$ RESULTS}

After using the LIDAR imagery, four of the 18 sites were considered acceptable, with three listed as marginal and 11 rejected. All the sites considered acceptable by the LIDAR imagery were classified as acceptable in TR-03-8 (Coutermarsh and Dwinal 2003). Two of the marginal sites were classified as acceptable in TR-03-8 and one was unacceptable. In two of these cases the LIDAR imagery showed some portion of the bank slope at or very near the $27^{\circ}$ maximum and the third bank as being too high. It appears that tall grass was the reason for the riverbank in the third case appearing higher than it was. All 11 that were rejected had been classified unacceptable in TR-03-8. If we consider the two sites classified as marginal from our LIDAR analysis that were acceptable in TR-03-8 as incorrect, then the overall results were 16 correctly identified sites. This results in an $88 \%$ success rate using the LIDAR imagery compared to a $16 \%$ success rate using conventional techniques alone. It should be noted that the results reflect using LIDAR imagery in addition to the conventional techniques described in TR-03-8.

In most cases, the LIDAR DEM matched the surveyed surface within six inches to one foot. Since the minimum vertical step capability of our vehicles was 1.83 feet, the LIDAR had the necessary resolution to determine terrain clearance where there were actual LIDAR points. As discussed earlier, the DEM can have errors associated with interpolating between points. Vertical or nearvertical surfaces were difficult to capture and thick vegetation can mask the true ground surface enough to affect the characterization of the potential crossing site. A detailed look at the results follows with comparisons to the ground surveys and illustrative examples of some of the problems mentioned above. A complete set of LIDAR imagery of each site can be found in the appendix and the site contour maps and aerial photos can be found in Appendix A of TR-03-8.

\section{Crossing site examples}

Site 1 had not been chosen by the terrain team and was discovered during our on-site inspections. The site had several interesting bank conditions varying from steep to stepped to a shallow shelving beach. Figure 2 shows the DEM. Three ground survey transects were collected and compared against the LIDAR DEM and those comparisons are shown in Figures 3, 4, and 5. In the following comparisons between the LIDAR and surveys, the survey transects are shown in red and the LIDAR data are shown in blue. 


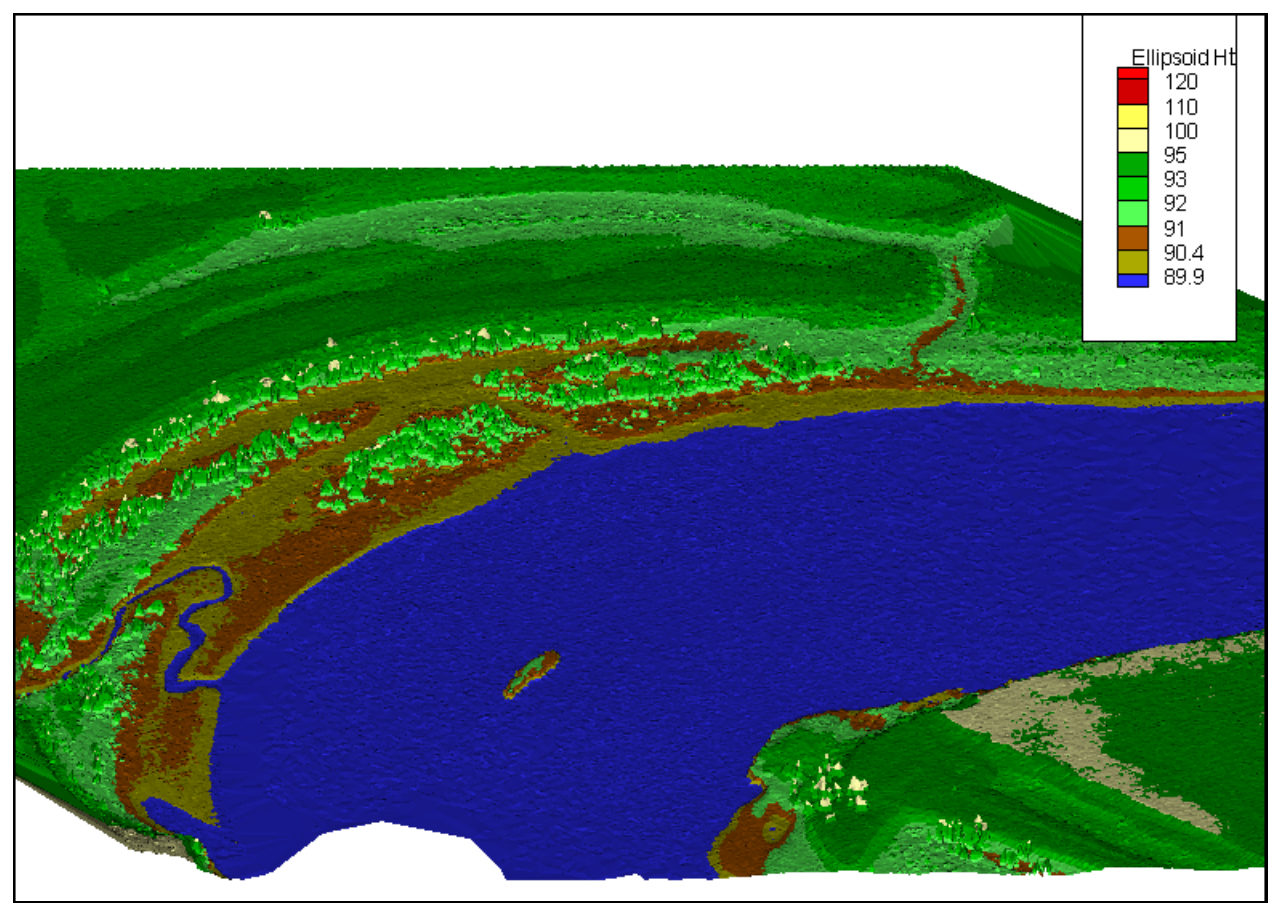

Figure 2. Site 1 LIDAR DEM looking north. The relative ellipsoid heights in meters of the colors are shown in the legend.

The west bank at Site 1 was a low slope with leafy brush, tall grass, and a few widely spaced small trees. The LIDAR and ground surveys agree generally to less than 0.5 - $\mathrm{ft}$ difference on this bank in all three transects. The east bank is steeper and more difficult to match. In the first two transects the two survey heights agree to generally within a foot, with some difference in the horizontal spacing. The third transect shows that the height of the small secondary bump near the water on the east bank disagrees between the surveys by about a threefoot height difference and a fifteen-foot horizontal difference. These differences could be as much a problem with our ground survey GPS positions as with possible LIDAR height differences. The profiles from the two systems are very similar and either represents the actual bank profiles. 


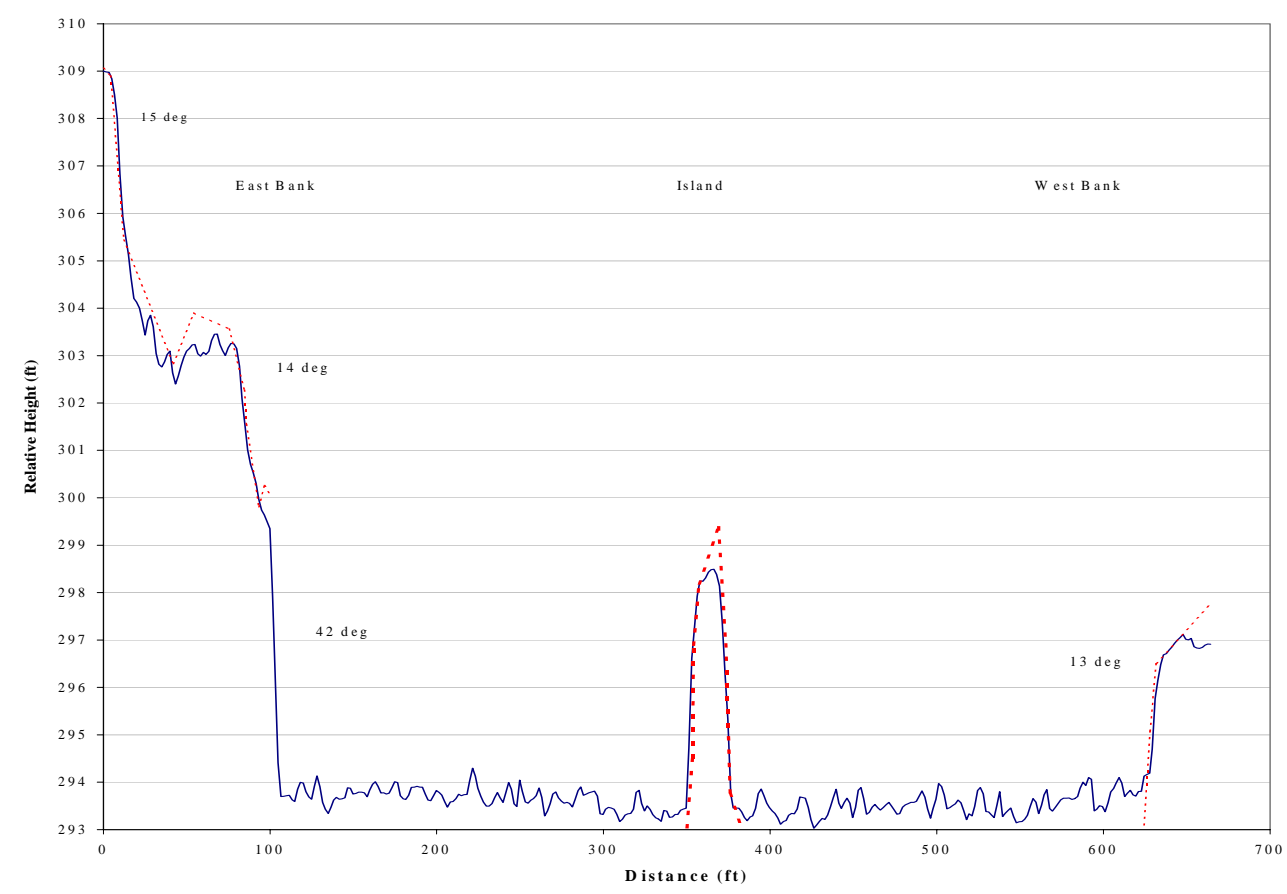

Figure 3. Ground survey and LIDAR DEM comparison, Transect 1 . This transect projects through the small island shown in Figure 2 above.

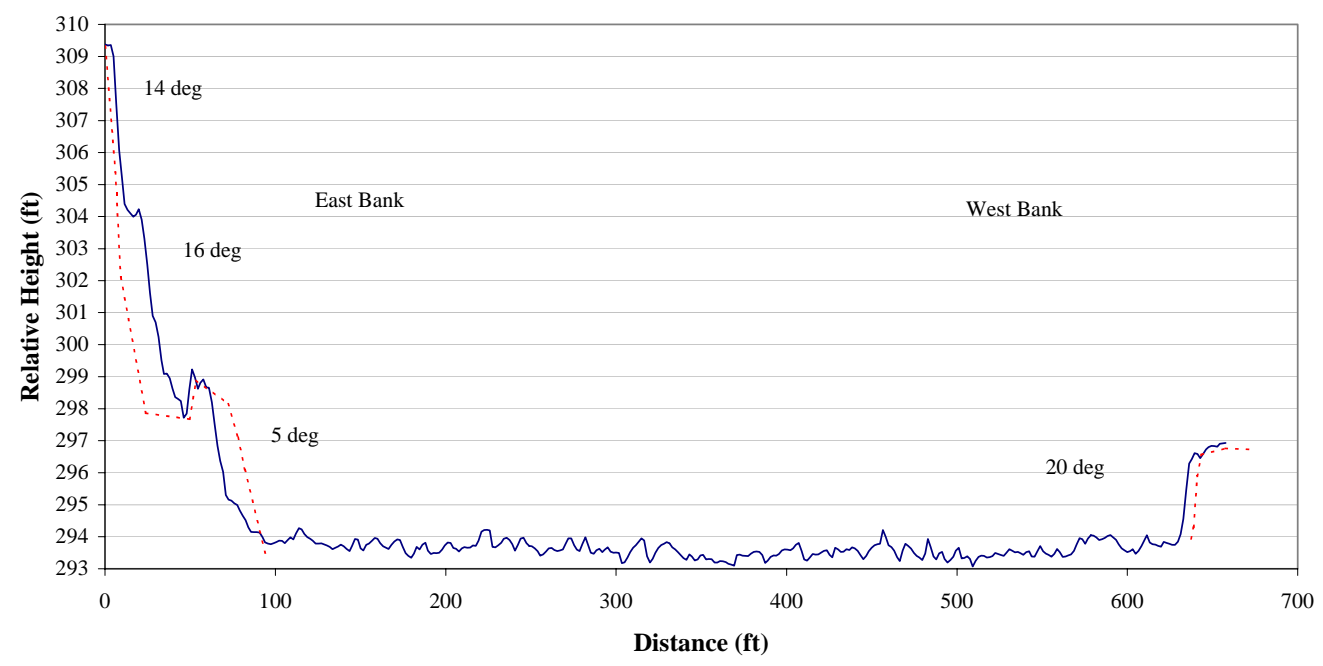

Figure 4. Site 1, Transect 2. 


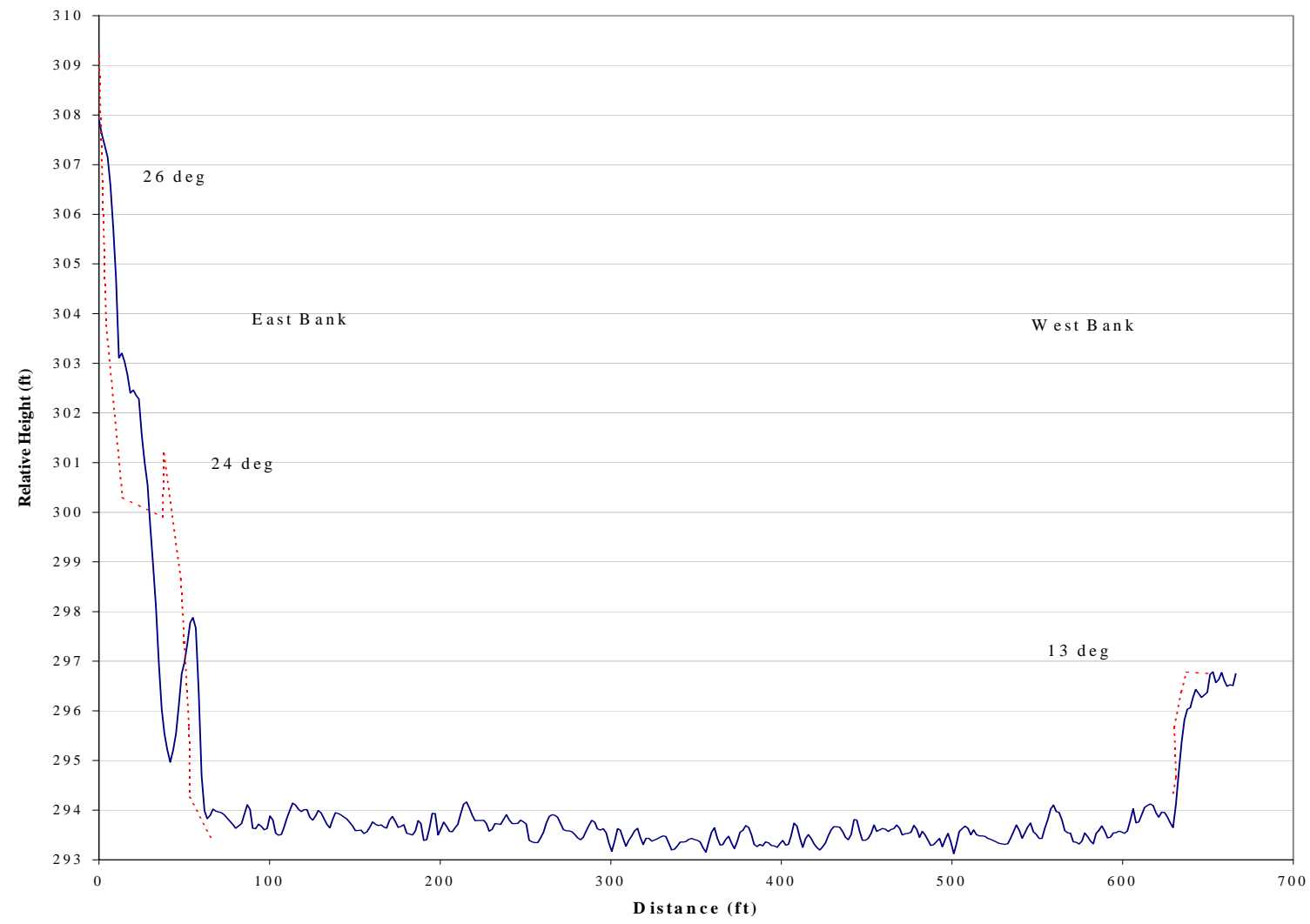

Figure 5. Site 1, Transect 3.

\section{Tree spacing}

Figure 6 is the LIDAR DEM of Site 3. This site was rejected by the terrain team because the trees along the west bank looked too thick in the aerial photographs to traffic through and because of the potentially soft ground indicated on the contour map. In the LIDAR imagery the trees appear conical because of the post-processing technique. In reality, most of the trees were deciduous and did not have a leaf structure to the ground. 


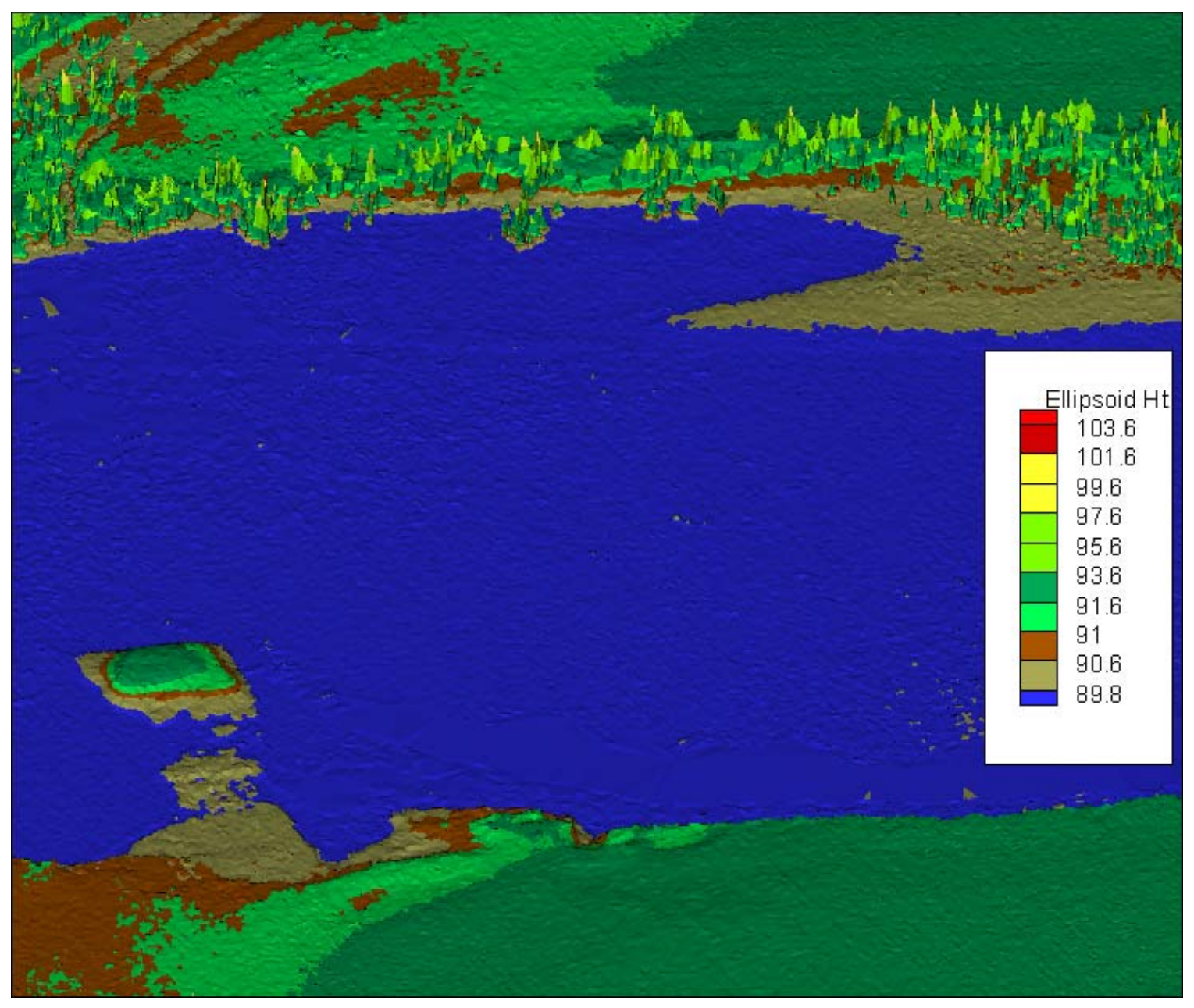

Figure 6. LIDAR DEM of Site 3 looking at brush and trees on the west bank.

By using various analysis tools available in the post-processing software, we could estimate a rough spacing between the trees adequately enough to determine if it would be possible to travel between them. It was also possible to infer something about tree trunk diameter by measuring tree height from the DEM and inspecting the aerial photographs for tree type. The terrain shown as potentially soft on the contour map appears as a lower elevation (brown areas) behind the trees beyond the bank. The color indicates the area is at the same elevation as portions of the riverbank leading into the water. 


\section{Marginal sites}

Following are the three sites classified as marginal from the LIDAR survey. The first two examples from Site 2 and Site 20 were found to be marginal because of bank slope measurements and/or height. The last example, at Site 9, was apparently because LIDAR returns from tall grass along the bank made the bank appear higher than it was.

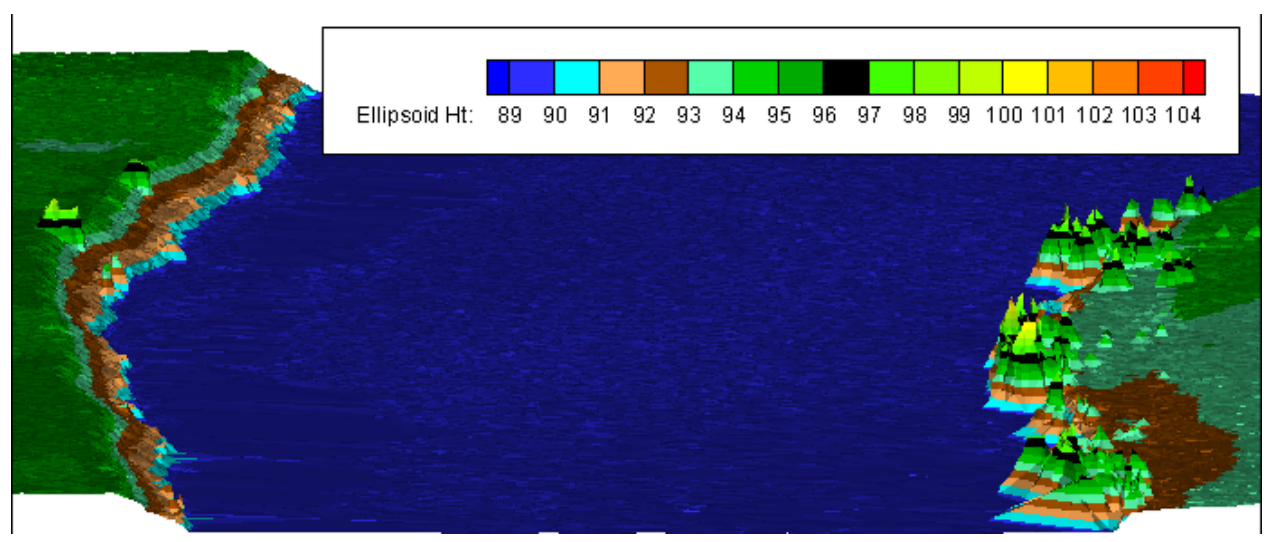

Figure 7. Site 2 LIDAR DEM looking north.

At this site the ground survey and DEM matched well, as shown in Figure 8.

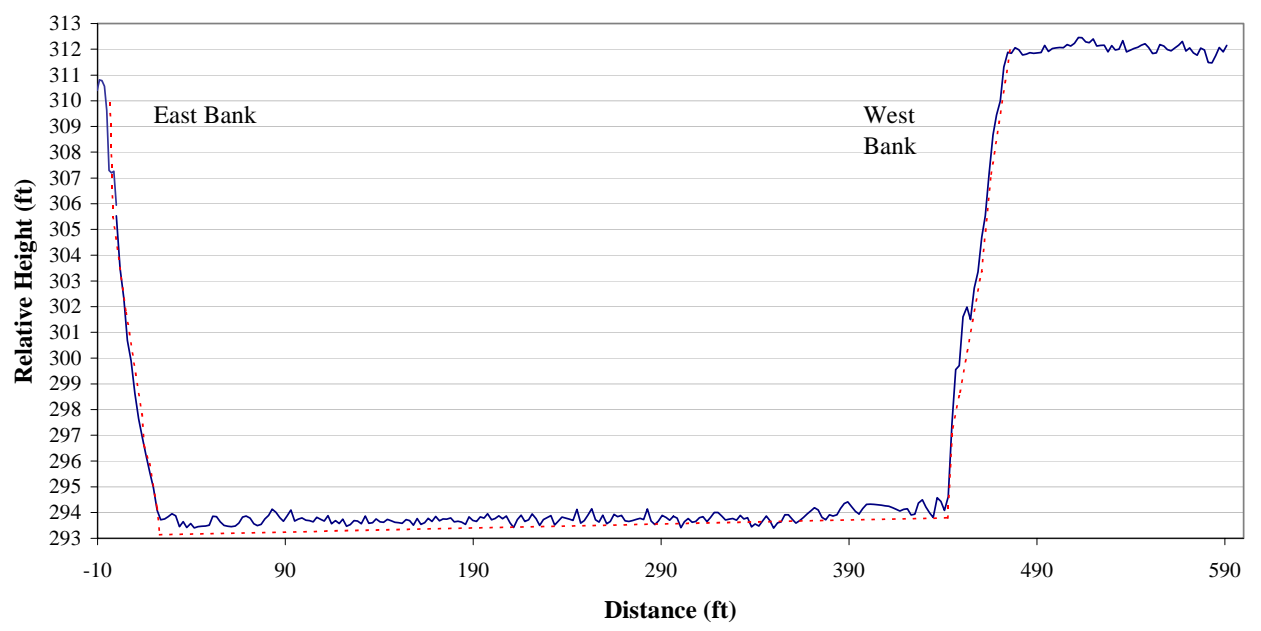

Figure 8. Ground survey and LIDAR DEM comparison, Site 2. 
Figure 9 shows a close-up of just the bank slope data taken from the LIDAR DEM. Both banks are superimposed on each other in the graph.

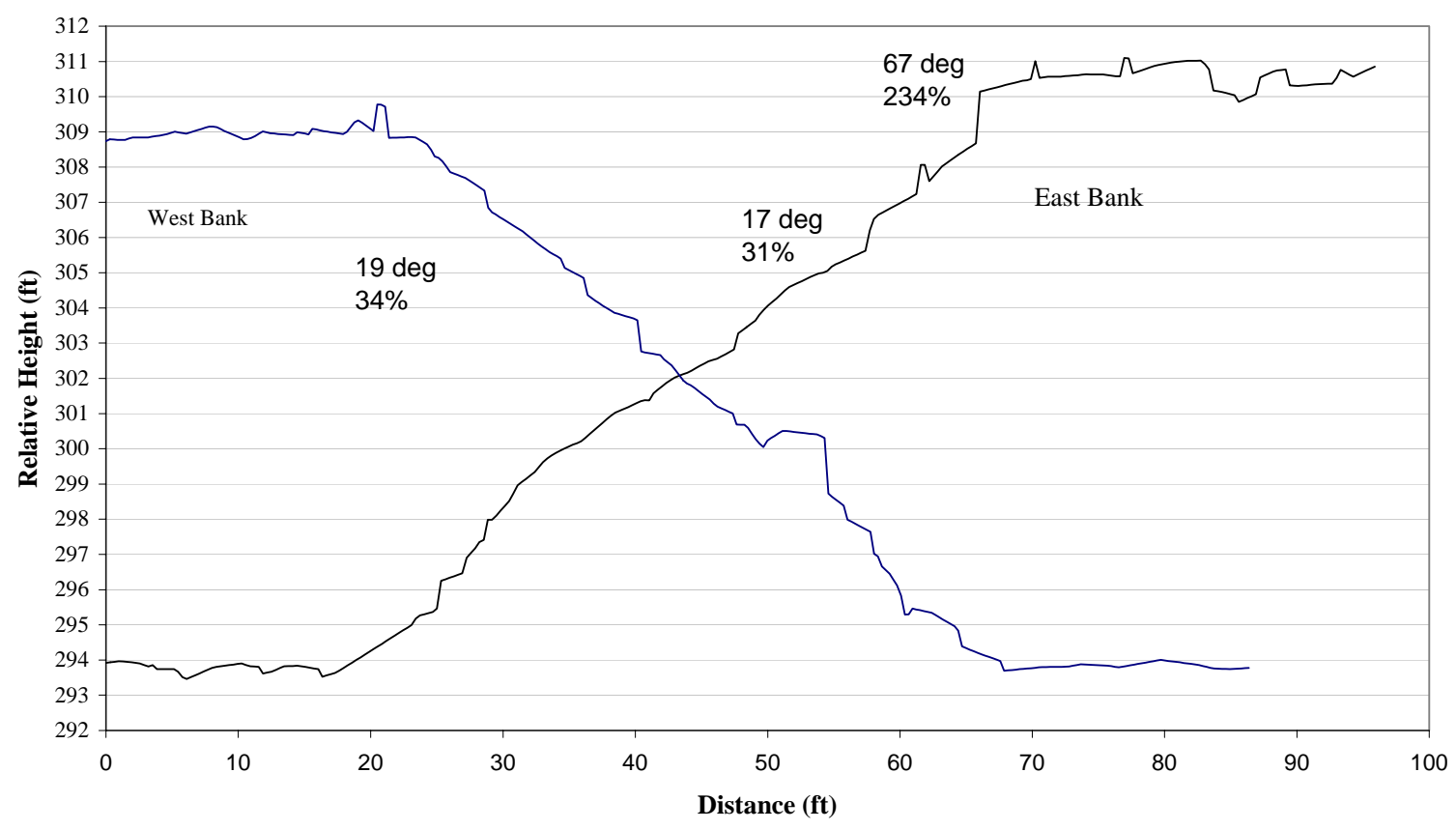

Figure 9. Site 2 bank slopes taken from the LIDAR data.

At the top of the east bank is a short section of bank about 1.5 feet high at $67^{\circ}$. It was felt that this section on an already steep slope would be difficult, if not impossible, to traverse and was the reason for classifying this crossing as marginal. The on-site inspection found that the slope of this section actually approached $90^{\circ}$ with the steep section being about 2 feet high and therefore not trafficable. The discrepancy of the DEM profile at the near- $90^{\circ}$ section seems characteristic of the technique and is illustrated further below. Figure 10 shows the DEM from Site 20. 


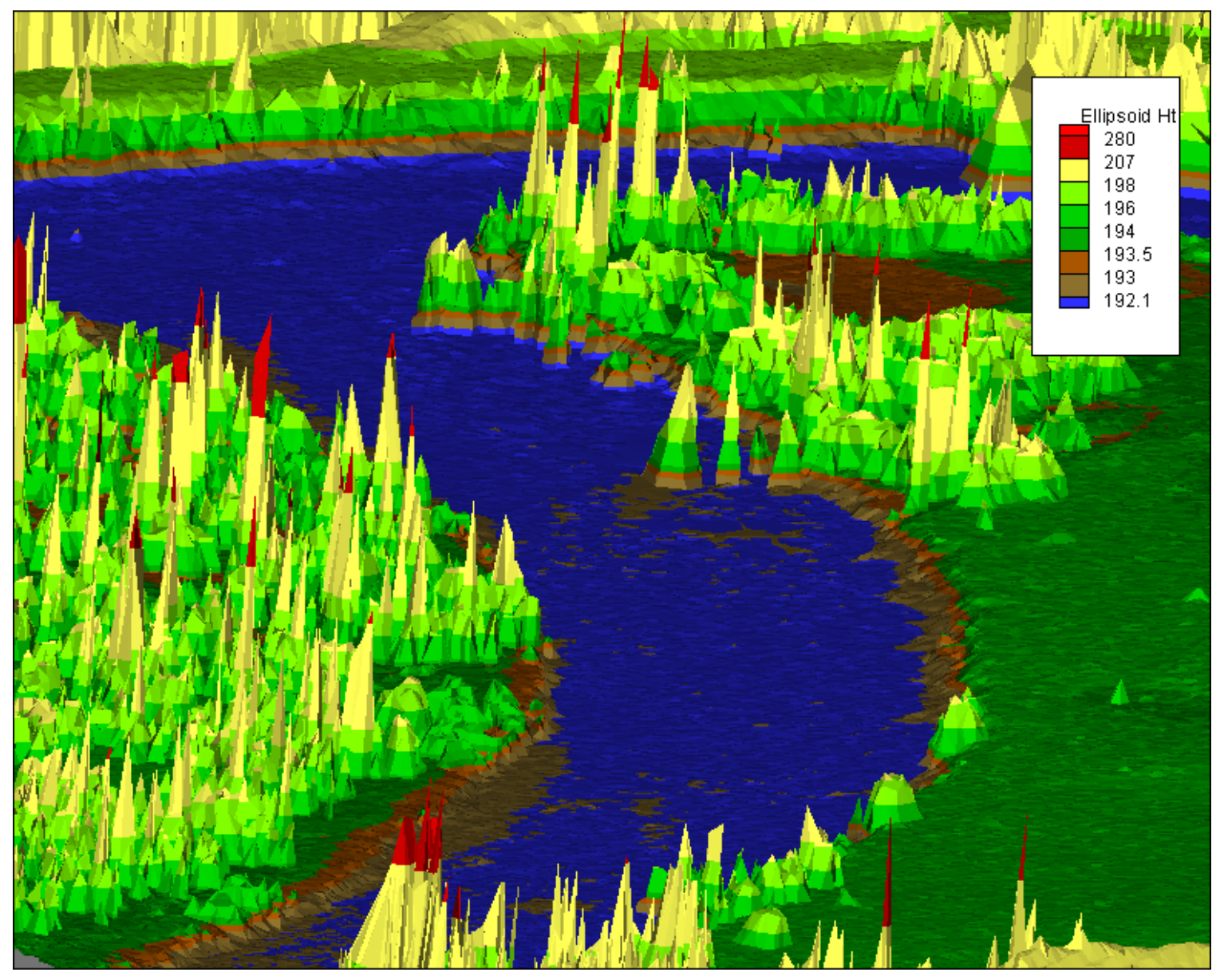

Figure 10. Site 20 LIDAR DEM looking south. The transect shown goes from right (west) to left (east) in this figure, starting in the open area on the right.

Figure 11 is the LIDAR and survey comparison profile.The LIDAR showed both banks to have 3-foot- to 5 -foot-high sections at or near the $27^{\circ}$ maximum slope that our reference vehicles were capable of climbing. The site was classified as marginal based upon those measurements. In our on-site surveys we classified the site as unusable because of the slope and bank height with good agreement between the LIDAR and on-site surveys.

\section{Vegetation height errors}

Site 9's DEM is shown in Figure 12. This site was marginal because the west bank height appeared to be at or slightly over the three-foot acceptable maximum used in TR-03-8 (Coutermarsh and Dwinal 2003). A mown field was on the west 
side of the crossing with about a 15-foot-wide swath of tall grass along the immediate top of the bank. This row of grass showed up as a higher feature on the top of the bank. Figure 13 shows a profile of the west bank LIDAR data illustrating the effect. Referring to the horizontal distances in Figure 13, the water surface is from 0 to about 26 feet. The bank starts there and continues to about 31 feet, where the taller grass starts and continues to about 45 feet, which is the approximate beginning of the mown field. This mown field surface indicates the true top of the bank that results in a relative height from the water surface of about two feet, well within our acceptable bank height.

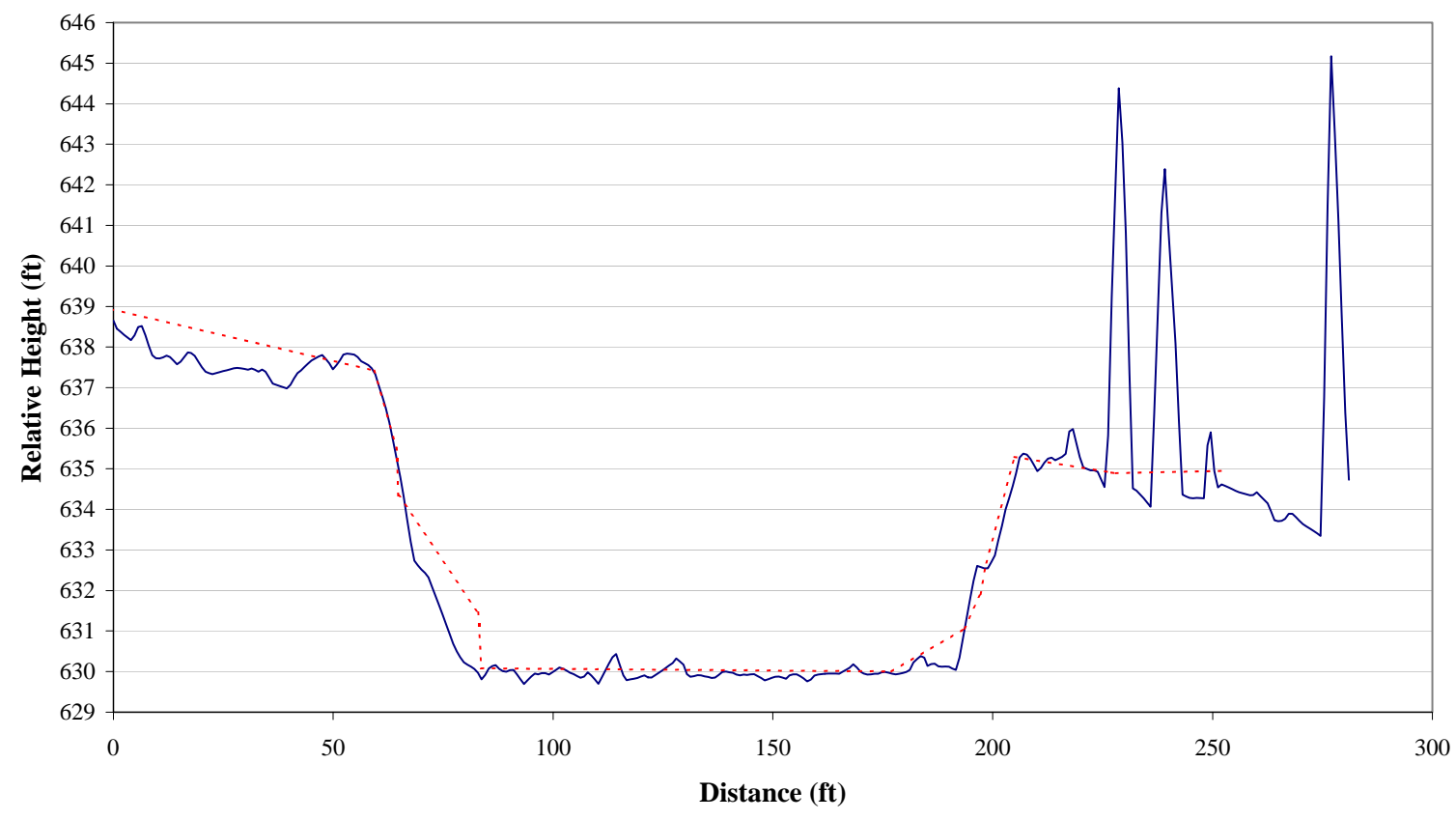

Figure 11. Site 20 LIDAR and ground survey comparison profile from west to east. The tall spikes on the right in the LIDAR data are trees.

As mentioned earlier a potential problem with the LIDAR imagery is the difficulty in defining vertical or near-vertical surfaces. Some of this effect was shown in a section of the east bank at Site 2 and another example can be seen in the data from Site 4. During the on-site surveys the sections of the bank were measured as approximately 11 feet high with sections of the face at $90^{\circ}$ as shown by the dashed line in Figure 14. 


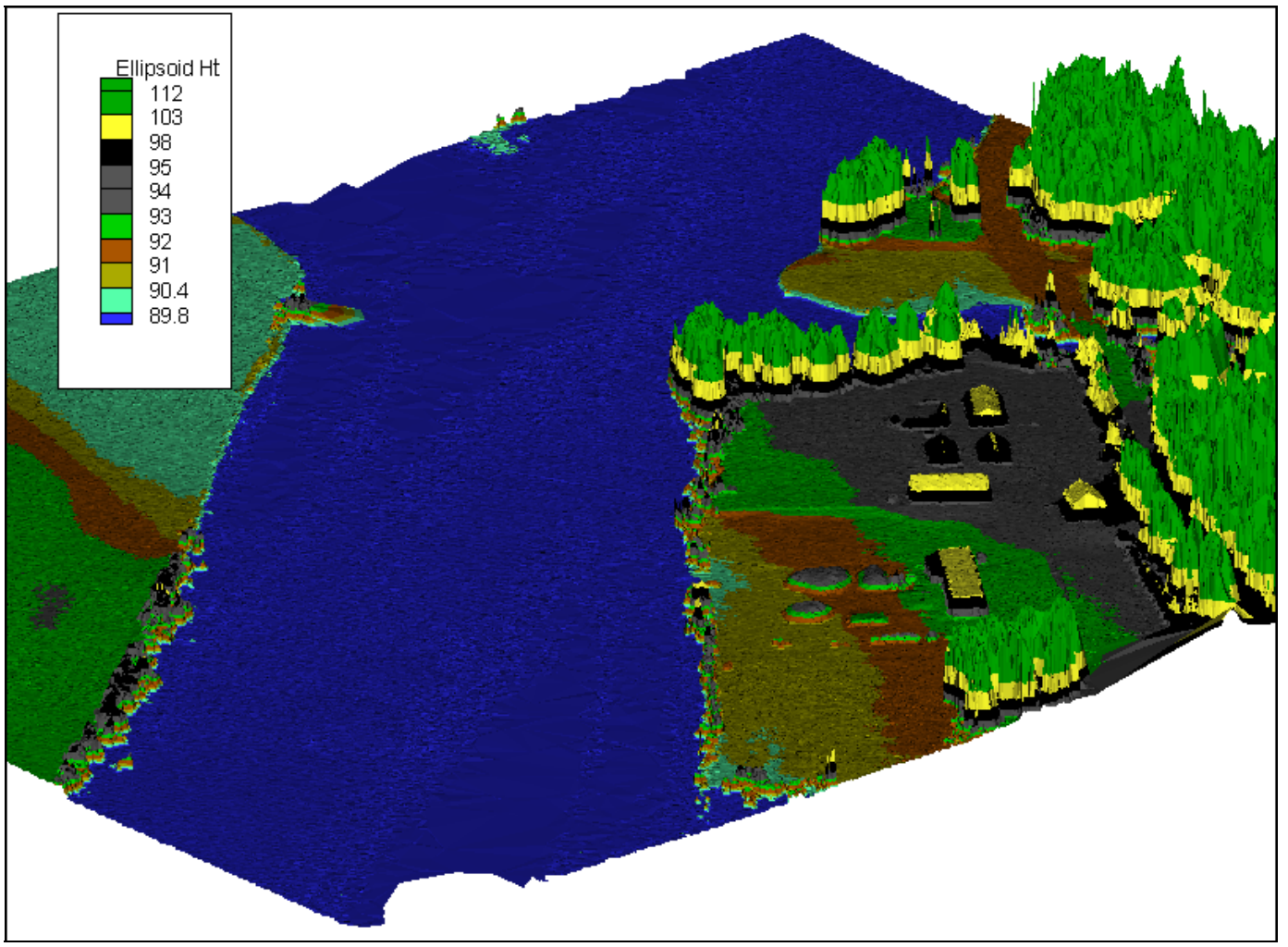

Figure 12. Site 9 LIDAR DEM looking north.

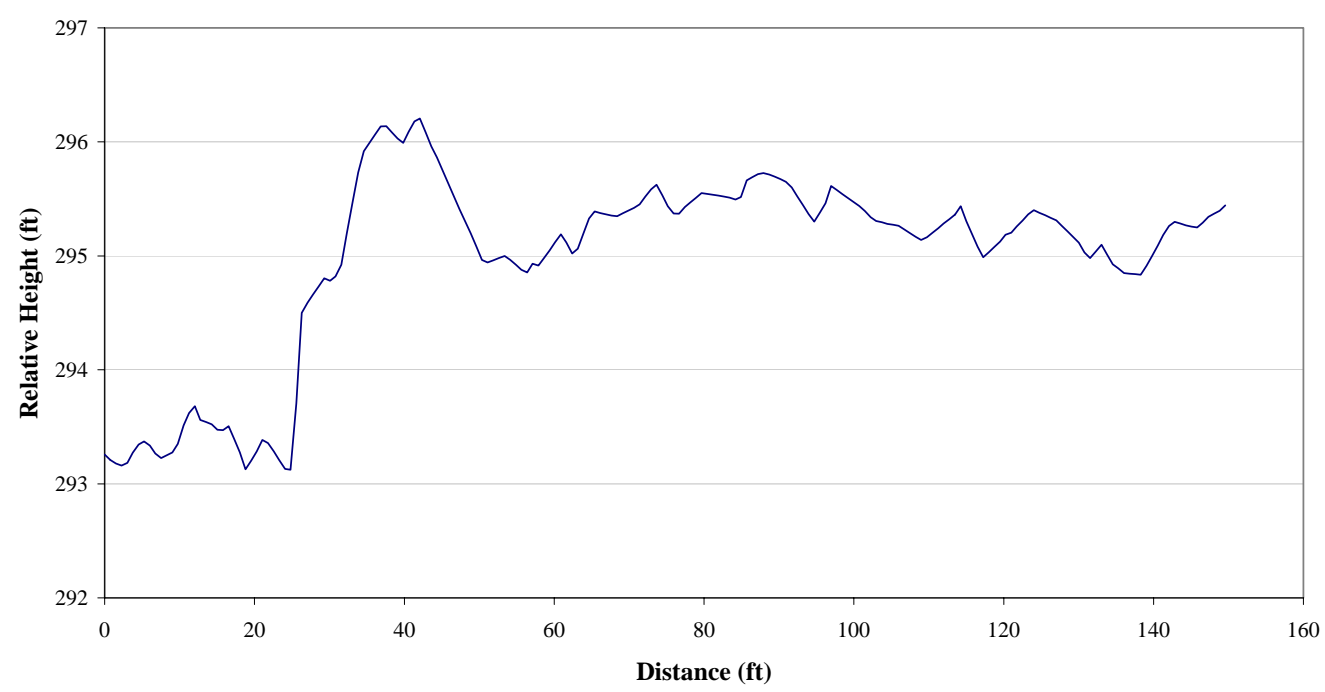

Figure 13. Profile of west bank. 


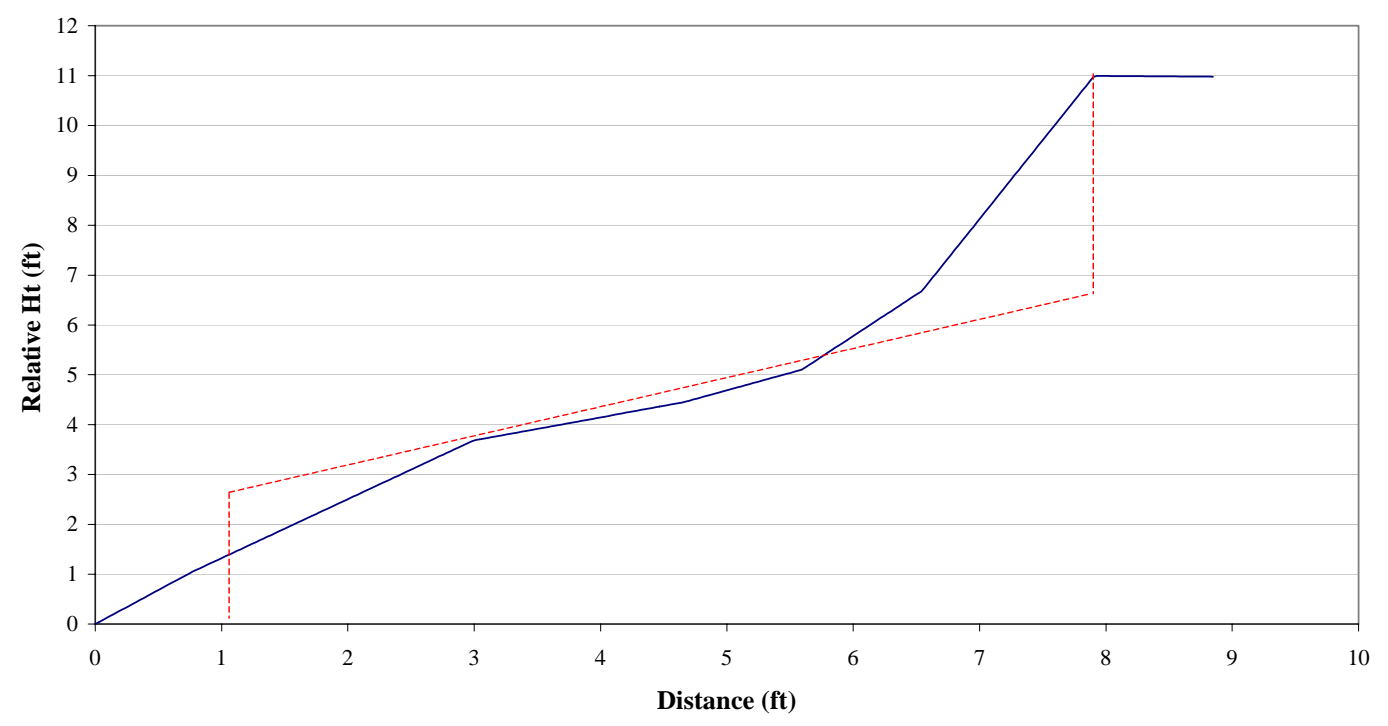

Figure 14. Site 4 east bank comparing ALSM data (solid line) with approximated measured bank profile (dashed line).

The LIDAR data seem to have smoothed the lower vertical surface into a slope of $50^{\circ}$ and the upper near-vertical surface into a slope of $72^{\circ}$. Some of this variation may be due to the difficulty in picking the exact location in the LIDAR data that corresponds to the measured on-site location. The same effect can be seen on the vertical sides of buildings where there is less uncertainty.

\section{Road/trail recognition}

Site 5 was chosen by the terrain team in part because of the presence of a trail on the east bank leading into the water. This feature is circled in the LIDAR DEM as shown in Figure 15. Once in the DEM a cross section can be plotted as shown in Figure 16, and a centerline slope can be calculated for the road from the water up, which, in this case was $22^{\circ}$. 


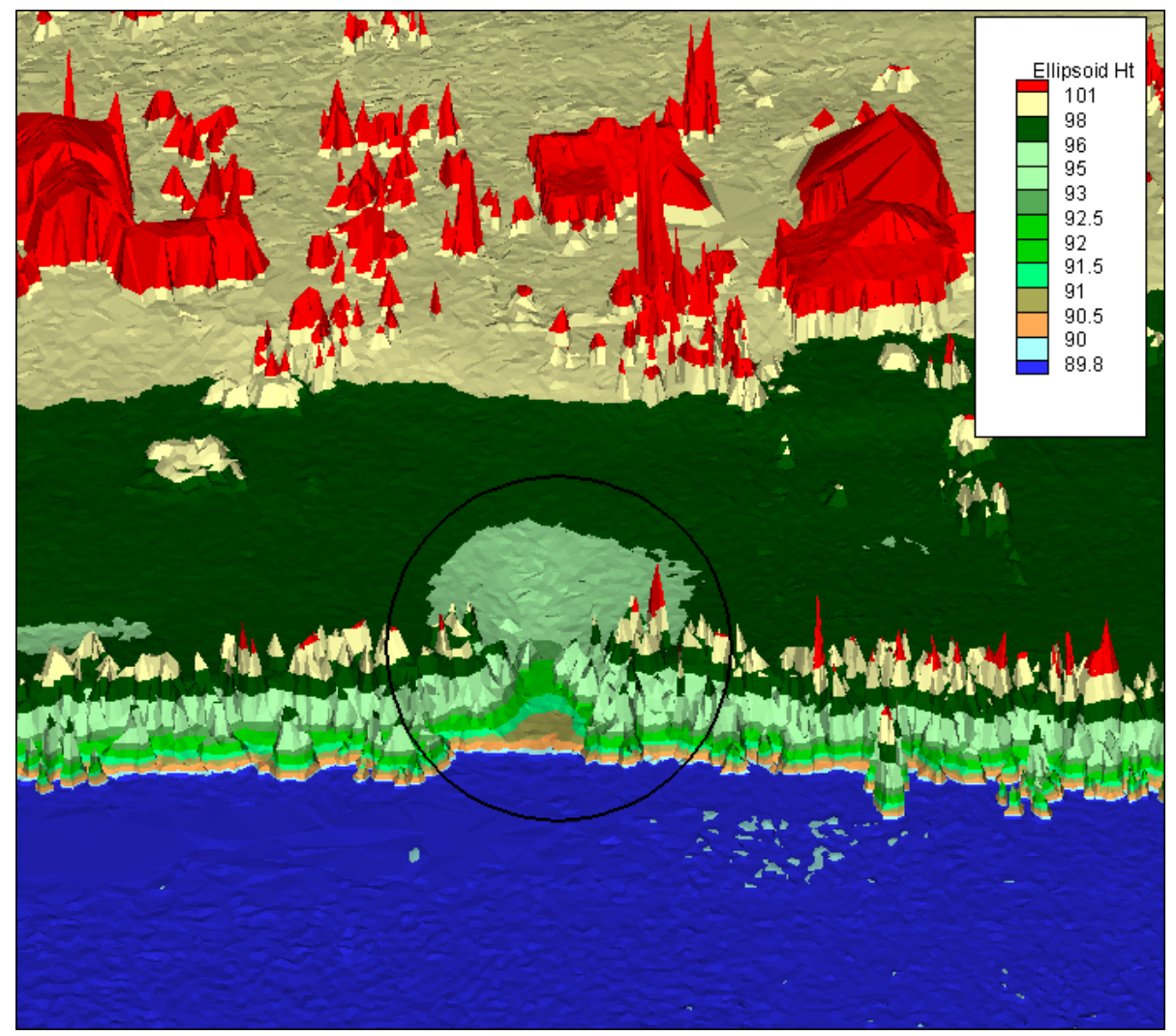

Figure 15. Site 5 east bank DEM showing road leading into the river. Buildings are in the background.

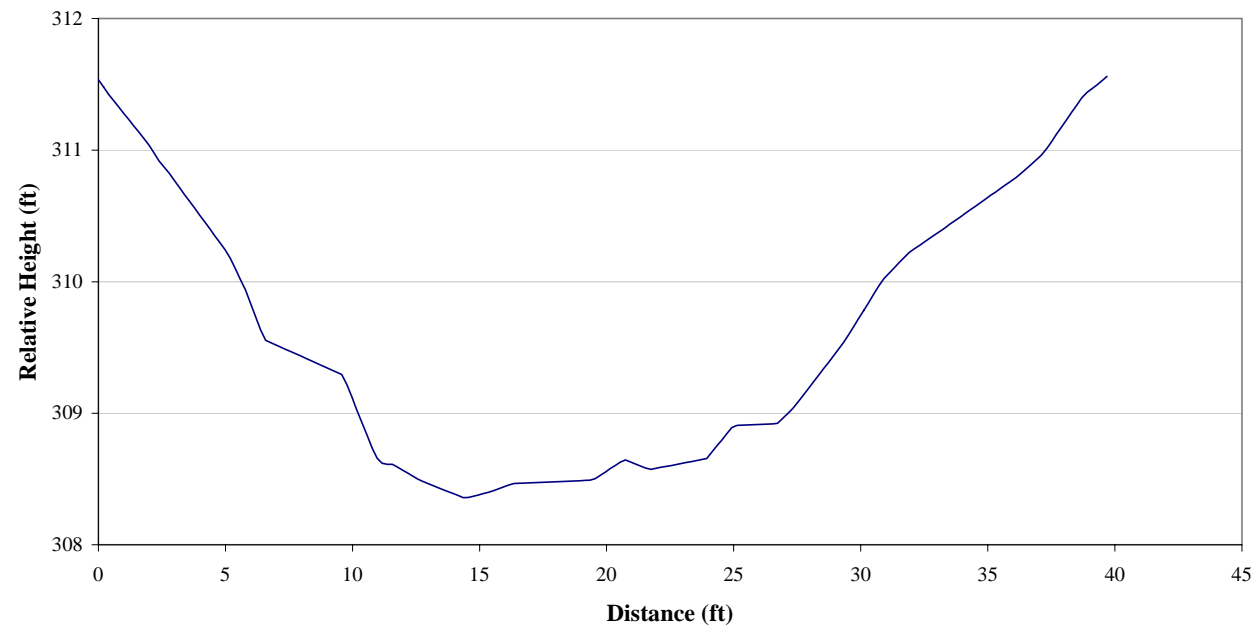

Figure 16. Cross section of road at Site 5. 
The clearings and trails in trees can also be seen quite easily in Figure 17, which shows the area adjacent to the west bank at Site 16 . Widths and slopes for these areas, as well as general tree heights and vegetation thickness, can be determined especially when the DEM is combined with the aerial imagery.

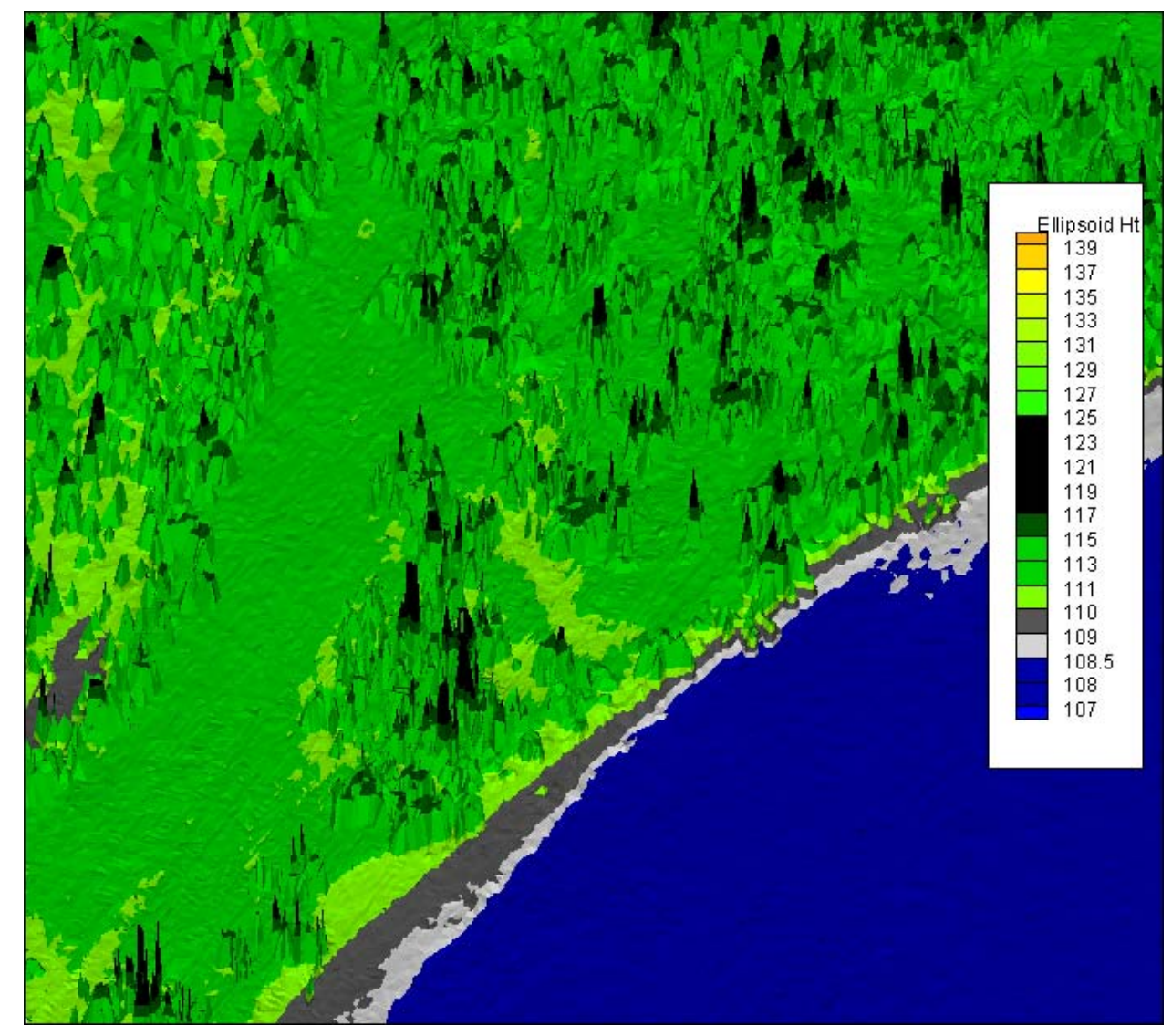

Figure 17. Trails and cleared areas in trees adjacent to Site 16. 


\section{CONCLUSIONS}

The information provided by the LIDAR imagery allowed an $88 \%$ success rate for remote crossing site selection. This was accomplished using a relatively unsophisticated analysis of the LIDAR data using only the first returns with no point filtering or intensity analysis. The predominant feature looked at was bank slope.

The data were useful in determining travel lanes through trees and vegetation. The ability to rotate terrain and zoom in on portions greatly increased the efficiency and effectiveness of the analysis, allowing us to find paths and open areas that were screened from certain viewing angles. We found many areas where the vegetation was too thick to allow the LIDAR to penetrate to the ground and thus modeling the terrain below this cover was difficult. A more sophisticated post-processing technique would perhaps improve the range of ground cover in which this would be effective.

The conical tree shapes made it difficult to determine actual spacing between trunks, but educated guesses were possible by determining vegetation height and referring to the aerial photographs to determine vegetation type when possible.

One of the biggest problems with the data was determining near-vertical surfaces. This becomes important when the height of these features is near the maximum step height the vehicles can negotiate, especially if the surface is superimposed on a slope. If the vertical height is less than the maximum that the vehicle can negotiate, it is probably less important that the LIDAR data might in fact represent it as a slope rather than a vertical surface.

Coutermarsh and Dwinal (2003) noted that several potential crossing sites were ignored because the contour map indicated the presence of wet ground. The LIDAR imagery did not solve this problem, but a more sophisticated analysis, perhaps using intensity returns, might provide a better result. Indirectly, however, terrain height could be used to infer some of this information, e.g., terrain next to the river that was at or slightly below the elevation of the water surface, with colorization of different elevation levels, was readily discernable.

Coupled with conventional aerial or satellite imagery and contour maps, the LIDAR technology increased the ability and accuracy of determining bridging sites remotely. Although not $100 \%$ accurate, it did provide a much-improved capability that at best makes a remote determination feasible and at worst greatly decreases the risk of on-site reconnaissance by culling out most of the unsuitable sites, allowing the commander to concentrate resources on only the sites most likely to be acceptable. 


\section{REFERENCES}

Coutermarsh, B.A., and B. Dwinal (2003) Remote determination of bridging/fording sites. U.S. Army Engineer Research and Development Center, Hanover, New Hampshire, Technical Report TR-03-8.

FM 90-13/FMFM 7-26 (1992) River Crossing Operations, Army, Marine Corps, Headquarters, Department of the Army, September 1992. 


\section{APPENDIX A. LIDAR RIVER CROSSING DATA}

For each site the LIDAR ALSM is shown, as well as graphs for available ground survey comparisons. In the comparisons, the solid blue line is the profile obtained from the LIDAR data and the red dashed line is the ground survey comparison.

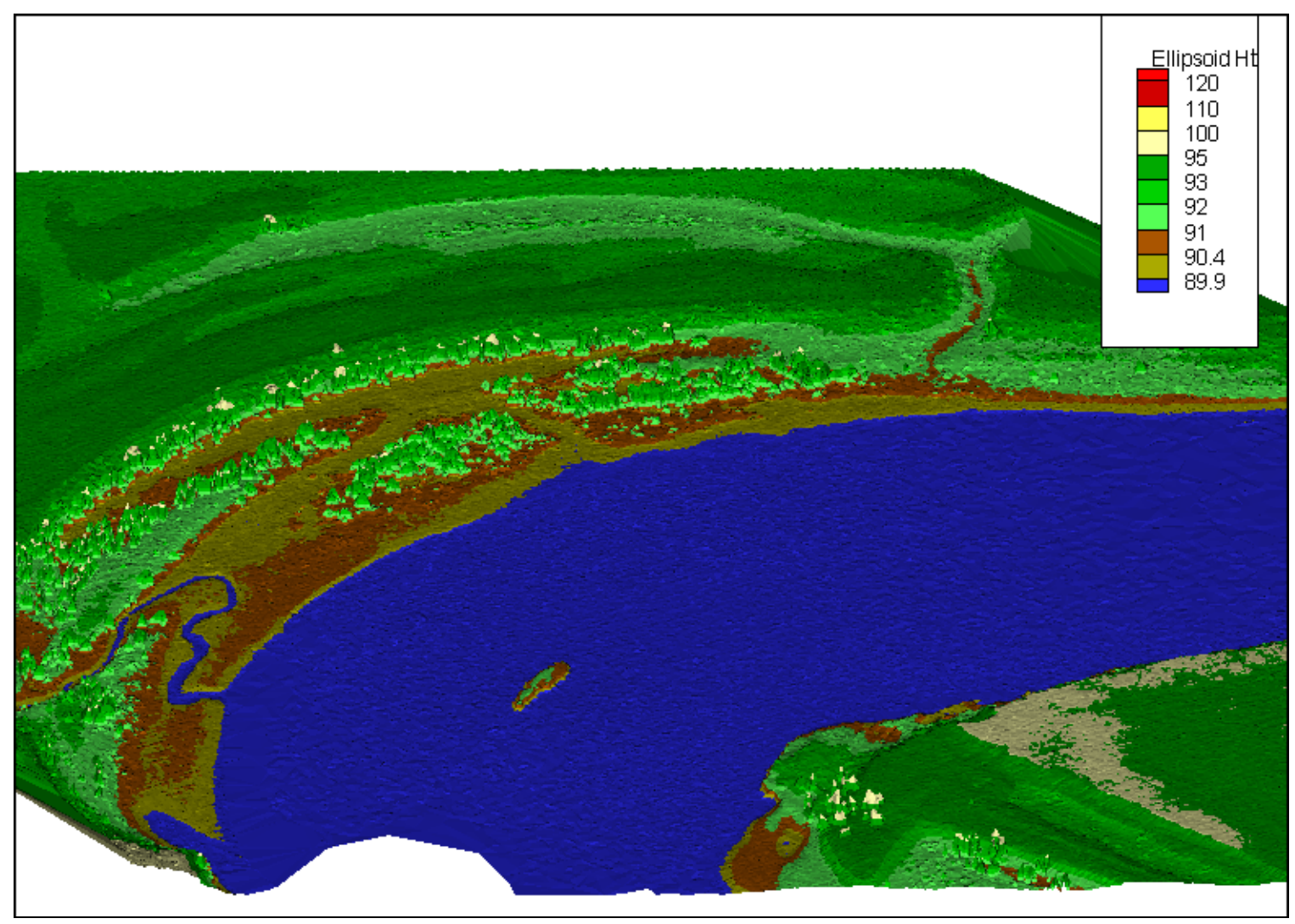

Figure A1. Site 1 ALSM looking north.

In the three ground survey comparisons below, the east bank is on the left side of the graph. 


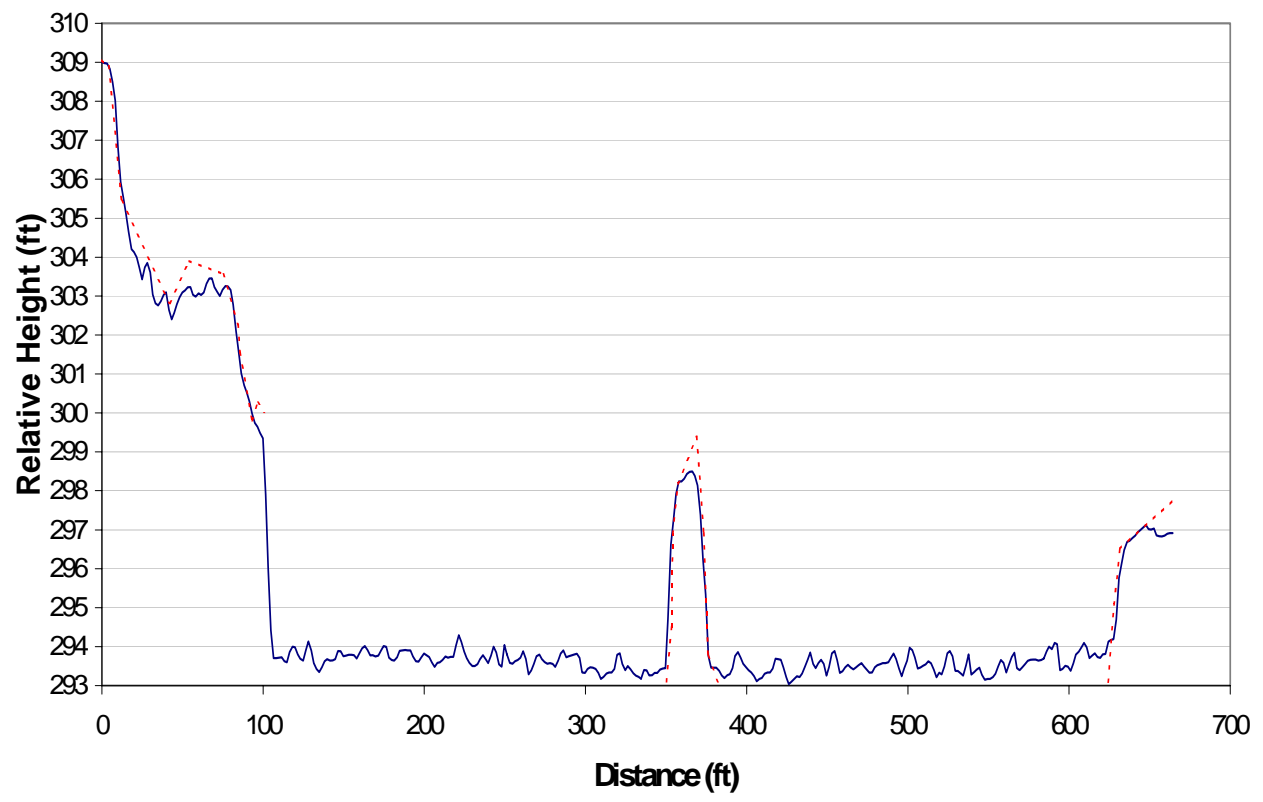

Figure A2. Site 1, Transect 1, through island. Water surface is from about distance 110 to 350 , then from 390 to 620 . The island is 350 to 390 .

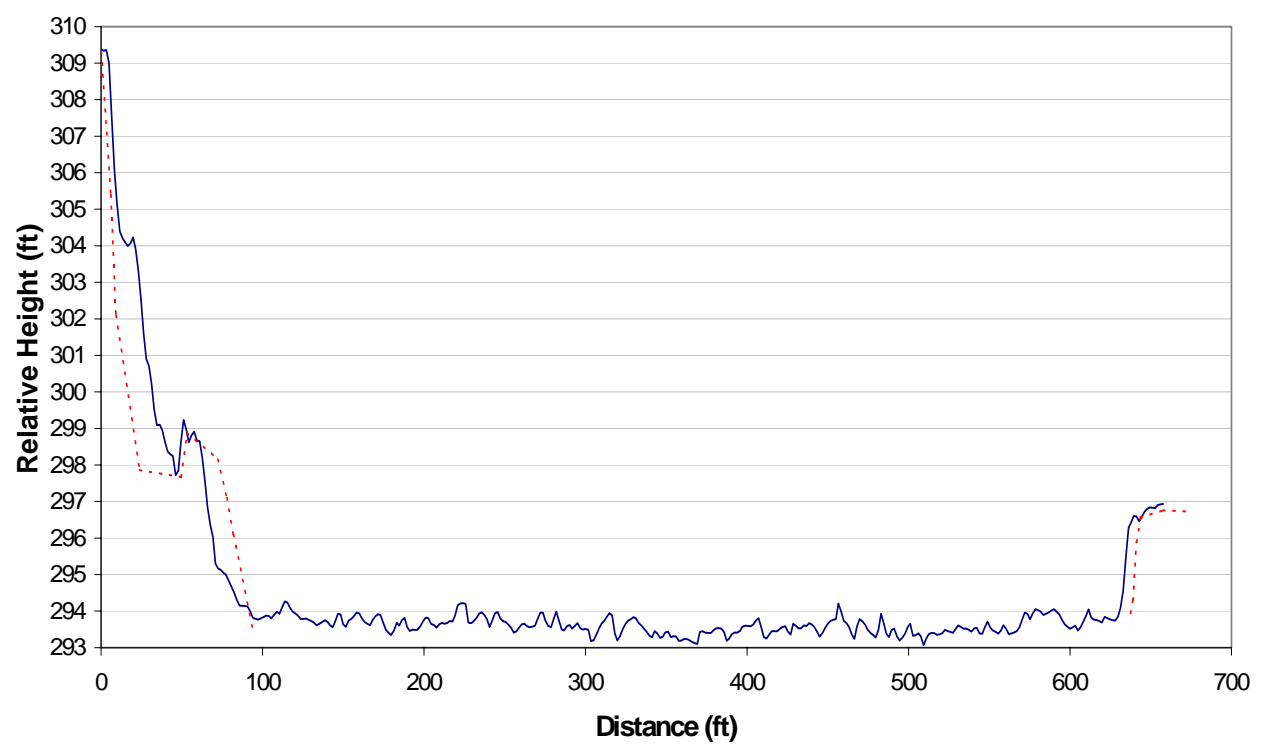

Figure A3. Transect 2. The water surface is from about distance 100 to 630 . 


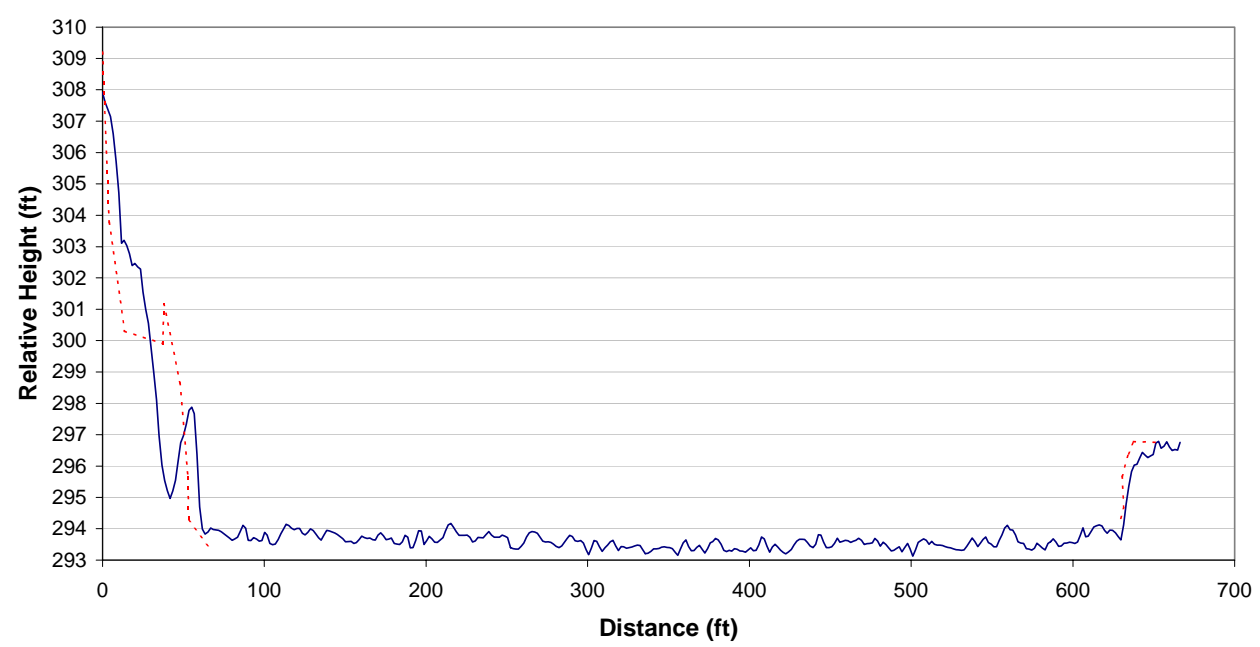

Figure A4. Transect 3. The water surface is from about 80 to 630 feet.

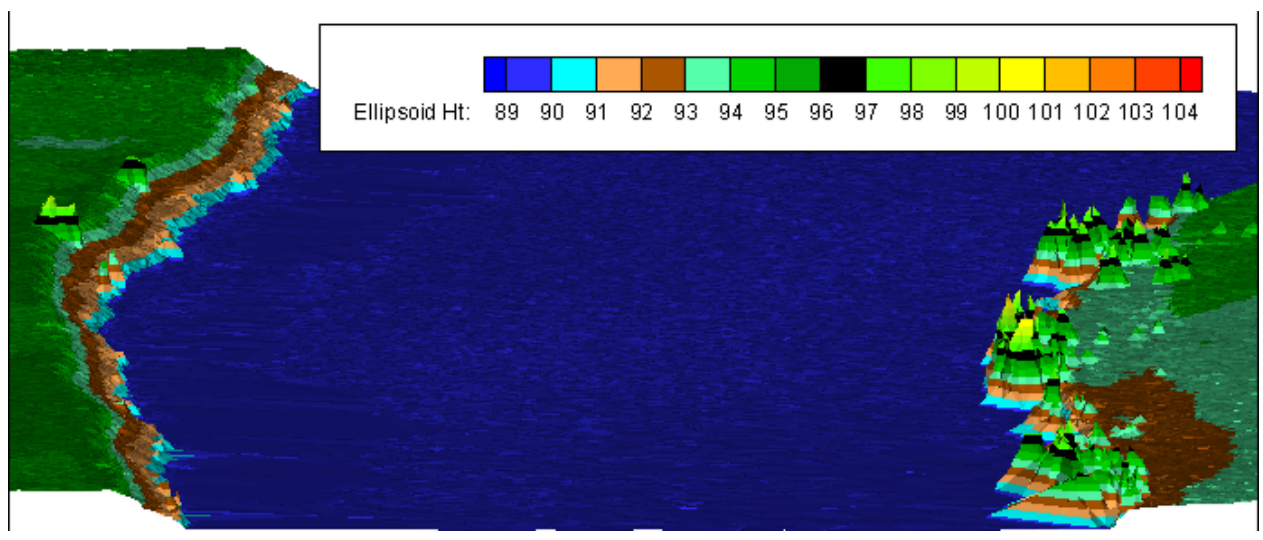

Figure A5. Site 2 ALSM, looking north. In the graphs below, east is at distance 0 . 


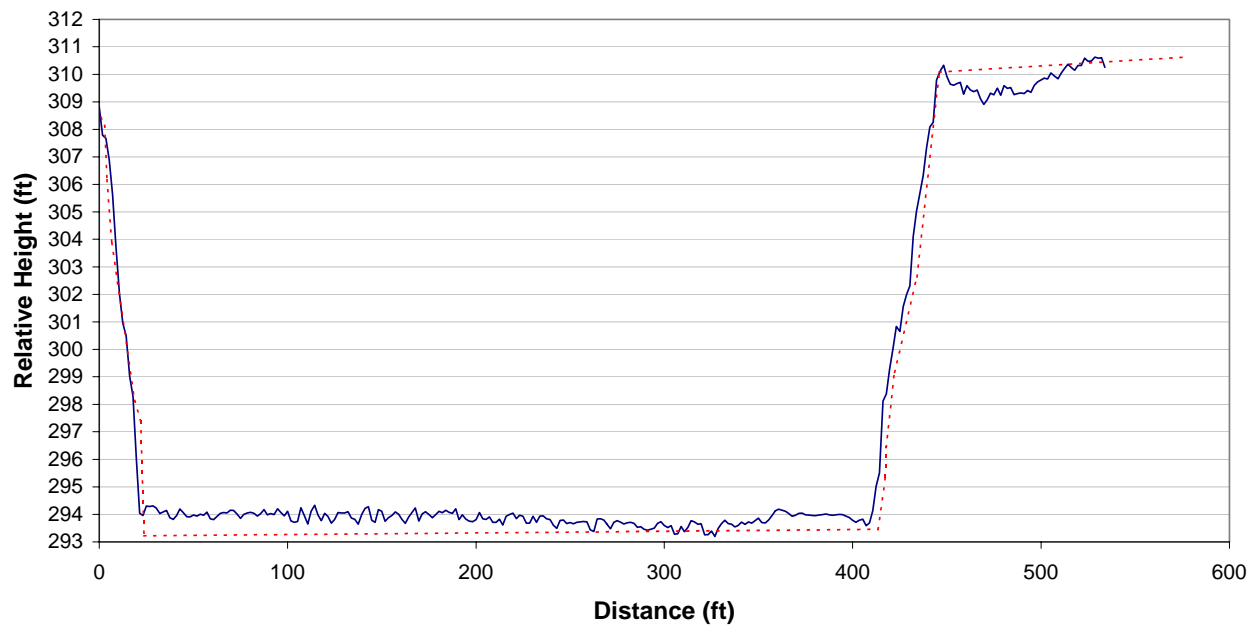

Figure A6. Site 2, Transect 1 . Water surface is from about distance 18 to 400 feet.

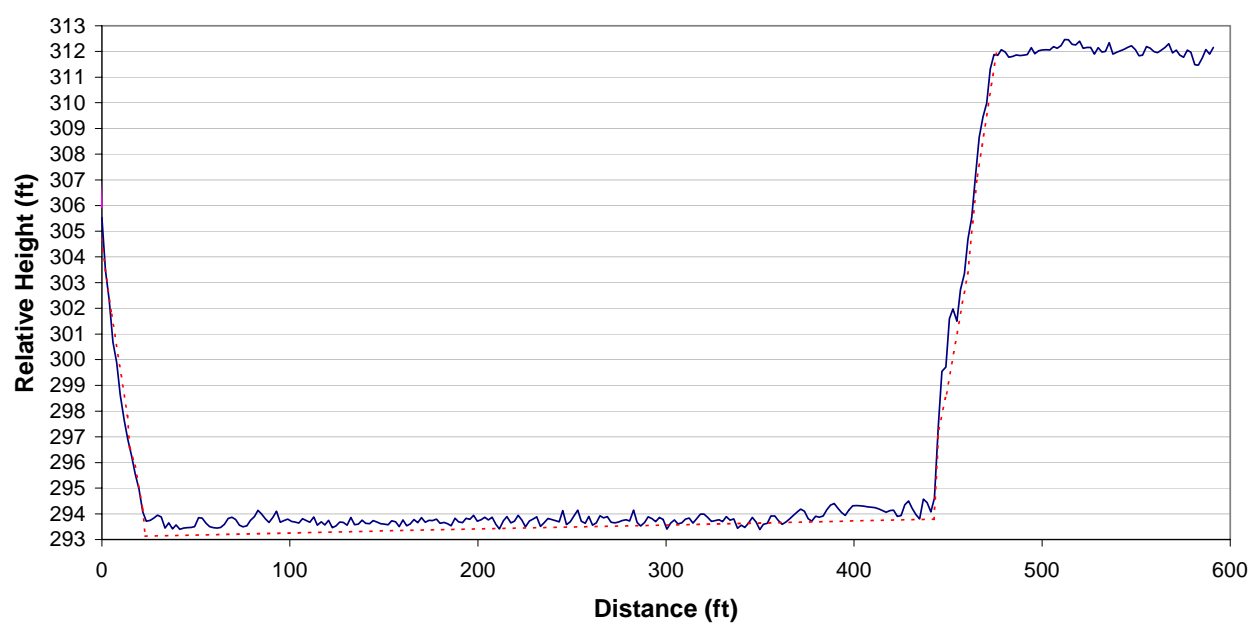

Figure A7. Site 2, Transect 2. Water surface is about distance 25 to 440 feet. 


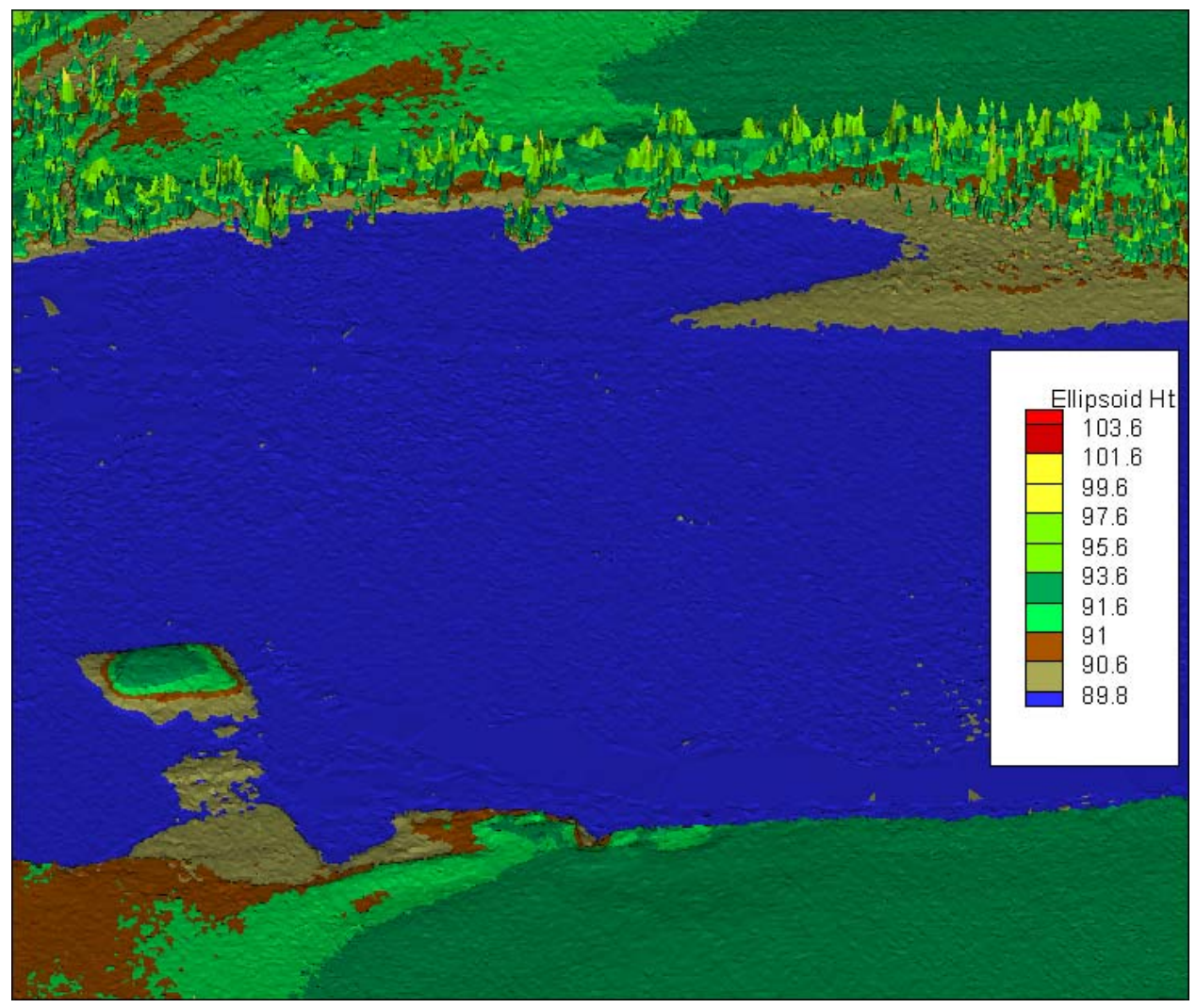

Figure A8. Site 3 ALSM, looking north. 


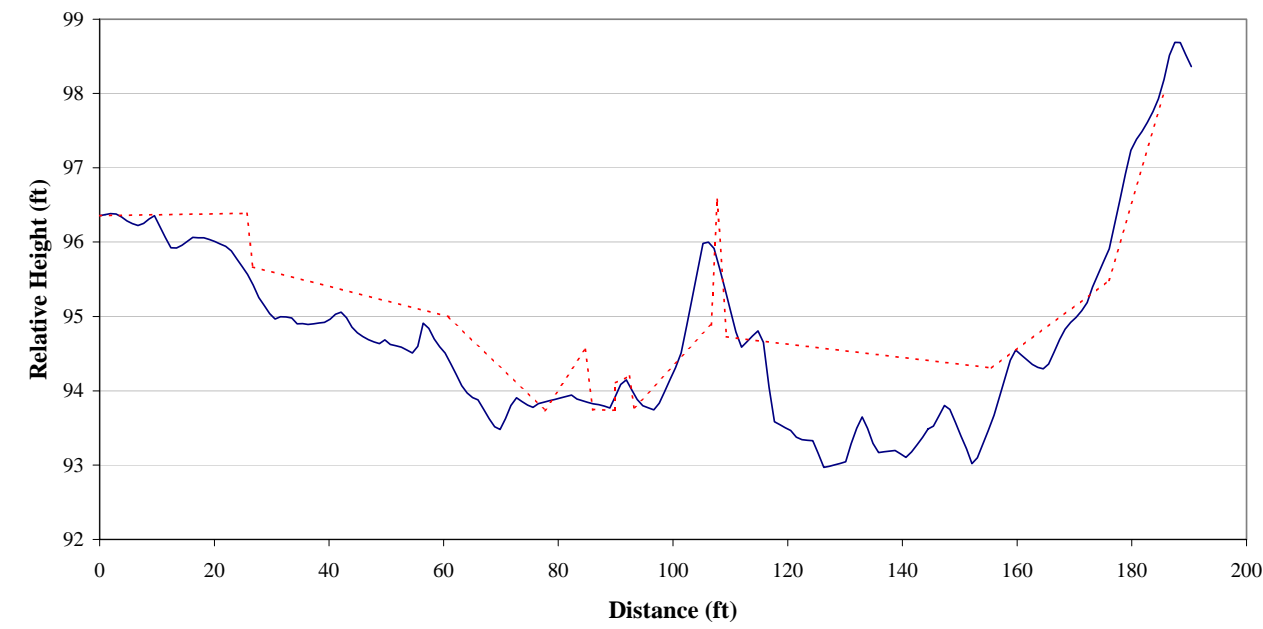

Figure A9. Site 3, Transect 1 ALSM and survey comparison from the south bank (foreground of ALSM image) to the island in left bottom of the ALSM data.

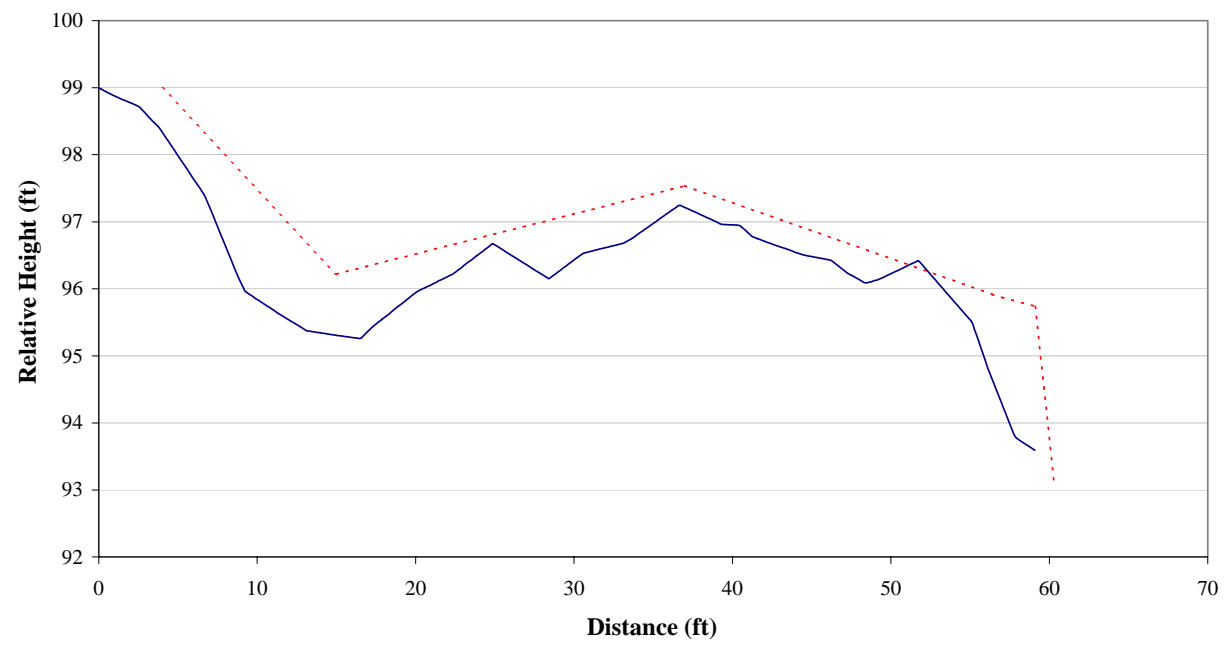

Figure A10. Site 3, Transect 2 from south bank to water. 


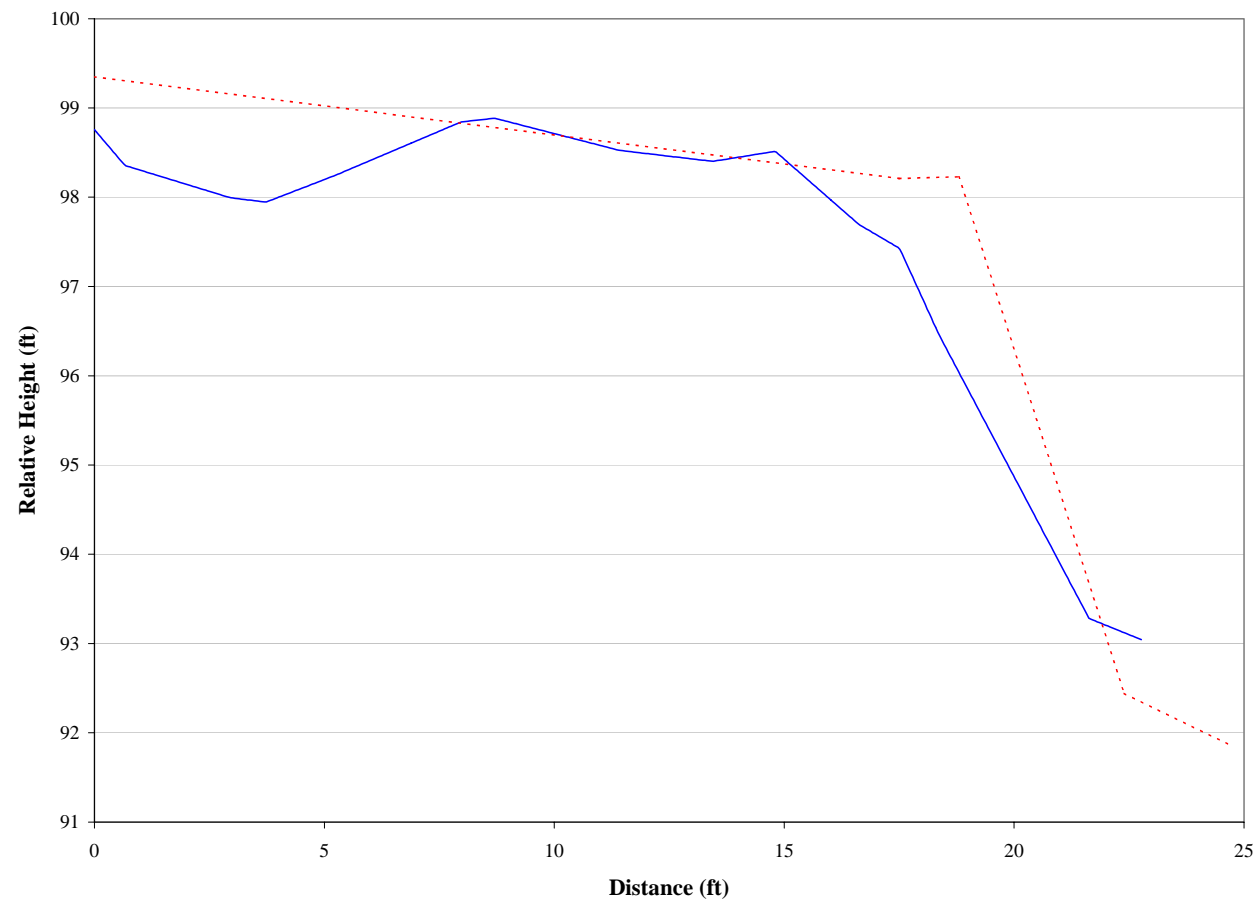

Figure A11. Site 3, Transect 3 from south bank to water.

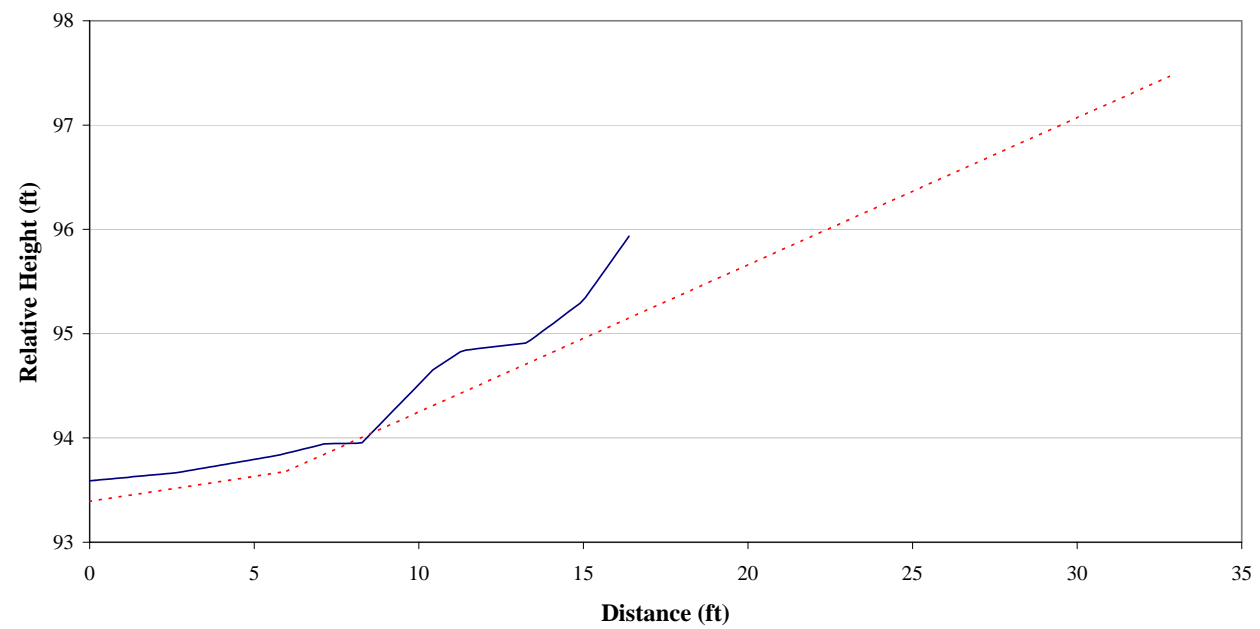

Figure A12. Site 3, Transect 4, north bank. Water surface is a distance 0. 


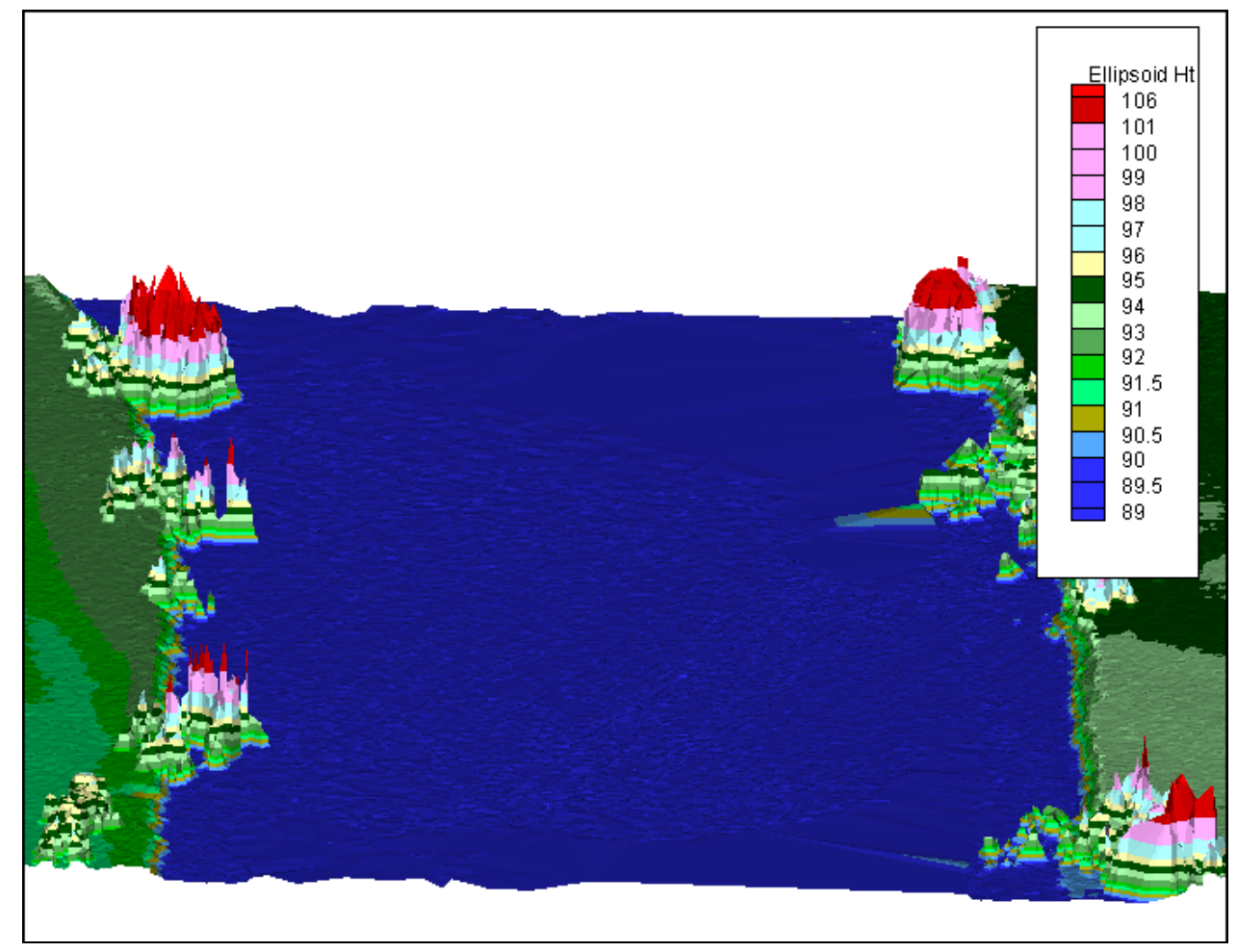

Figure A13. Site 4 ALSM looking north. 


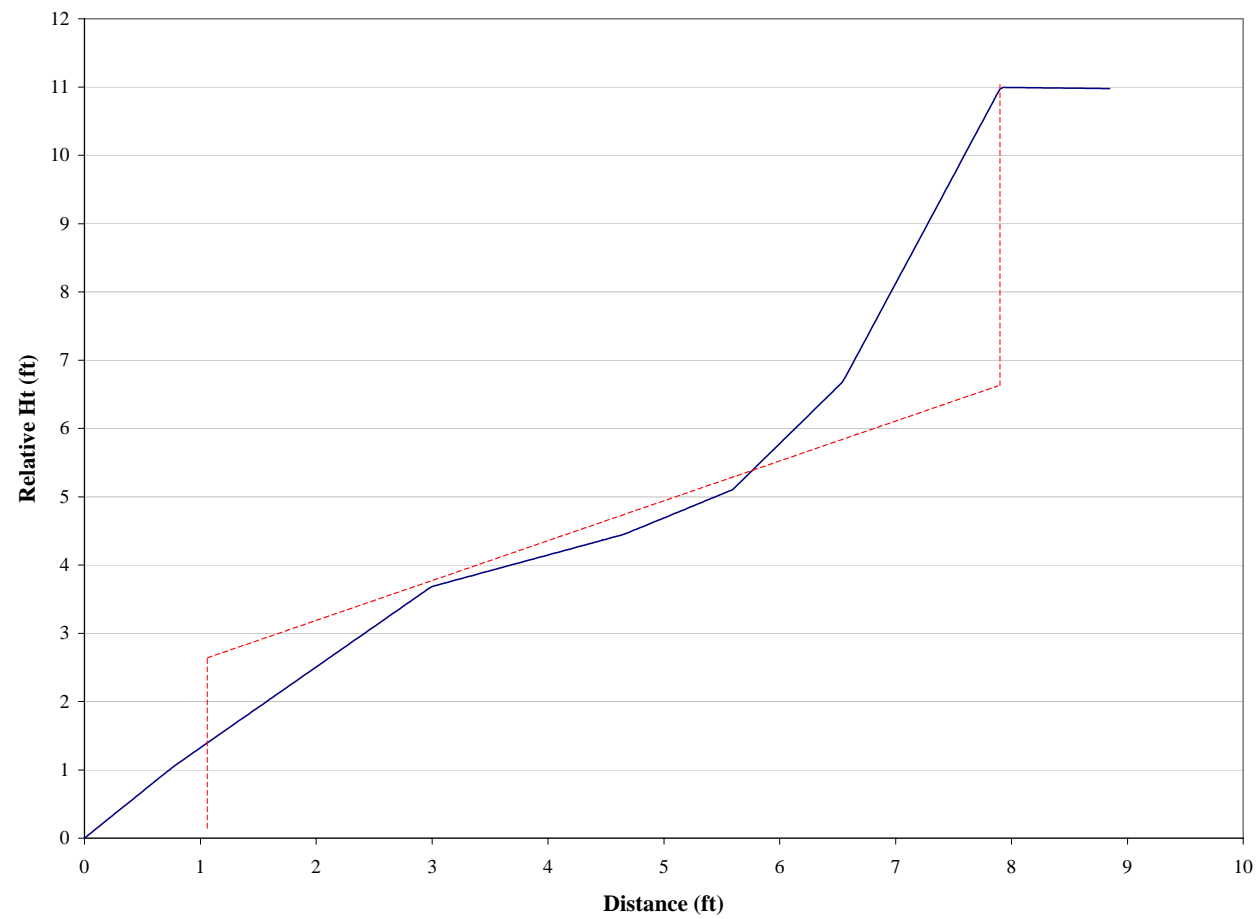

Figure A14. Site 4 east bank ALSM and approximated measured slope. 


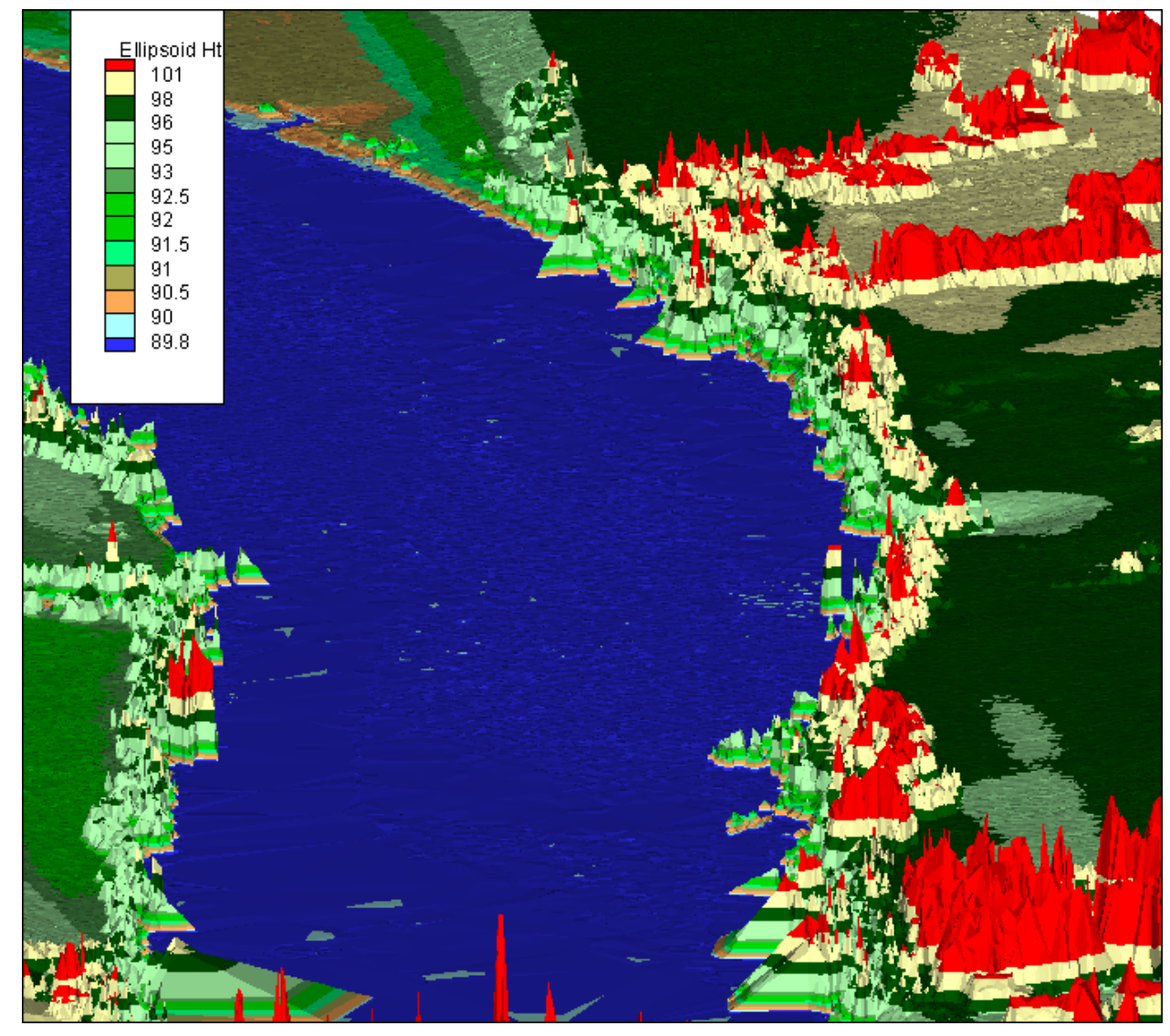

Figure A15. Site 5 ALSM looking north. The road on the east bank is about halfway up the image, partially obscured by trees. There is a light green circle coming from the trees indicating an elevation difference. 


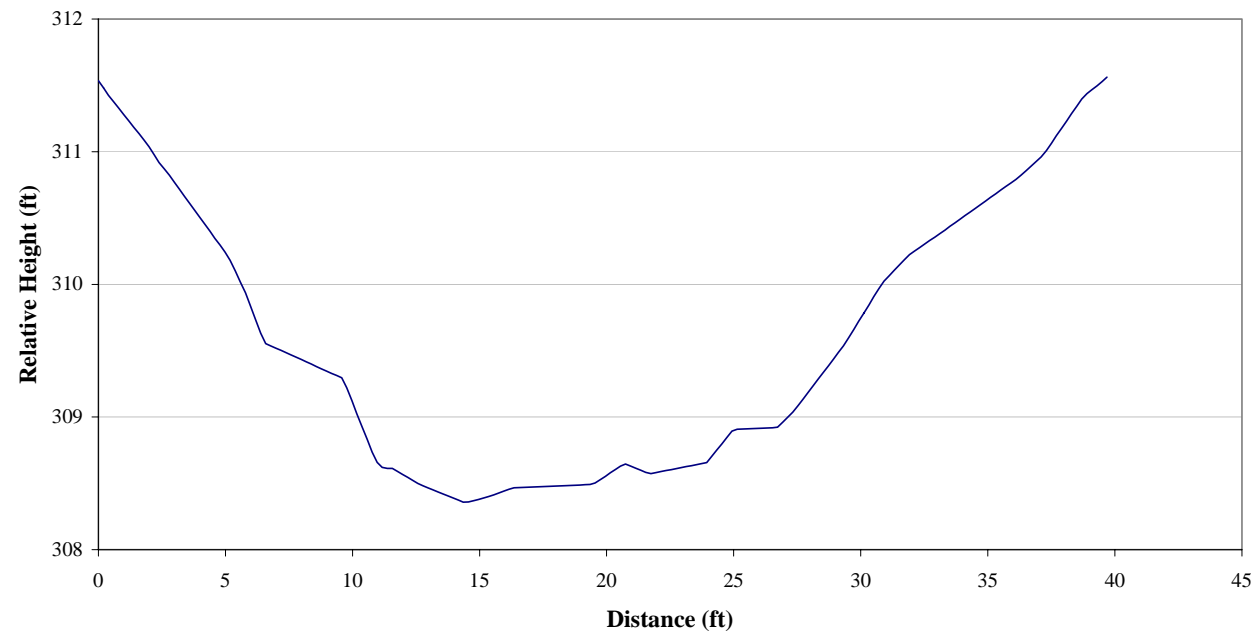

Figure A16. Site 5 road cross section from north to south. No ground survey available.

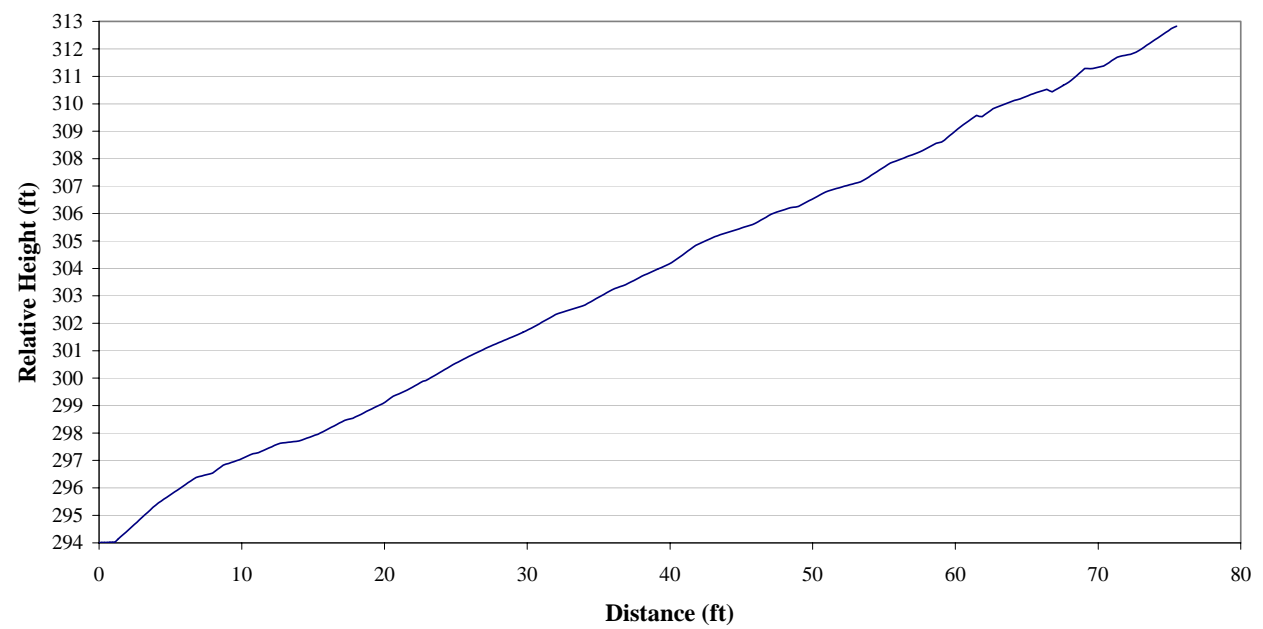

Figure A17. Site 5 road centerline slope from water surface up. No ground survey available. 


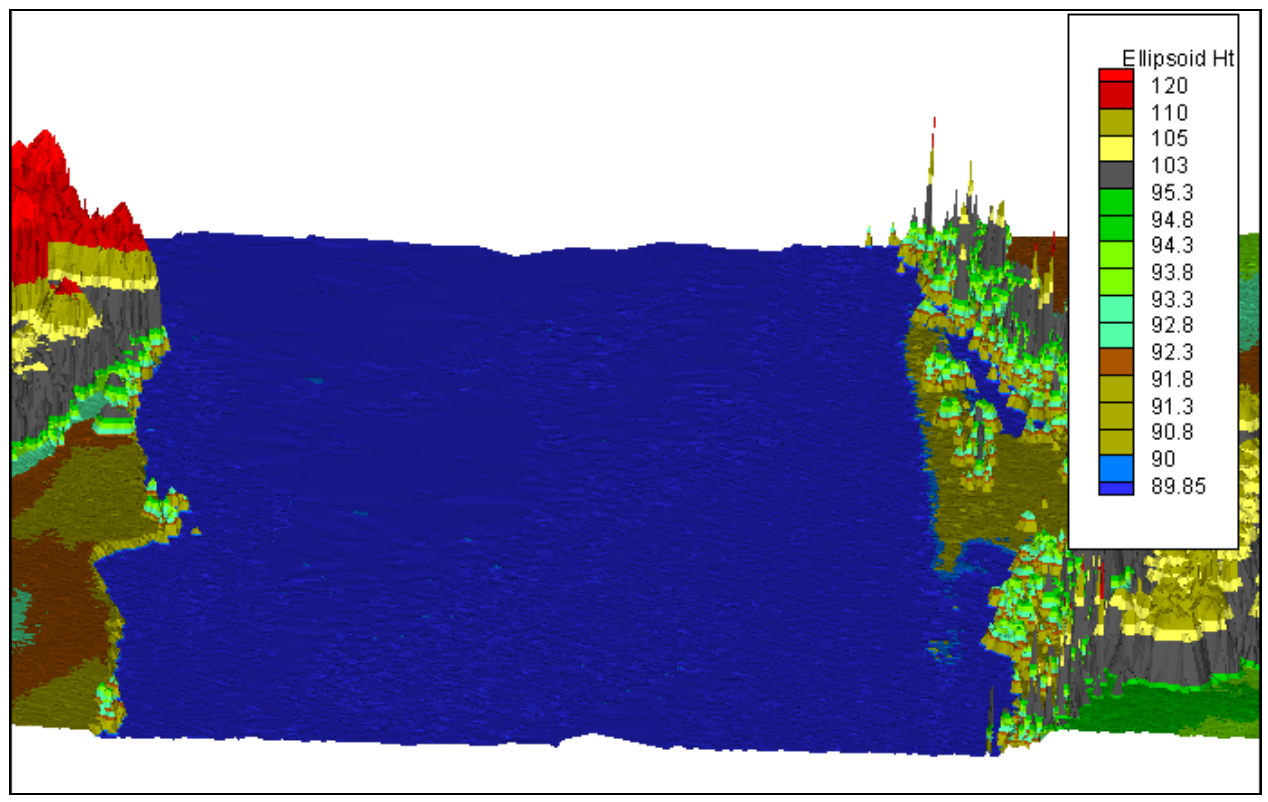

Figure A18. Site 6 ALSM looking north.

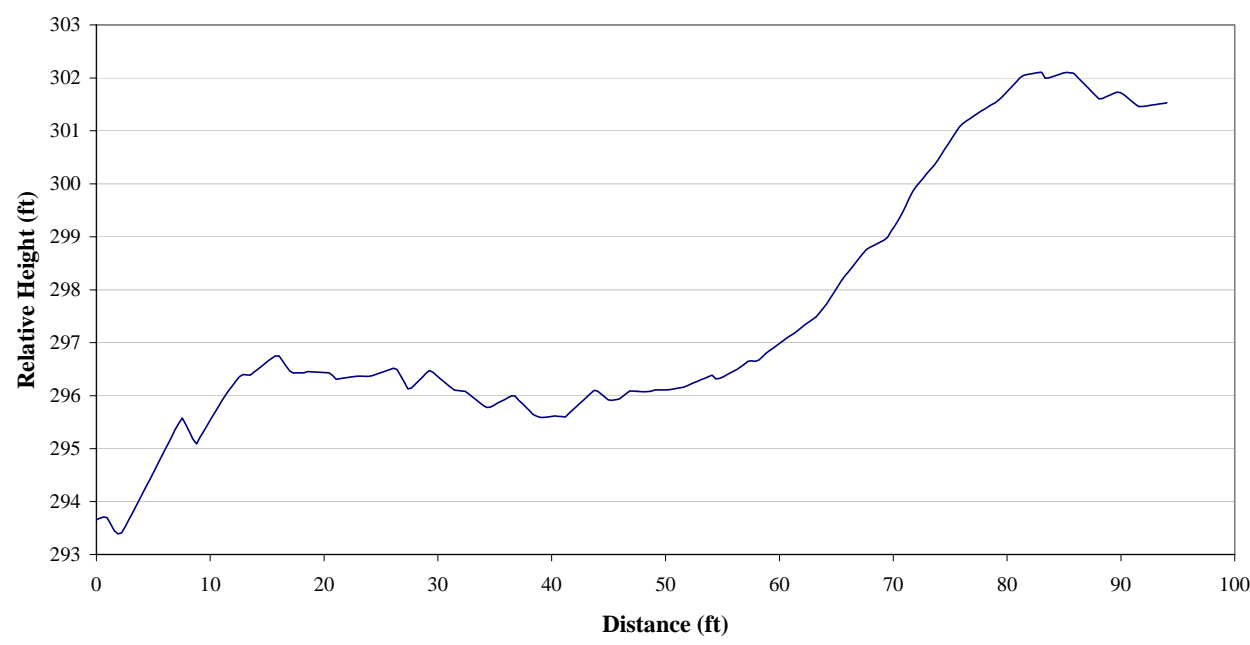

Figure A19. Site 6 east bank ALSM with water surface at distance 0 . No ground survey available. 


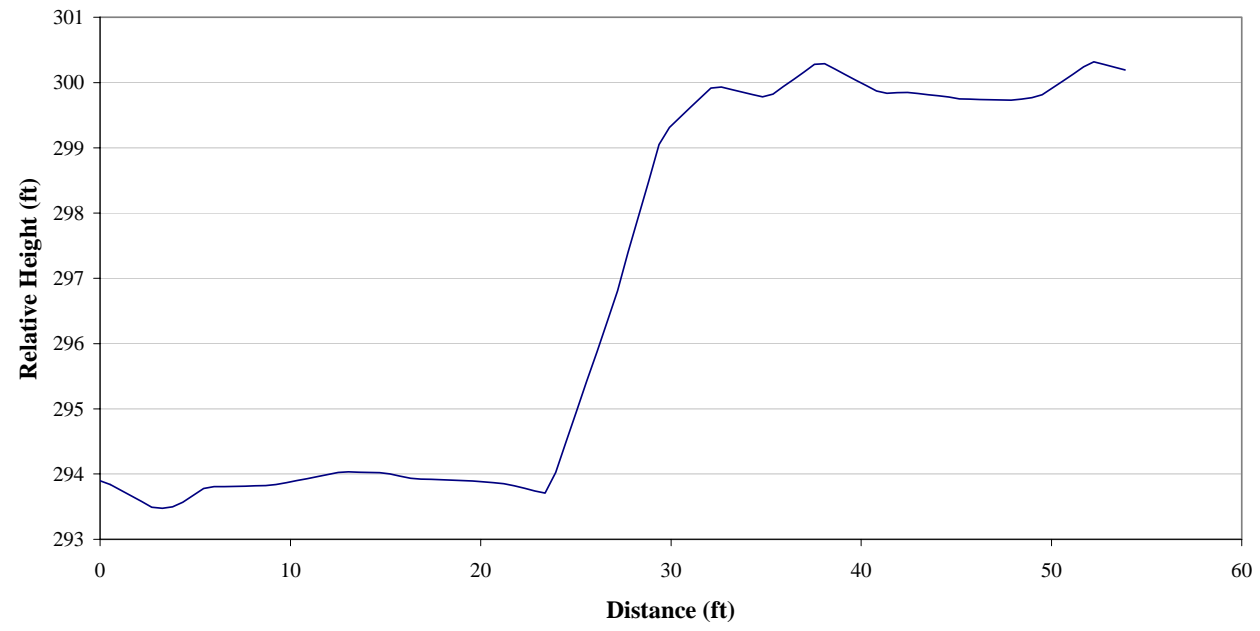

Figure A20. Site 6 west bank ALSM with water surface from distance 0 to 25 feet. No ground survey available.

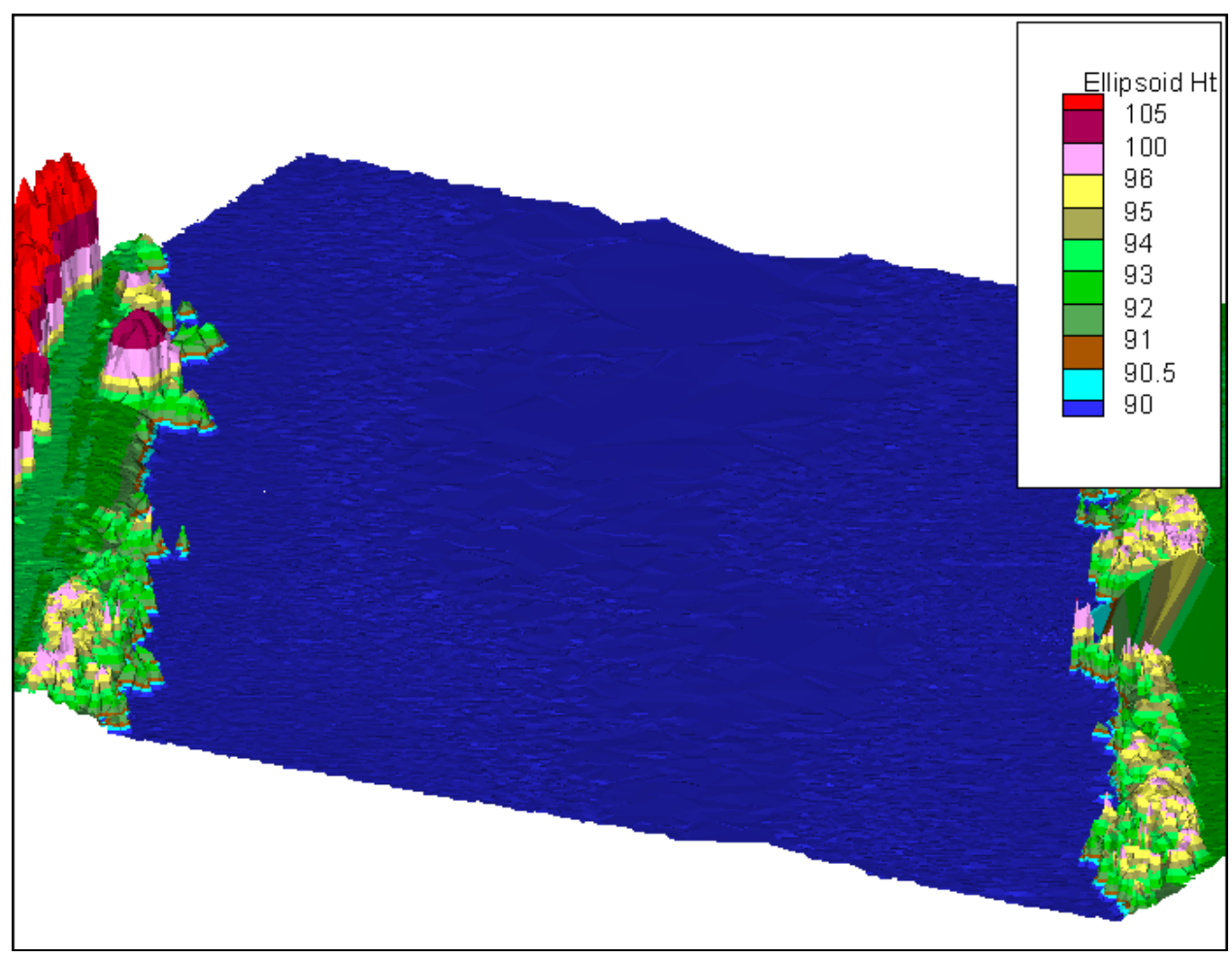

Figure A21. Site 7 ALSM looking north. 


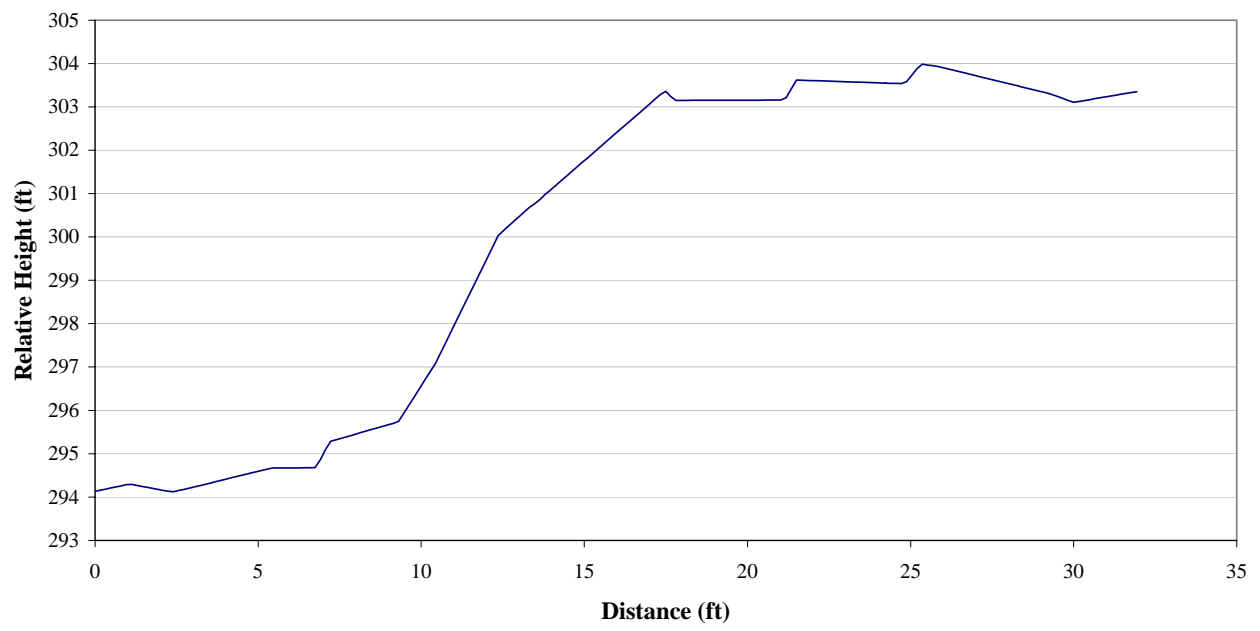

Figure A22. Site 7 east bank ALSM with water surface from about distance 0 to 7 feet. No ground survey data available.

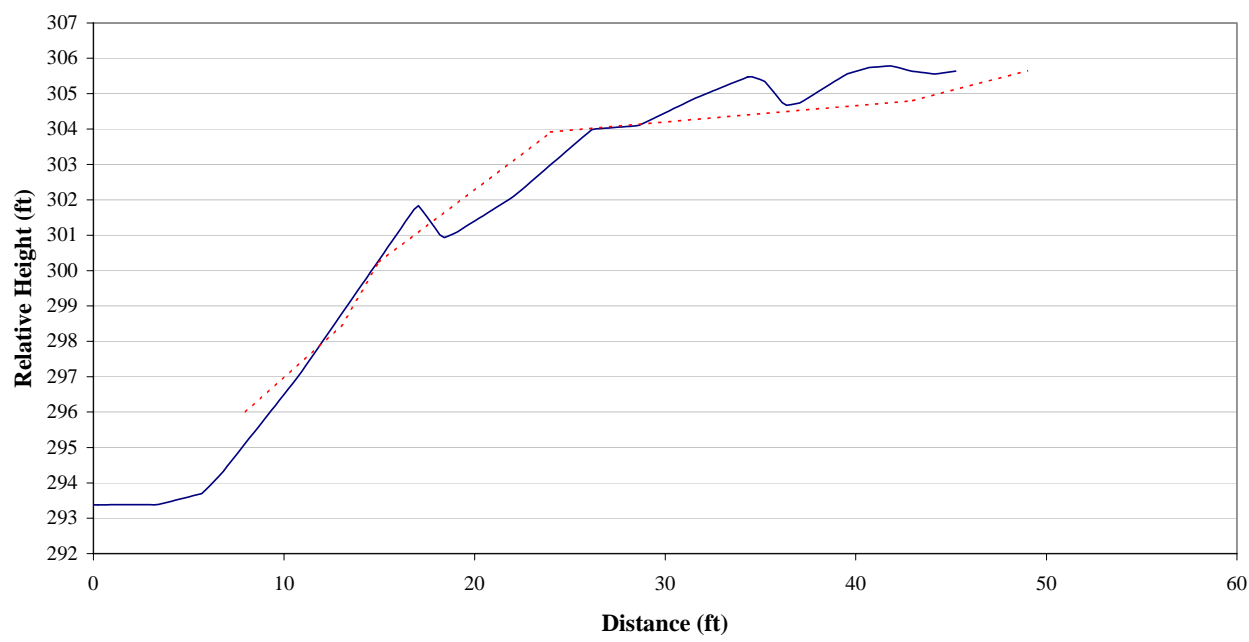

Figure A23. Site 7 west bank ALSM and ground survey comparison. Water surface is from distance 0 to about 5 feet. 


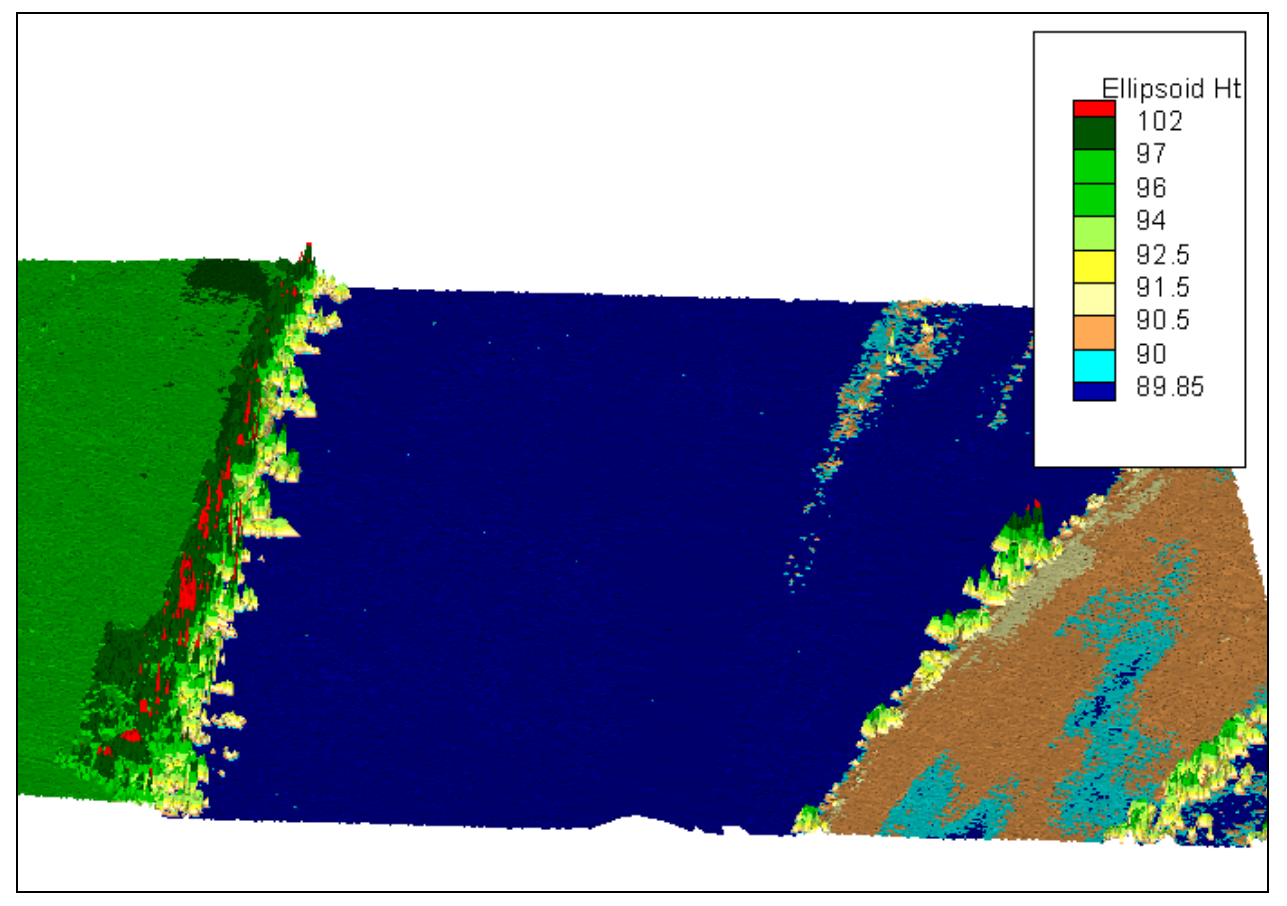

Figure A24. Site 8 ALSM looking north. 


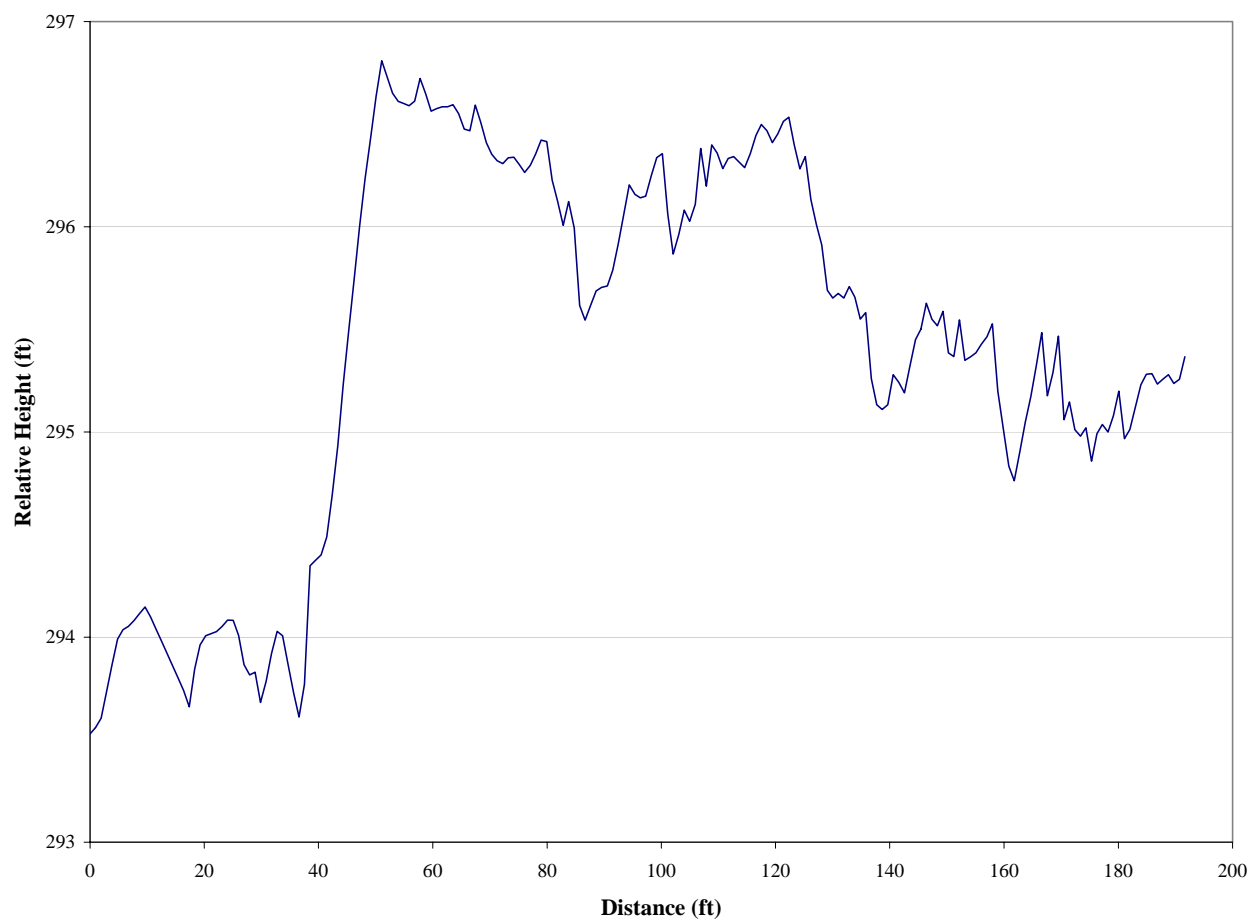

Figure A25. Site 8, east bank ALSM, a low marshy area with marsh grass. Water surface is from distance 0 to about 35 feet. No ground survey data available. 


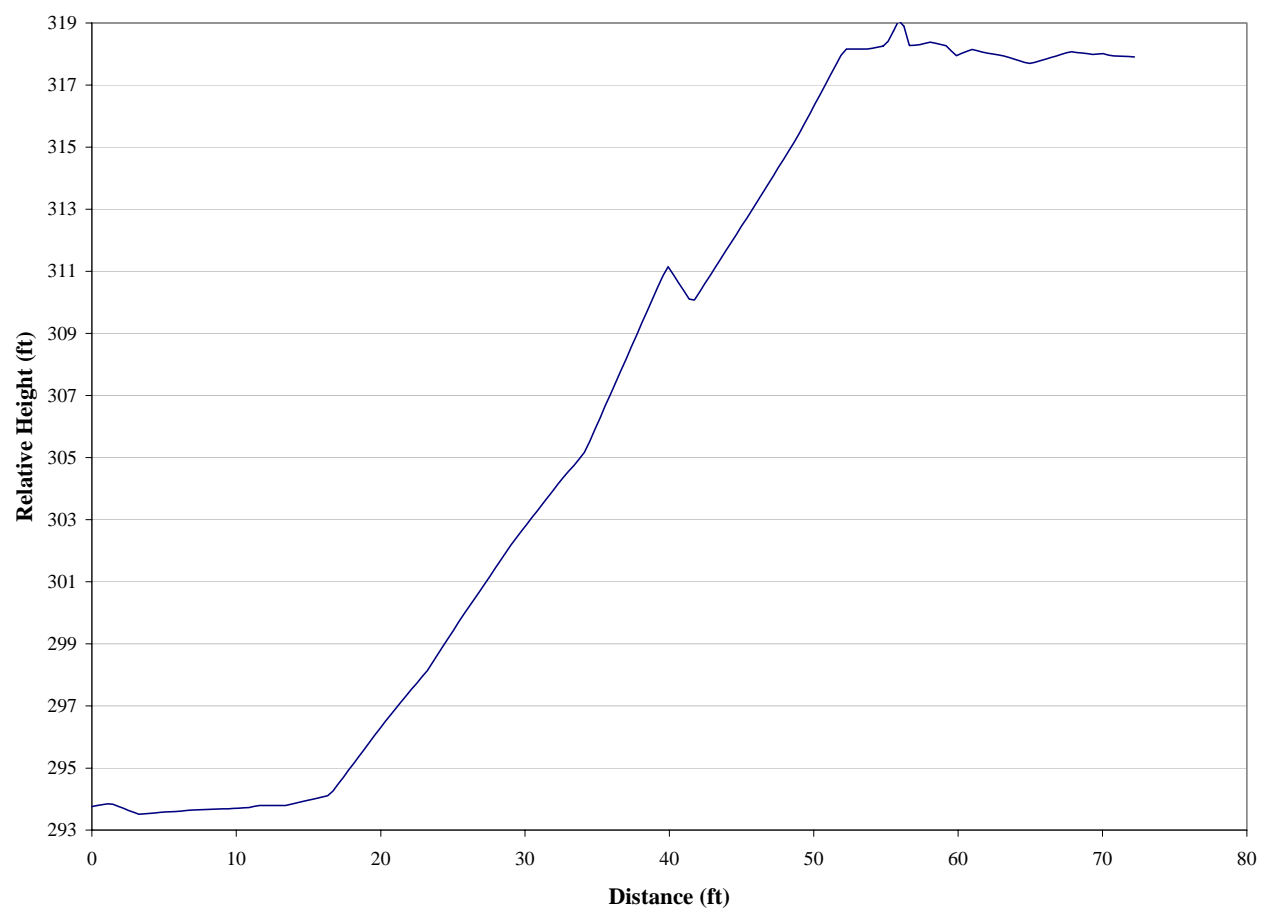

Figure A26. Site 8 west bank. Water surface is from distance 0 to about 15 feet. No ground survey data available. 


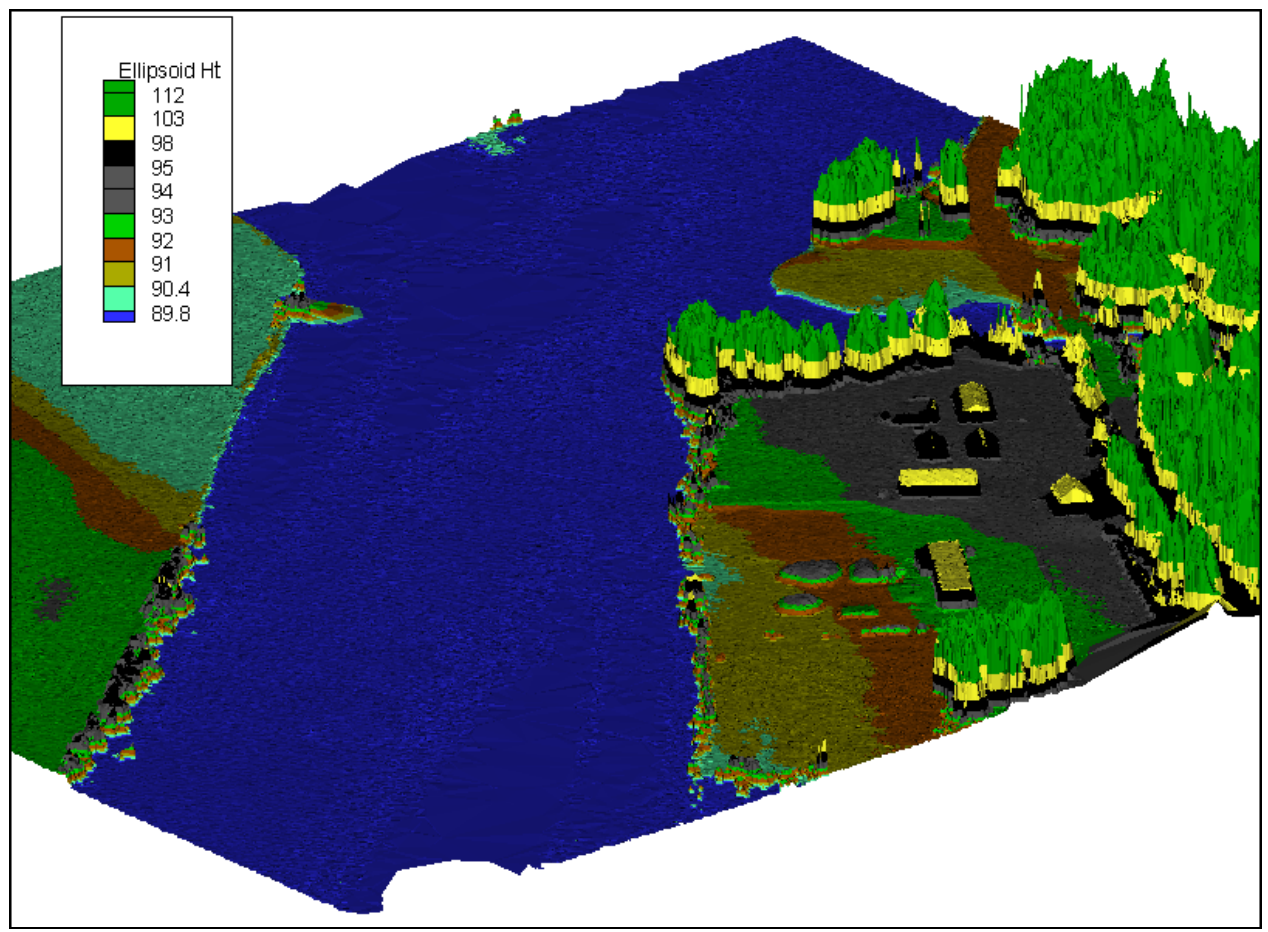

Figure A27. Site 9 ALSM looking north. A lumber yard is on the right in the image. 


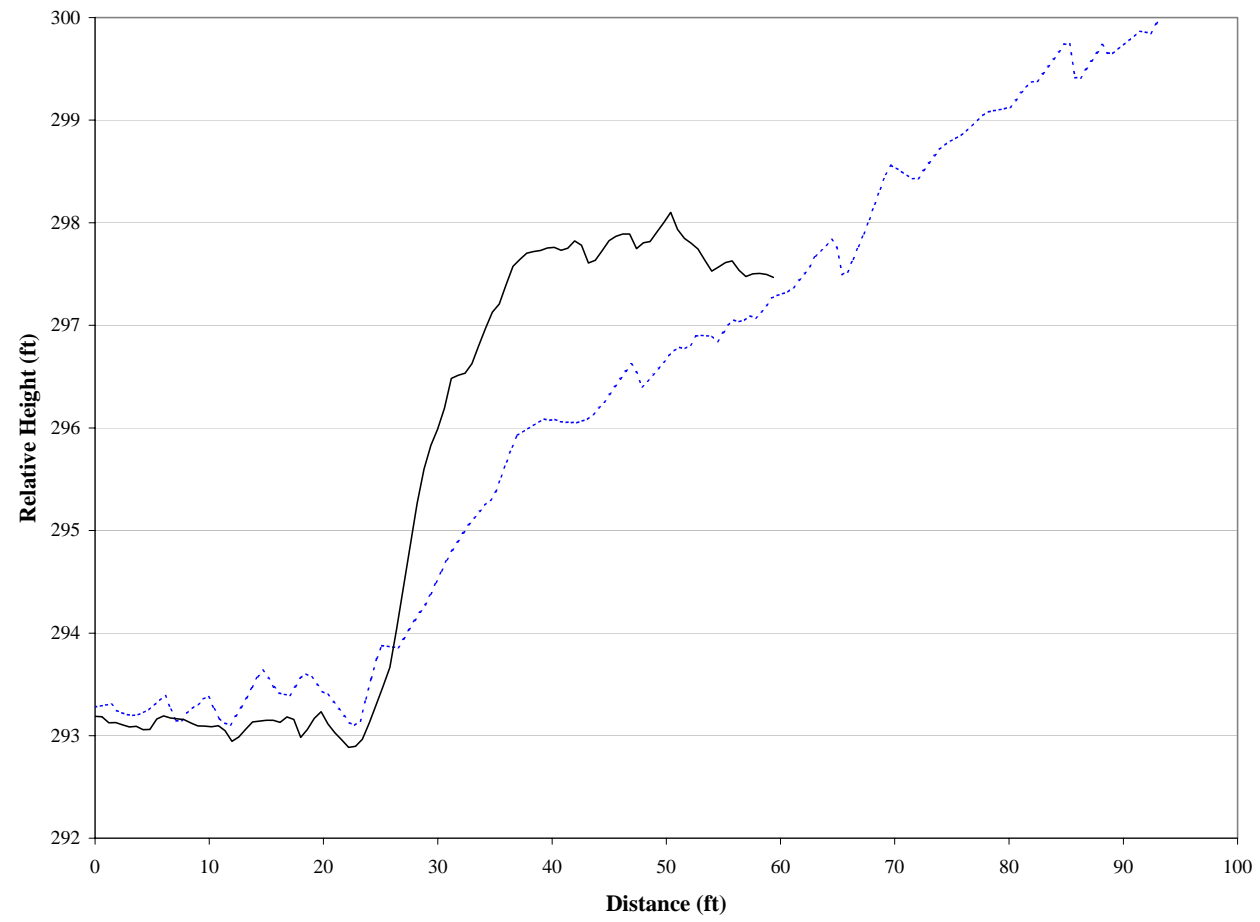

Figure A28. Site 9 east bank. Water surface is from 0 to approximately 23 feet. Dashed blue line is bank slope at a boat launching area. Black solid line is slope at another portion of the bank for comparison. No ground survey data available. 


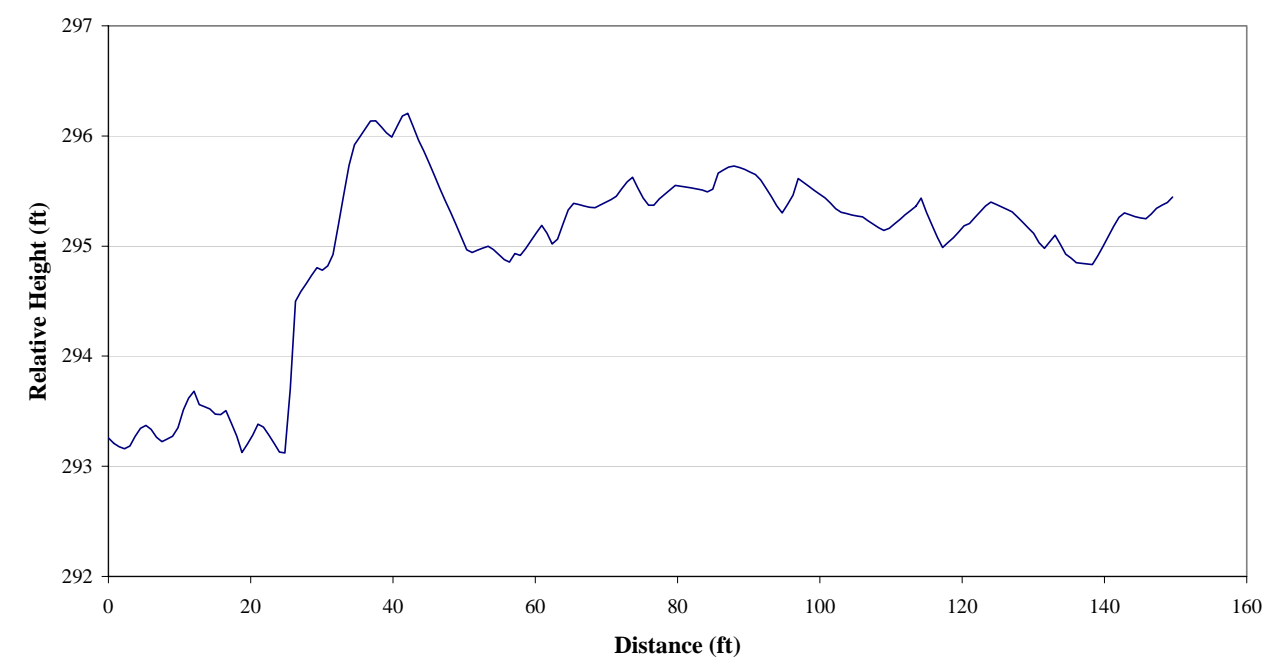

Figure A29. Site 9 west bank. Water is from distance 0 to about 22 feet. First peak after that is thought to be bank with thick grass taller than a mown field from about $\mathbf{5 0}$ feet onward. No ground survey data available.

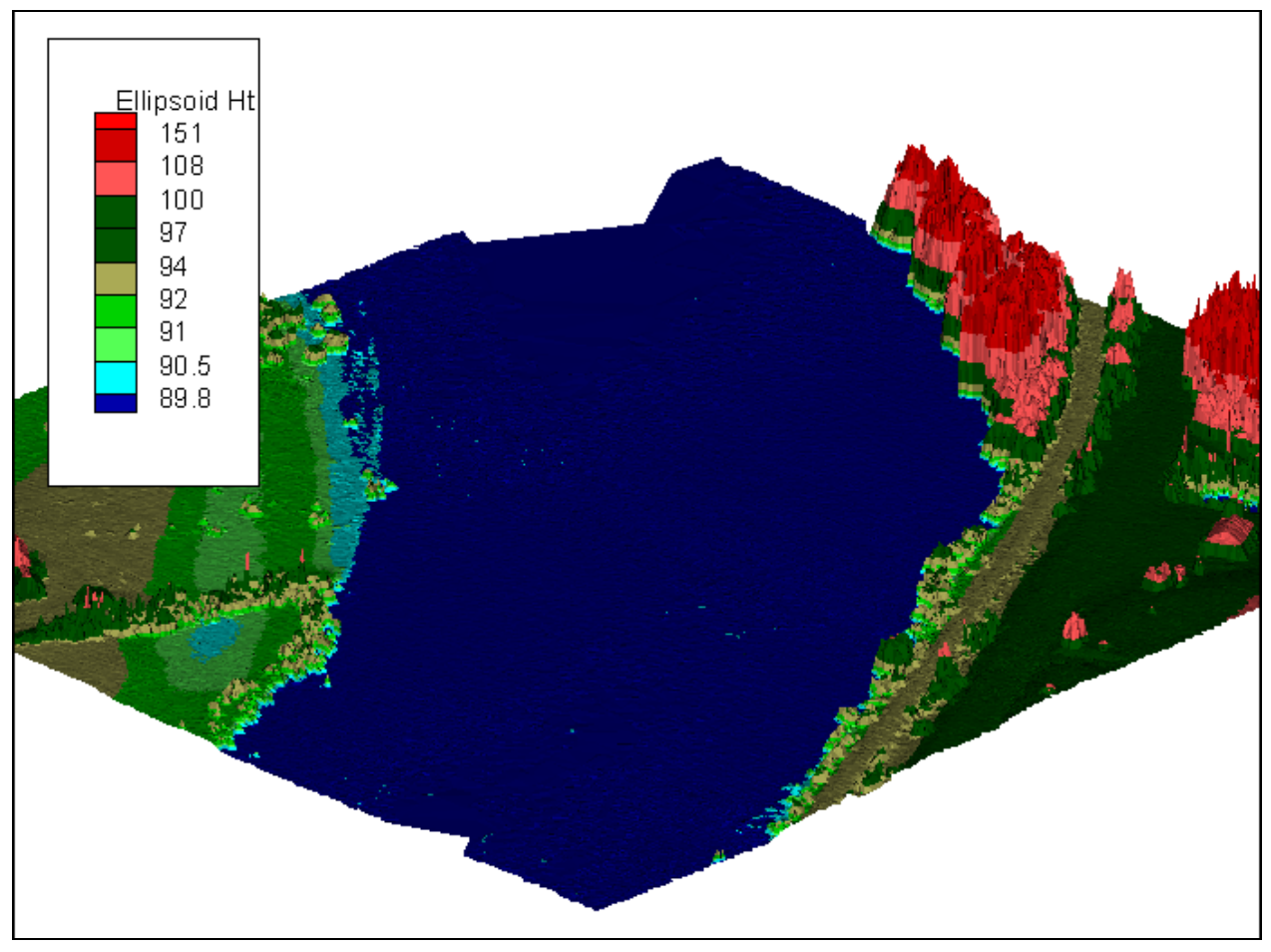

Figure A30. Site 10 ALSM looking north. The brown stripe on the right is a highway alongside the river. 


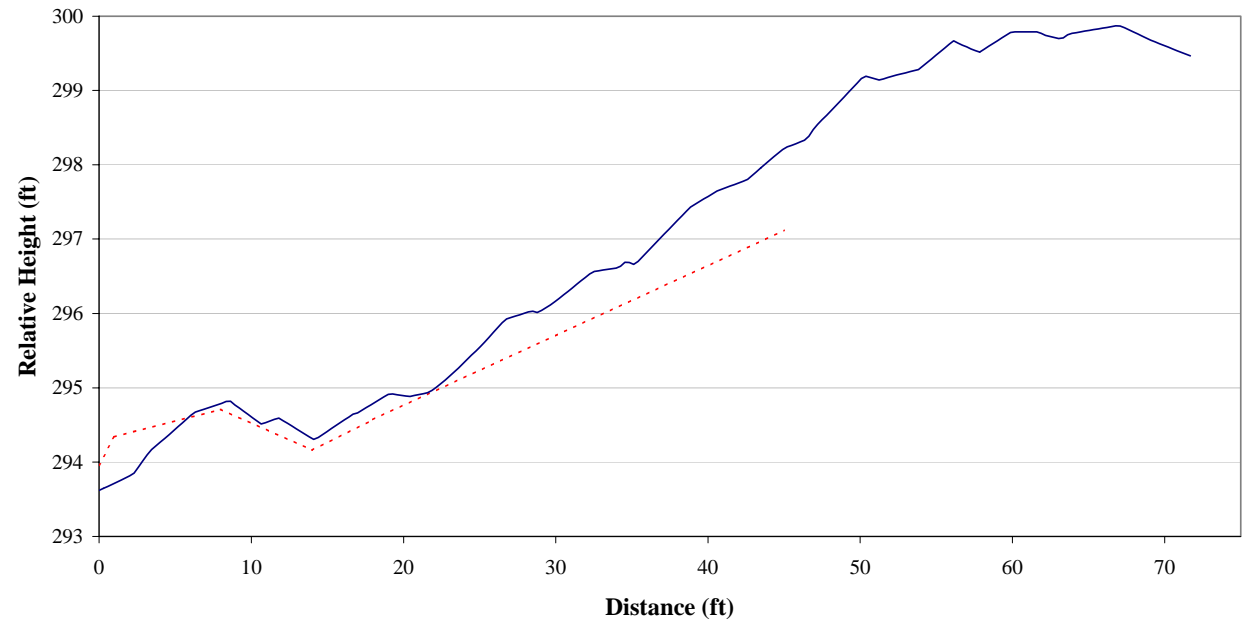

Figure A31. Site 10 east bank survey and ALSM comparison. Water surface is at distance 0 . 


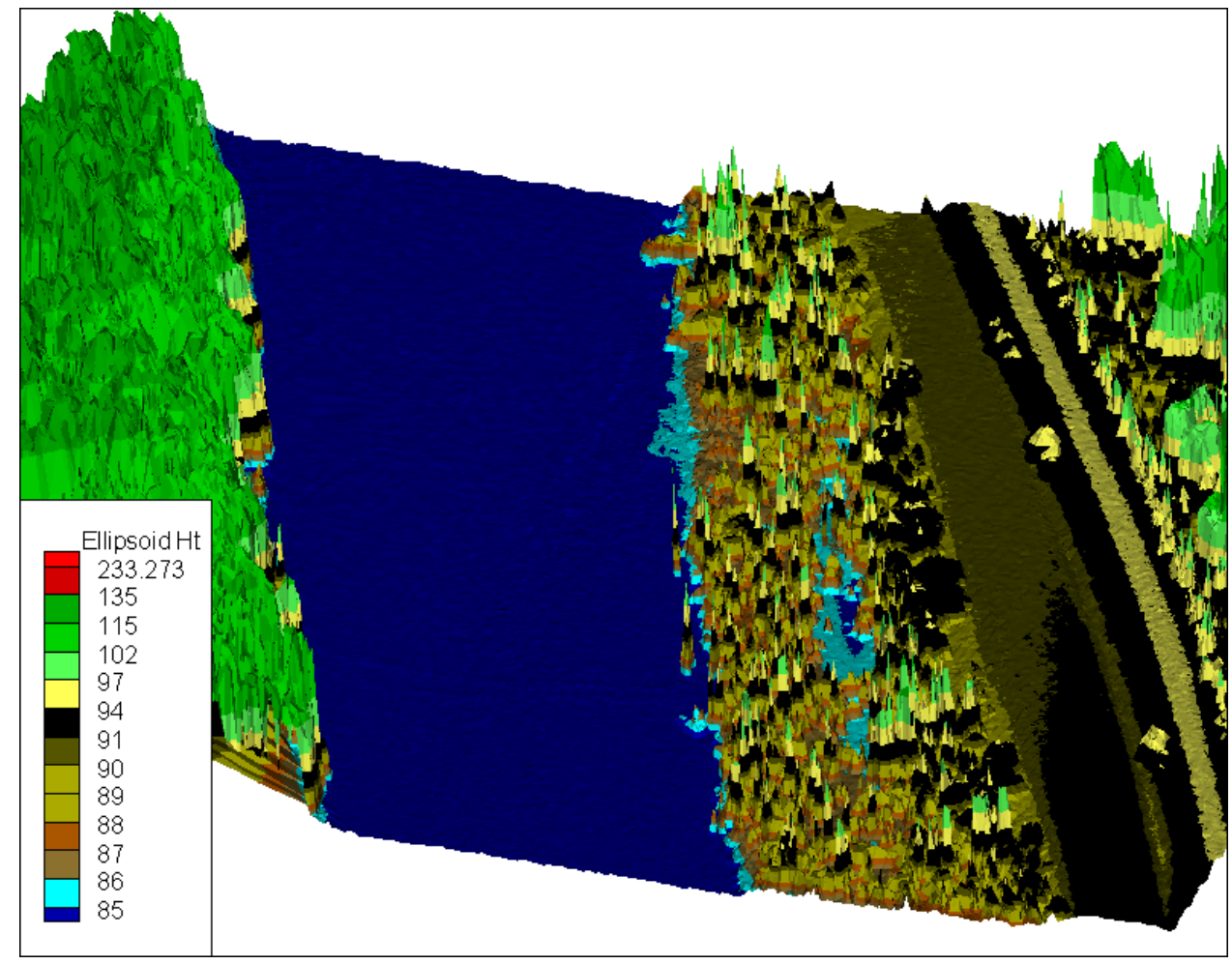

Figure A32. Site 13 ALSM looking north. The west bank was steep and heavily wooded. The east bank was a slightly raised floodplain with moderate trees and vegetation with some paths between. 


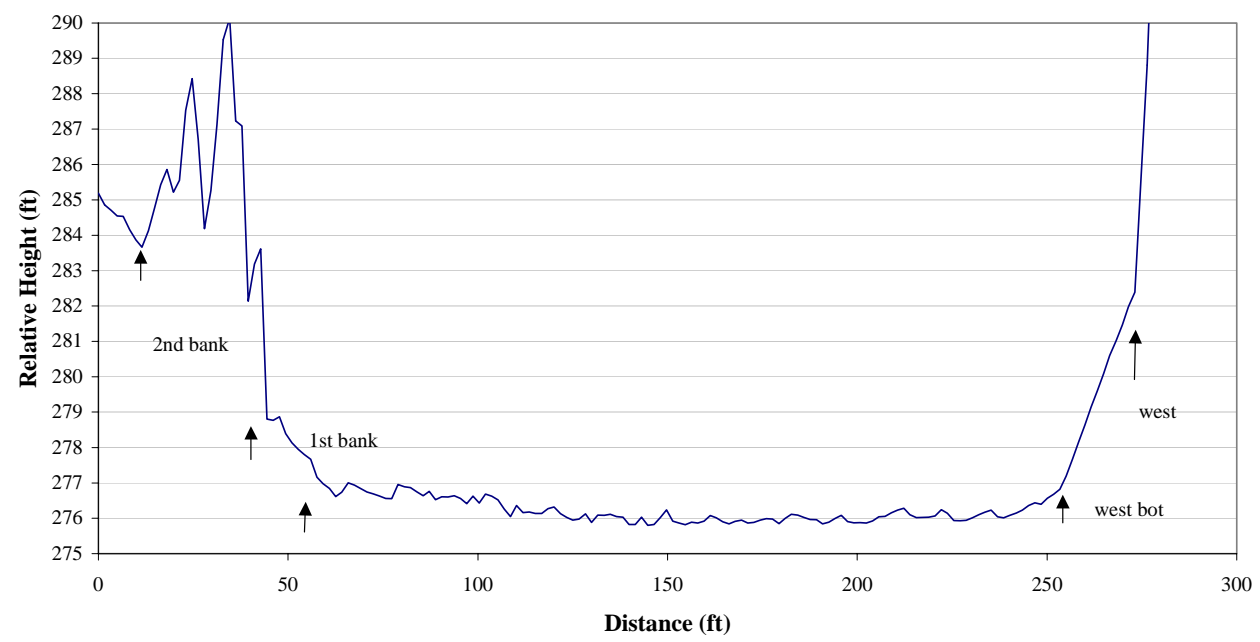

Figure A33. Site 13 ALSM profile. Distance 0 is at the east bank. The jagged profile between the first and second east side banks are vegetation. The water surface is from about distance 65 to 250 feet. 


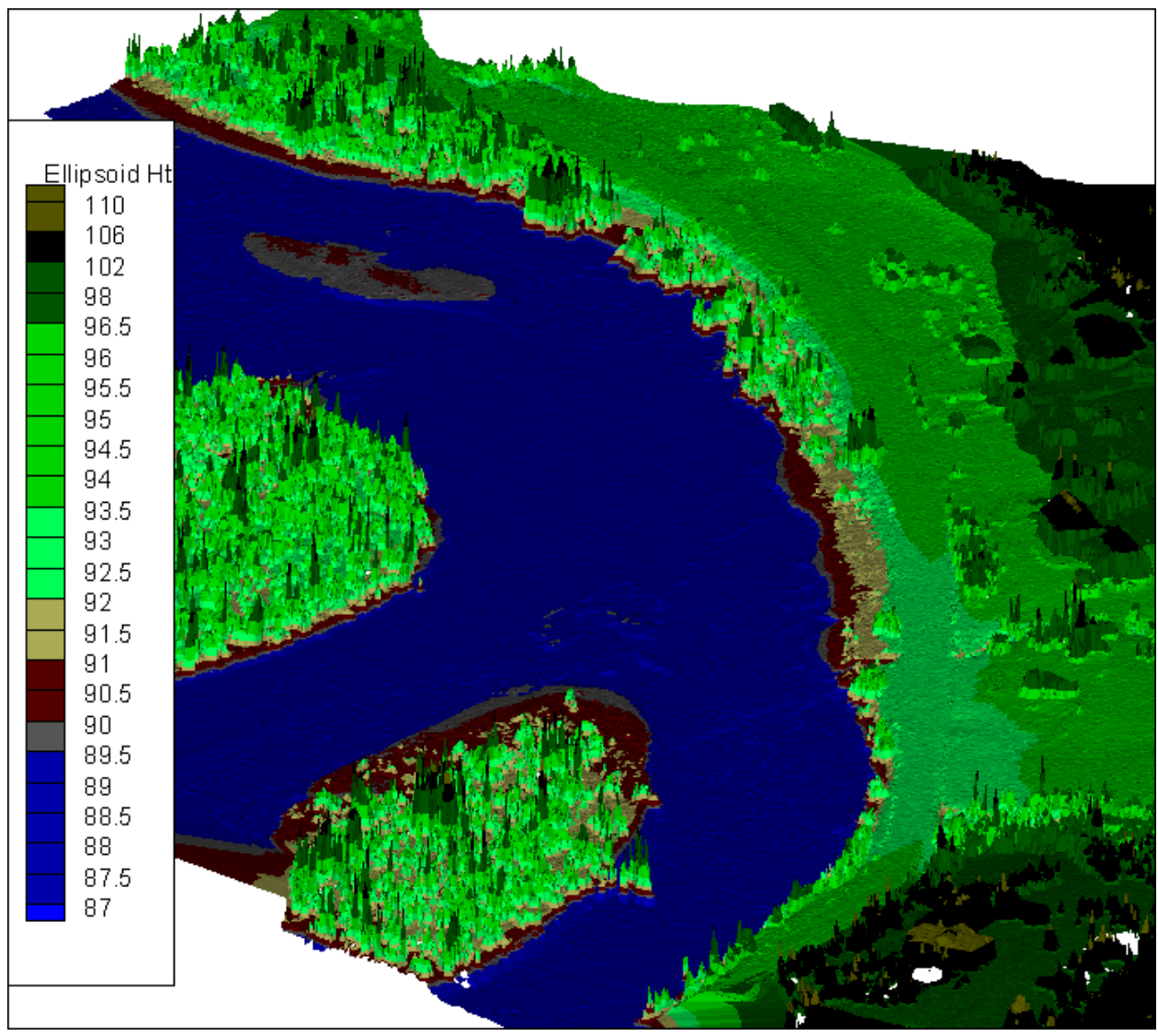

Figure A34. Site 14 ALSM looking north. A road runs along the eastern bank and houses are on the east side of the road. 


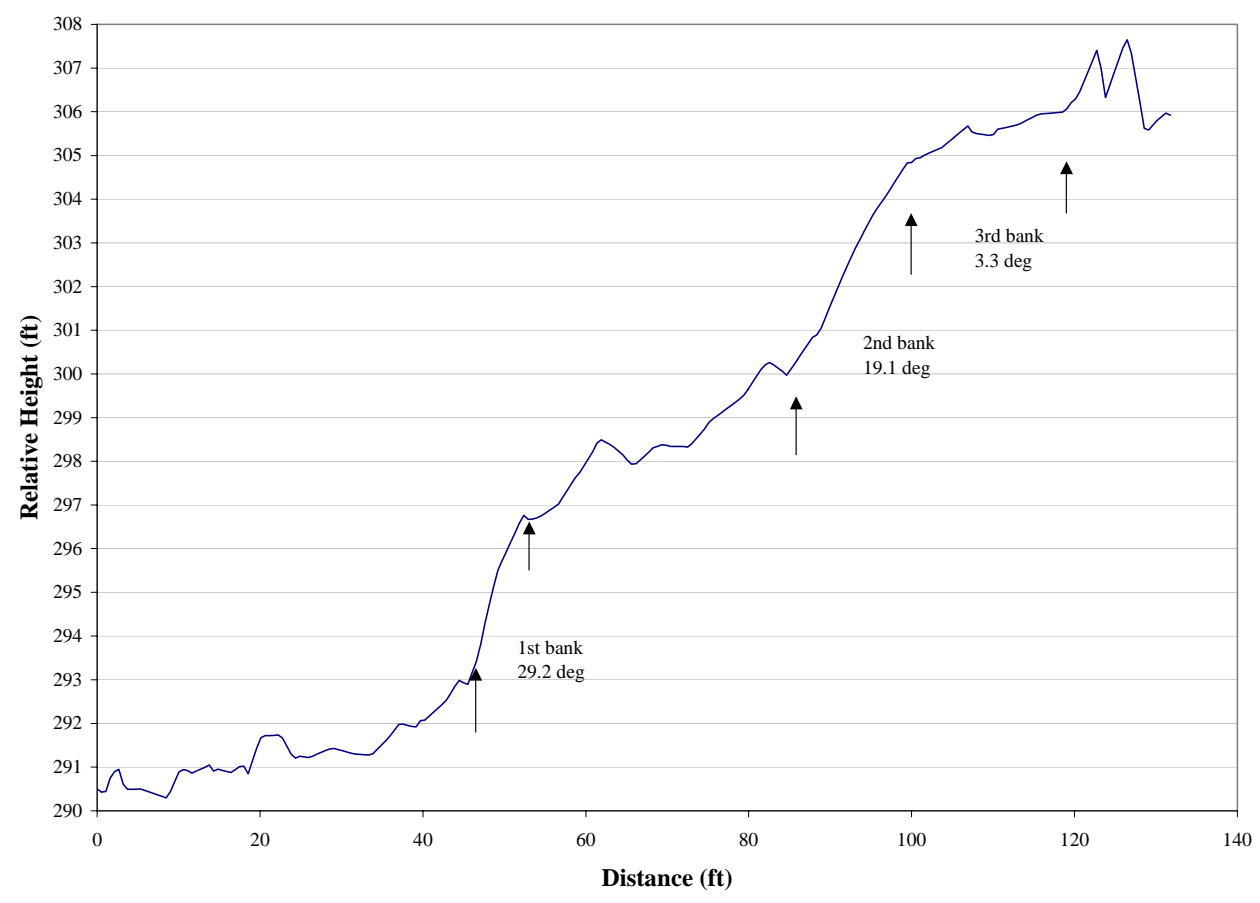

Figure A35. Site 14 east bank. Water surface is from distance 0 to 35 feet. No ground survey data available.

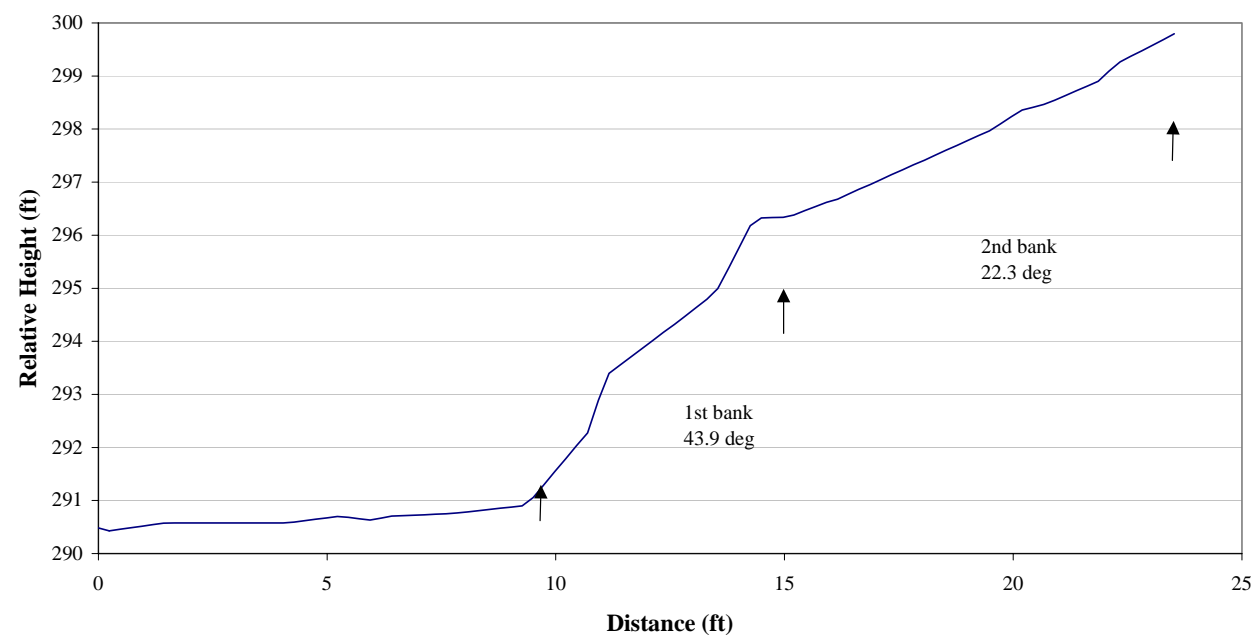

Figure A36. Site 14 west bank. Water surface is from distance 0 to about 7 feet. 


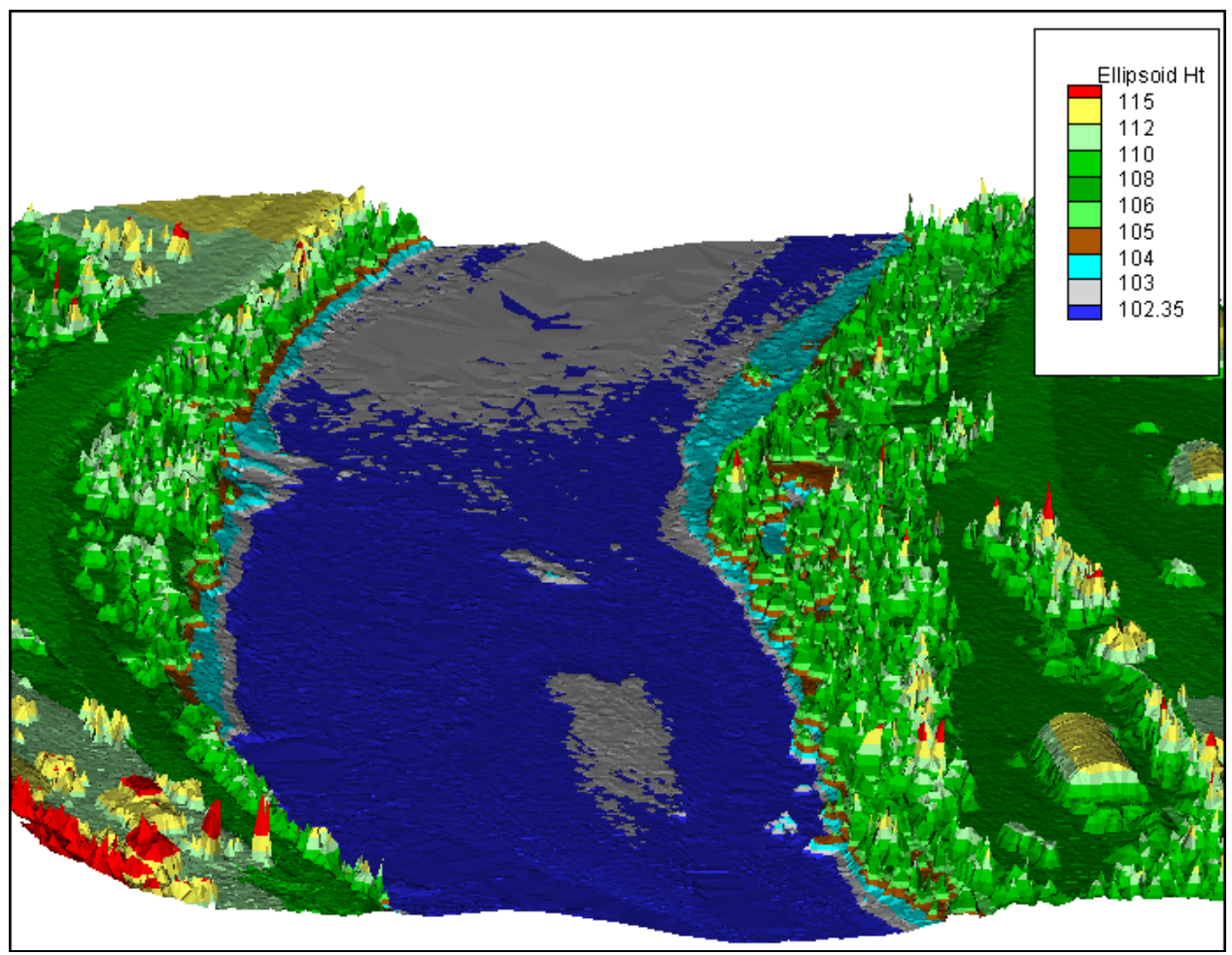

Figure A37. Site 15 ALSM looking north. There are roads on both sides of the river. There is a large Quonset-type shed on the east bank in the lower right of the image. 


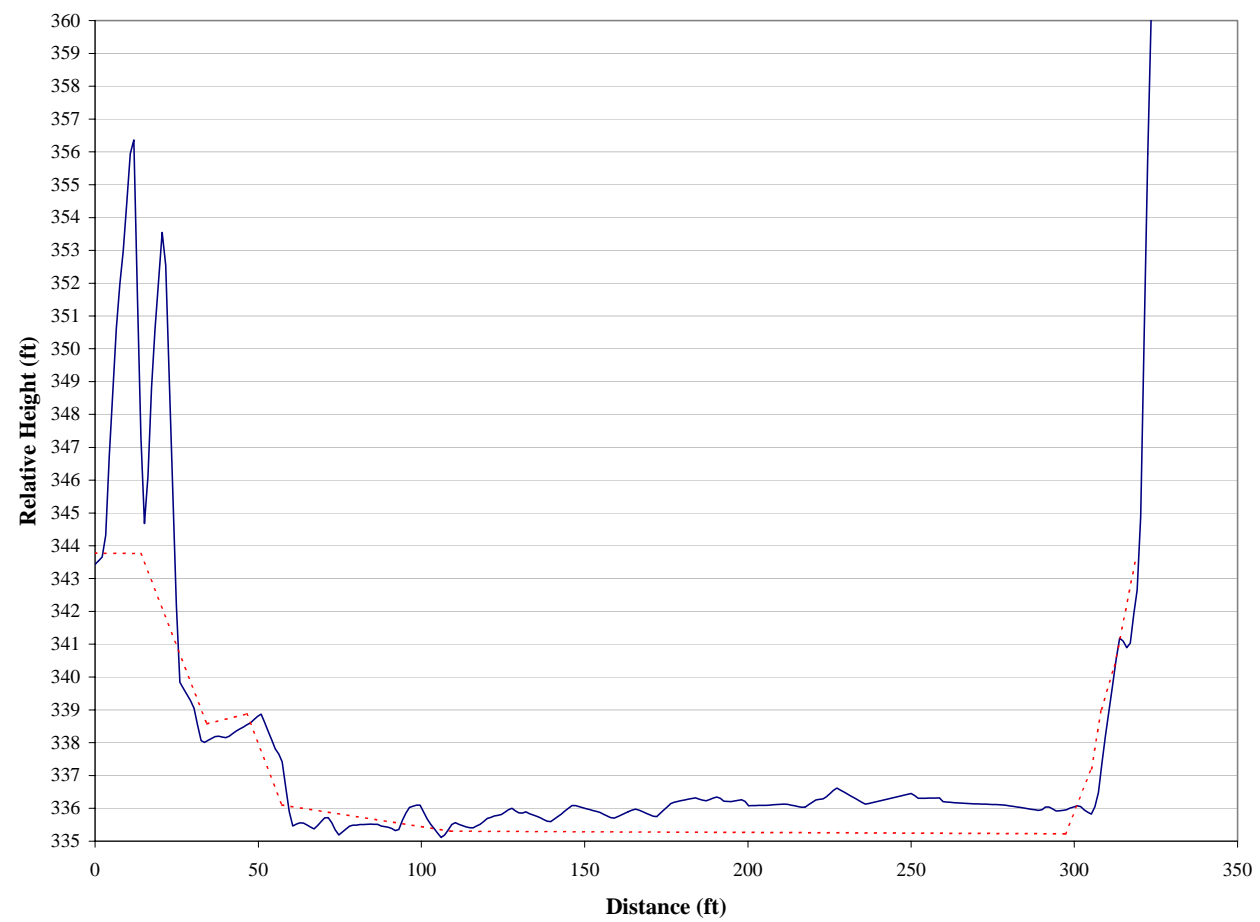

Figure A38. Site 15 ALSM and survey profile comparison. Distance 0 is on the east bank. Water surface is from about distance $\mathbf{7 0}$ to $\mathbf{3 0 0}$ feet. 


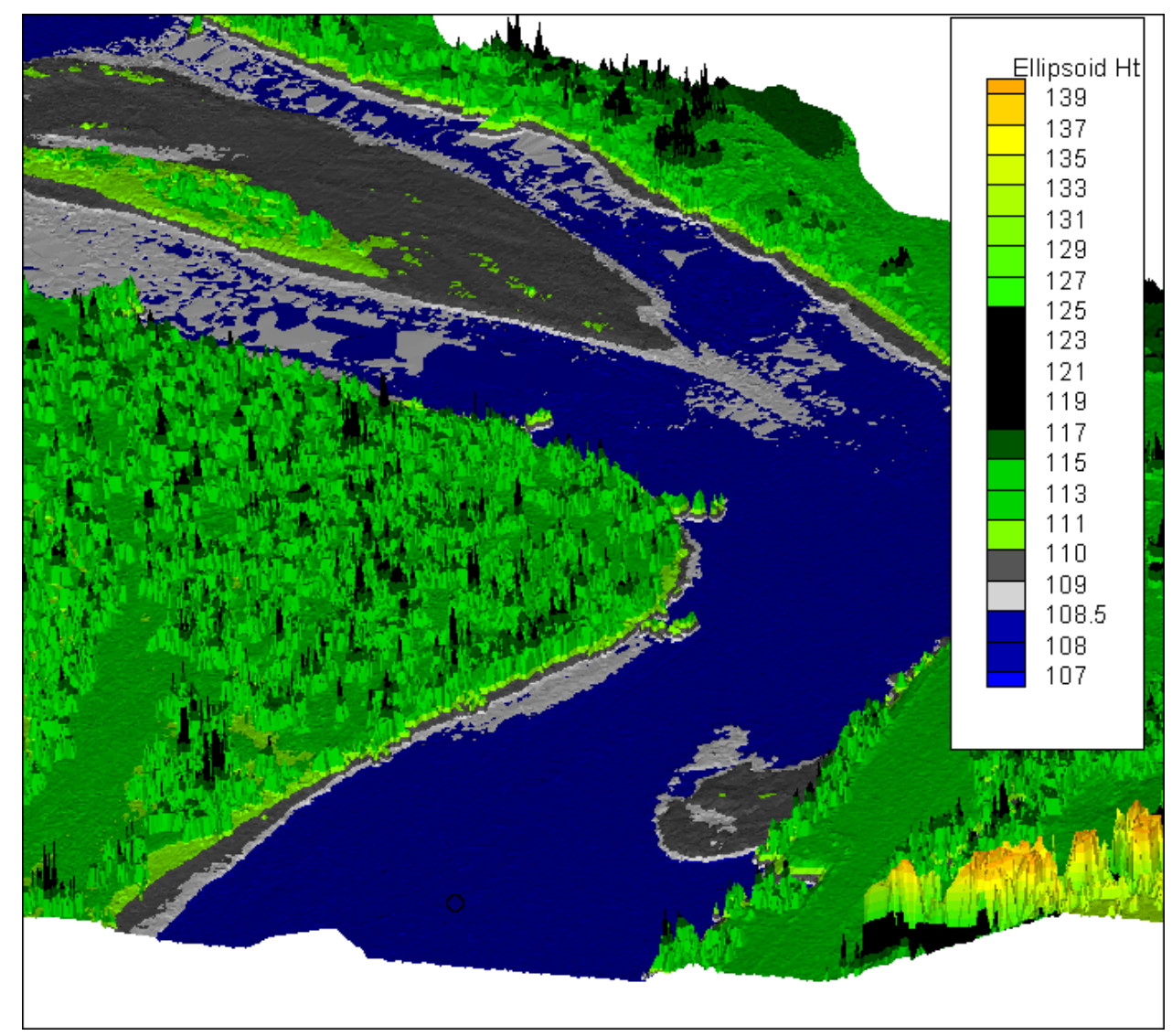

Figure A39. Site 16 ALSM looking north. Area on the west bank with clearings evident was discussed in text of report for trail recognition. 


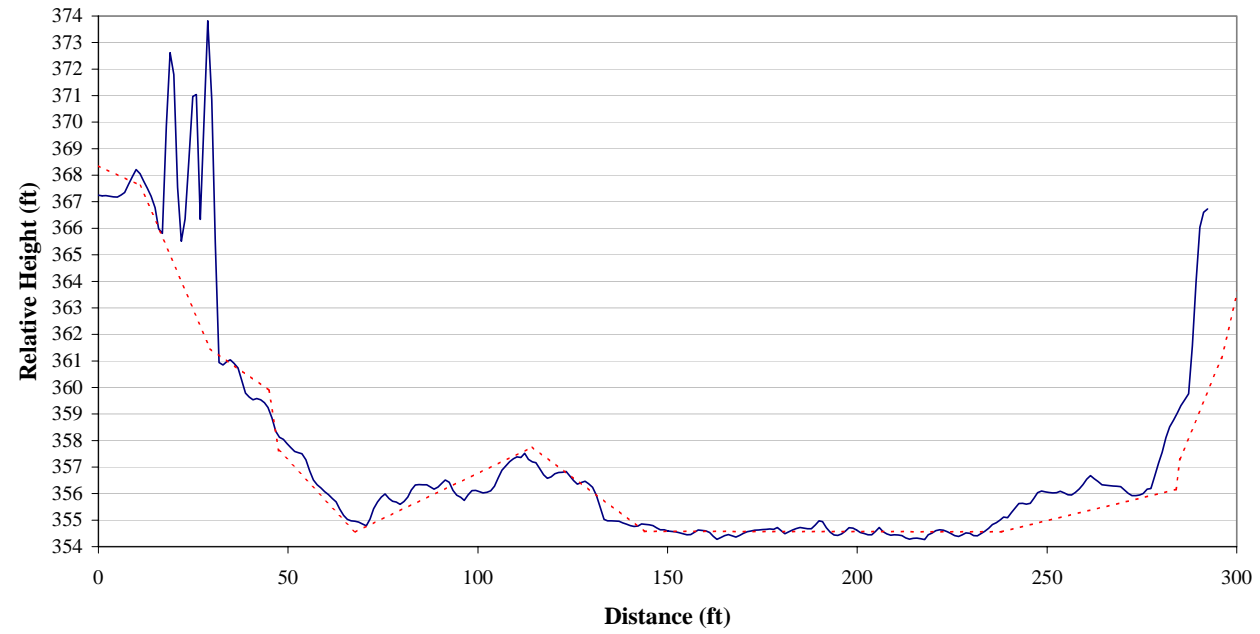

Figure A40. Site 16 ALSM and survey comparison. Distance 0 is on the east bank. 


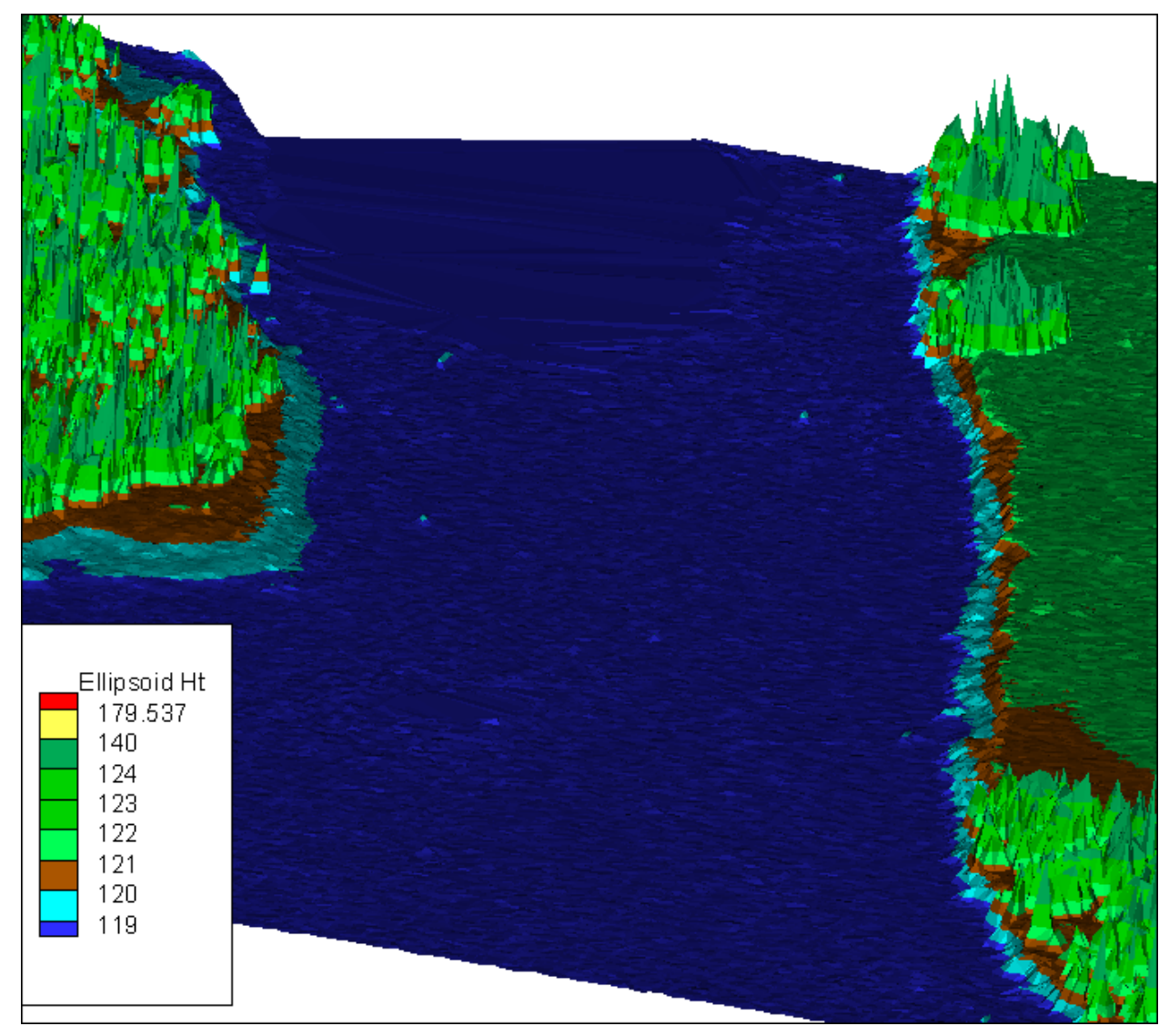

Figure A41. Site 17 ALSM looking north. 


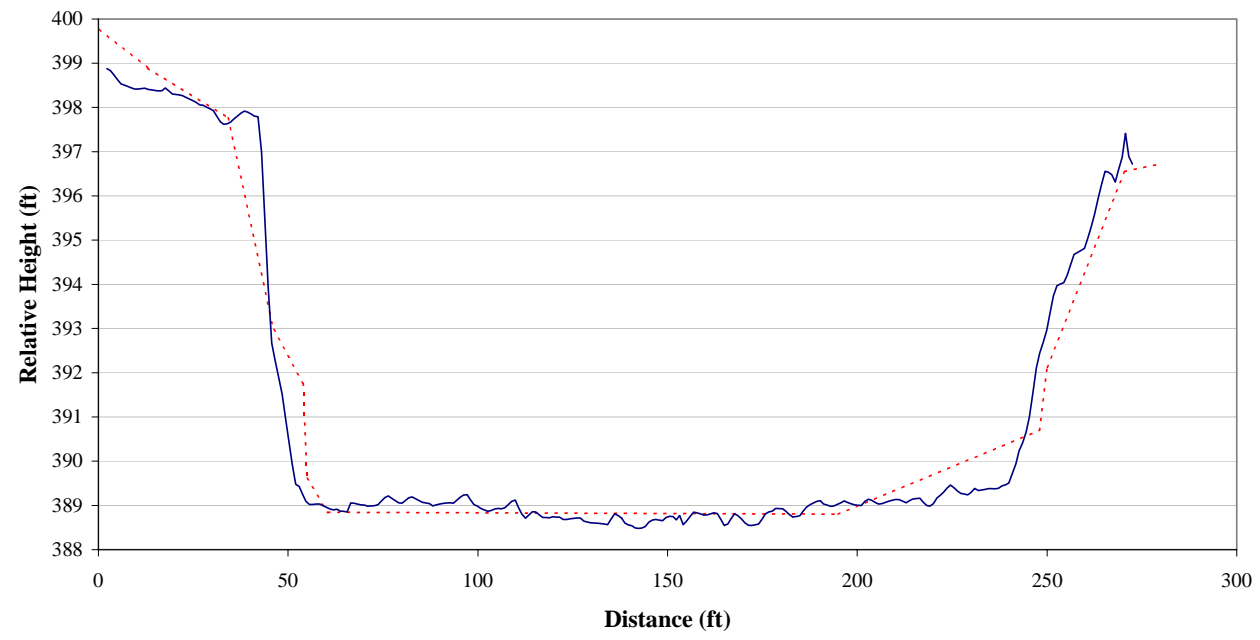

Figure A42. Site 17 ALSM and survey comparison. Distance 0 is on the east bank. The water surface is from about distance 55 to 200 feet. 


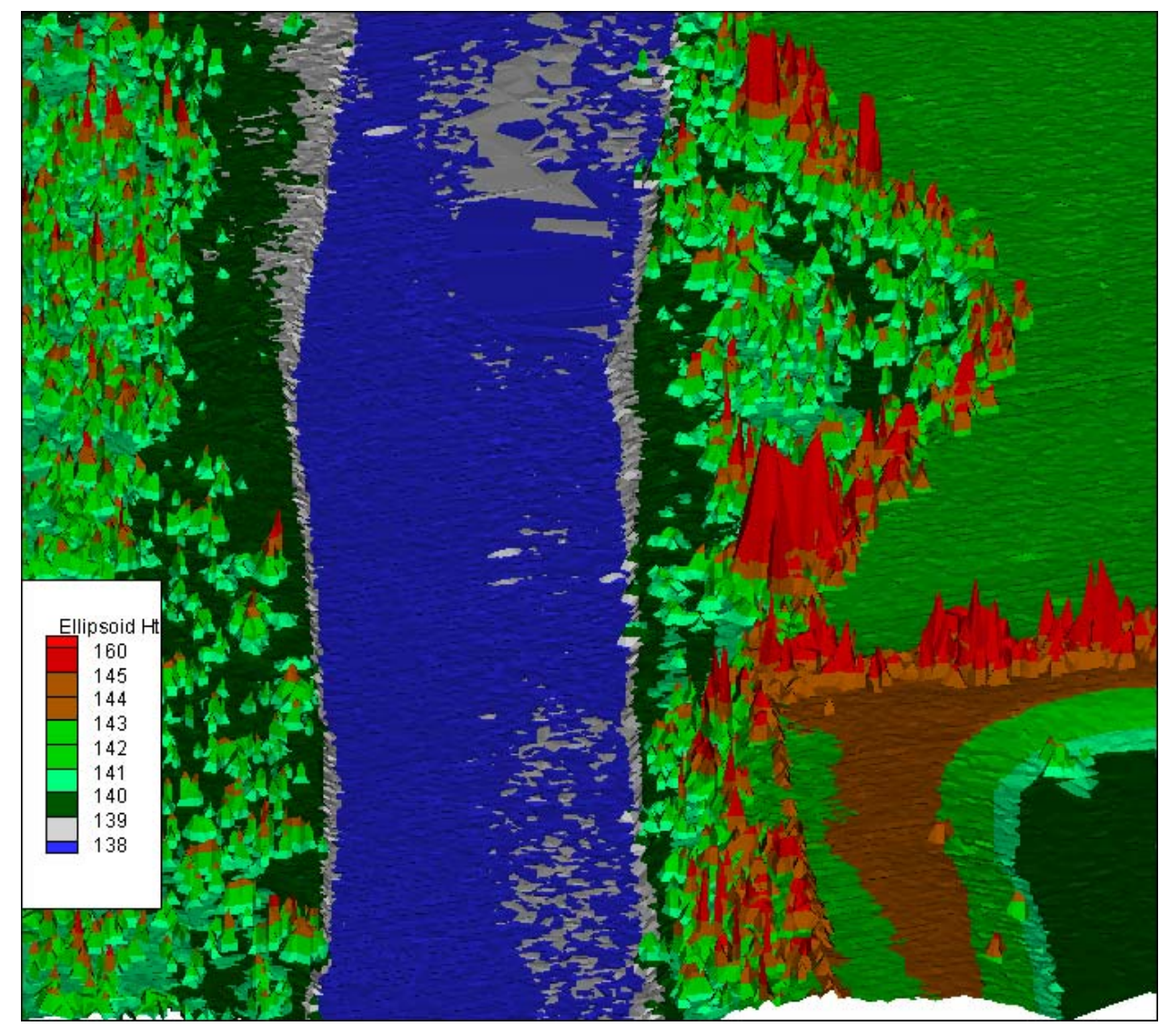

Figure A43. Site 18 ALSM looking east. 


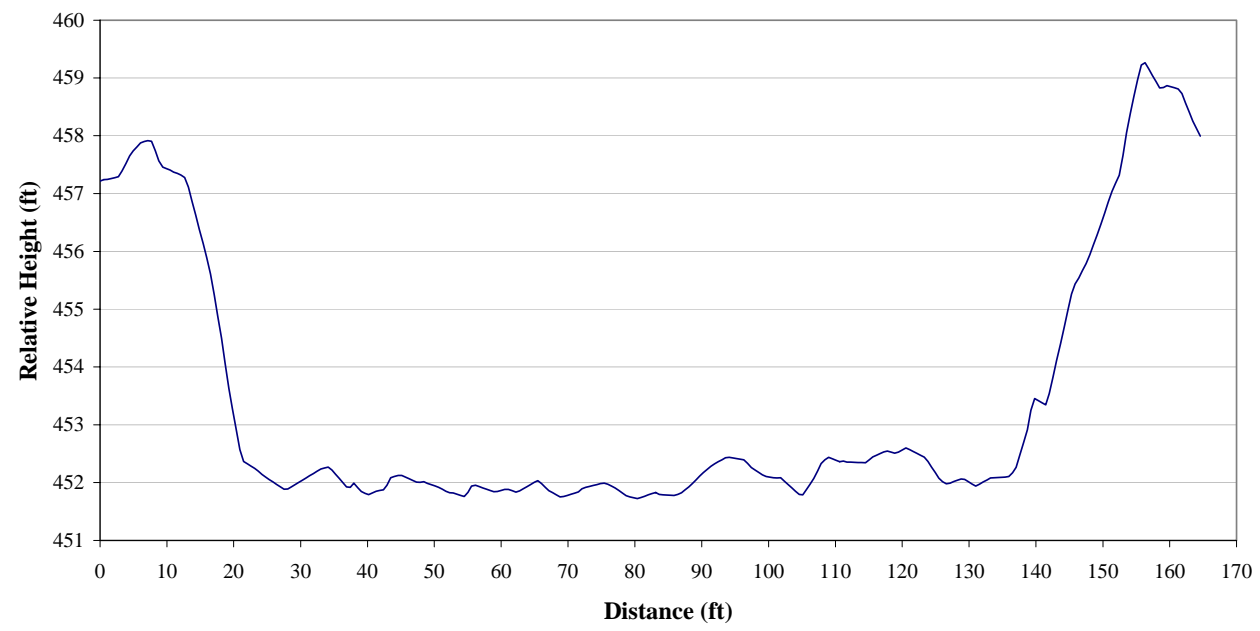

Figure A44. Site 18. Distance 0 is on the north bank. The water is from about distance 30 to 135 feet. No ground survey data available. 


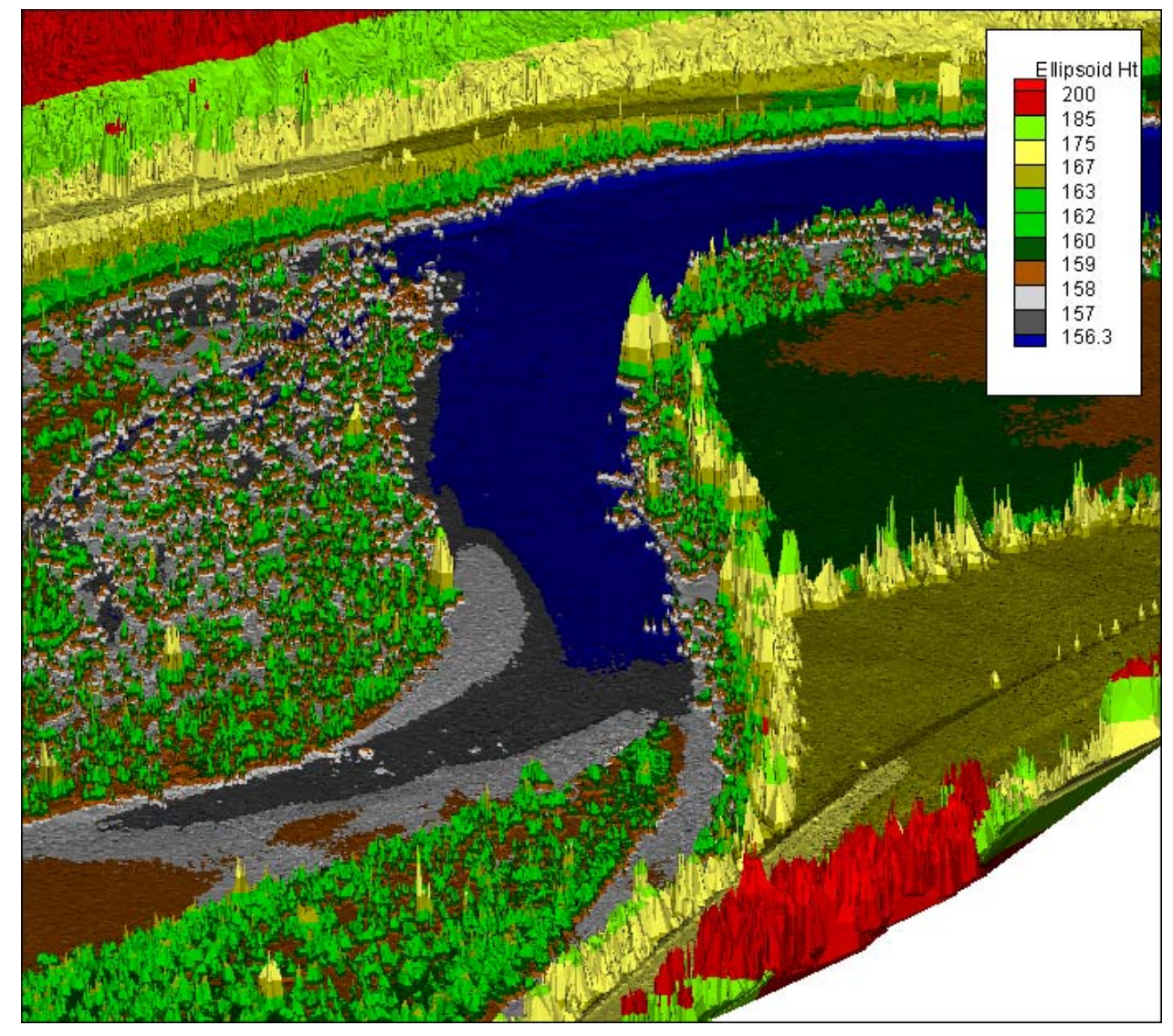

Figure A45. Site 19 ALSM looking north. 


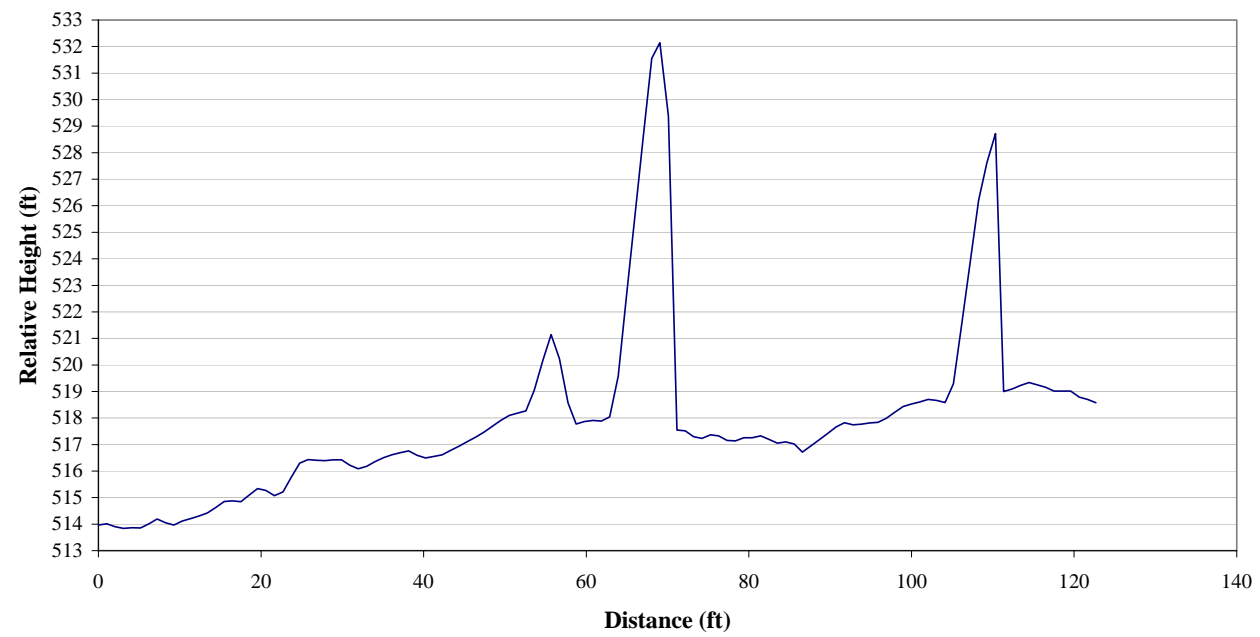

Figure A46. Site 19 east bank. Distance 0 is at water. The two tall spikes at about $\mathbf{7 0}$ and $\mathbf{1 1 0}$ feet are vegetation. No ground survey data available.

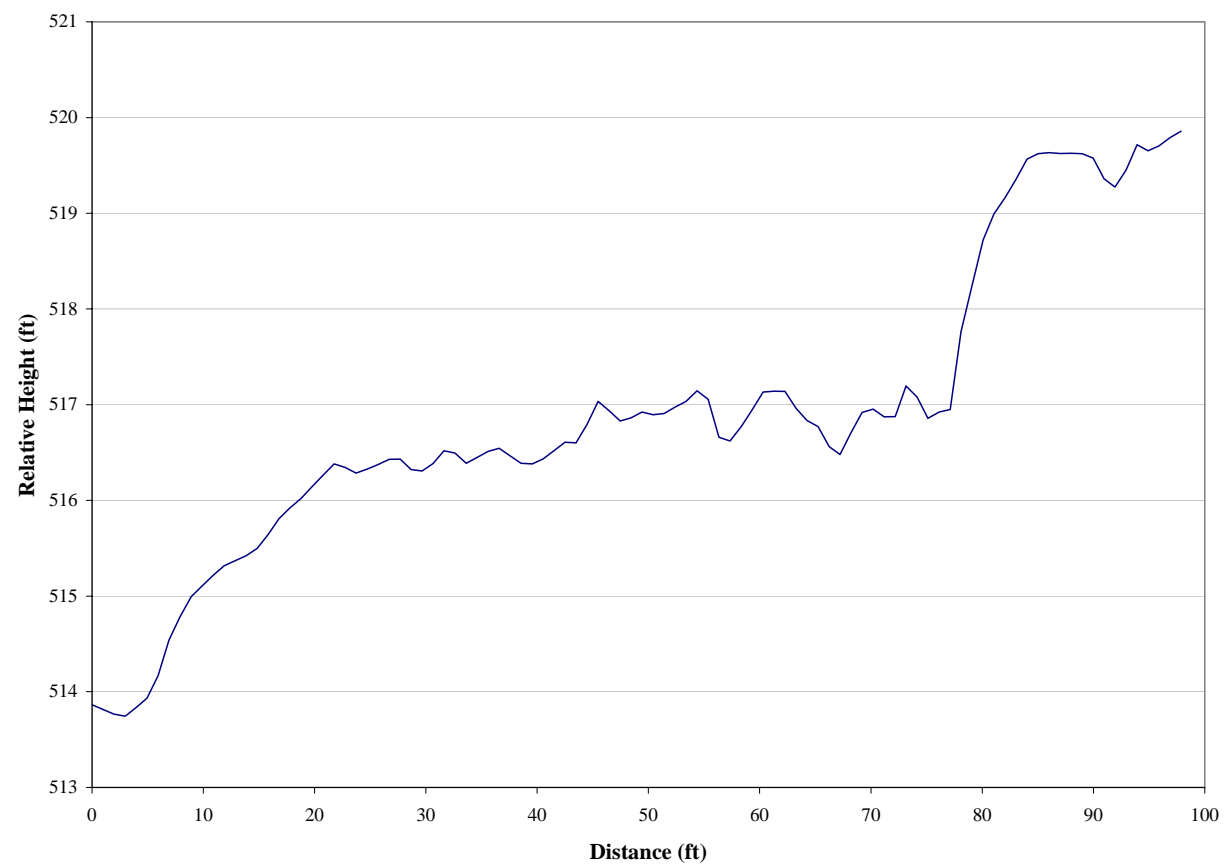

Figure A47. Site 19 west bank. Distance 0 is at water. No ground survey data available. 


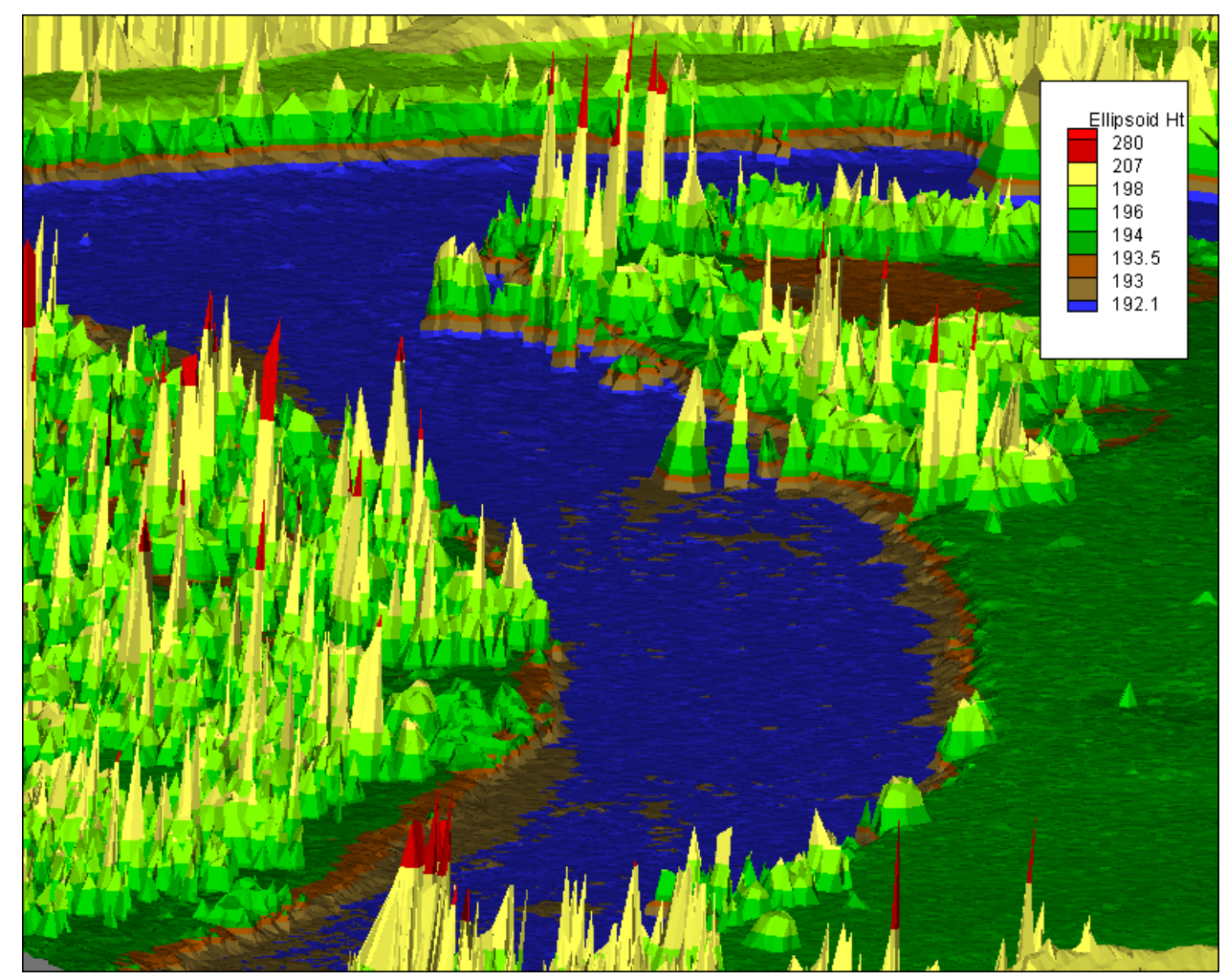

Figure A48. Site 20 ALSM looking southeast.

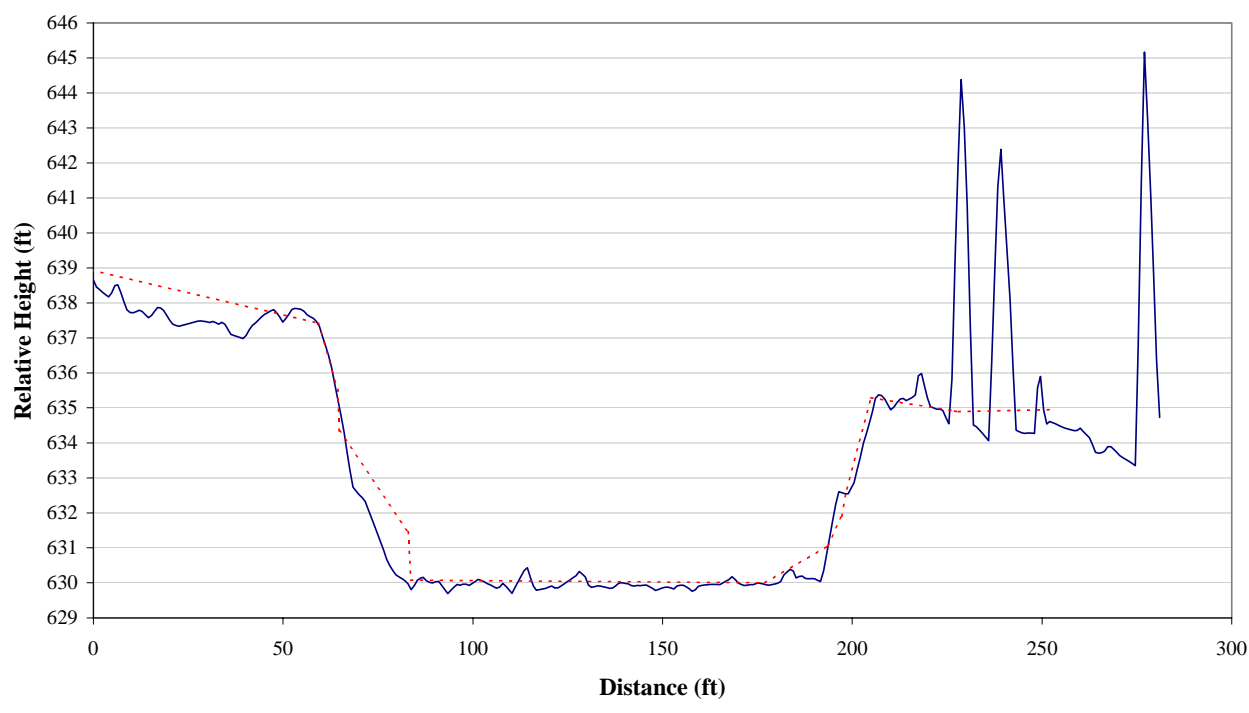

Figure A49. Site 20 ALSM and survey comparison. Distance 0 is on the southwest bank. The water surface is from about distance 85 to 190 feet. 


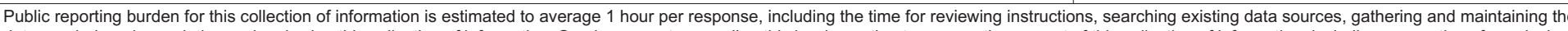

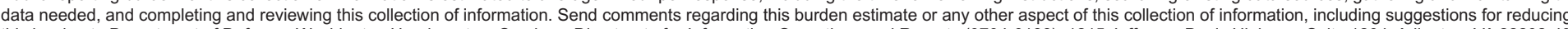

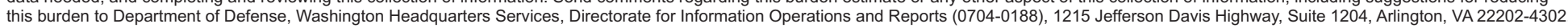

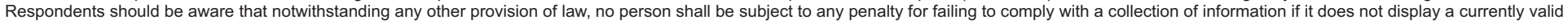
OMB control number. PLEASE DO NOT RETURN YOUR FORM TO THE ABOVE ADDRESS.
. REPORT DATE (DD-MM-YY)
July 2003
2. REPORT TYPE
Technical Report

4. TITLE AND SUBTITLE

Remote Assessment of Army Tactical

River Crossing Sites Using LIDAR Imagery
3. DATES COVERED (From - To)

5a. CONTRACT NUMBER

5b. GRANT NUMBER

5c. PROGRAM ELEMENT NUMBER

5d. PROJECT NUMBER

5e. TASK NUMBER

5f. WORK UNIT NUMBER

8. PERFORMING ORGANIZATION REPORT

ERDC/CRREL TR-03-11

10. SPONSOR / MONITOR'S ACRONYM(S)

11. SPONSOR / MONITOR'S REPORT NUMBER(S)

\section{DISTRIBUTION / AVAILABILITY STATEMENT}

Approved for public release; distribution is unlimited.

Available from NTIS, Springfield, Virginia 22161.

13. SUPPLEMENTARY NOTES

\section{ABSTRACT}

Tactical river crossings present impediments to Army units on the move because they require specialized procedures and equipment as well as more detailed planning and control than normal operations. A crossing site's suitability is highly dependant on riverbank geography. Commanders with accurate riverbank data can increase the speed of crossing operations, both by quickly and accurately determining appropriate sites and by minimizing the amount and type of equipment carried forward to effect the crossings. A previous study examined how conventional terrain analysis would be used to determine suitable crossing sites. In that study, there was a $16 \%$ acceptable site selection rate for remotely determined crossing sites. The most common problem, which was not detectable using conventional techniques, was that bank slope was too steep for vehicles to traverse. This study looks at using a Light Distance and Ranging (LIDAR) digital elevation model (DEM) to improve acceptable site selection rate. LIDAR data were collected at the sites identified in the previous study and inspected to see if the DEM would provide the information and resolution necessary to improve crossing site identification. The DEM was compared to selected onsite surveys and visual information collected previously to identify discrepancies. The LIDAR DEM analysis looked at 18 potential sites and resulted in an $88 \%$ acceptable site selection rate.

\begin{tabular}{|c|c|c|c|c|c|}
\hline 15. SUBJECT TERMS & \multicolumn{2}{|c|}{$\begin{array}{l}\text { Army bridging } \\
\text { Army fording } \\
\text { LIDAR }\end{array}$} & \multicolumn{3}{|c|}{$\begin{array}{l}\text { Tactical bridging } \\
\text { Tactical bridging site assessment } \\
\text { Tactical bridge sites }\end{array}$} \\
\hline \multicolumn{3}{|c|}{ 16. SECURITY CLASSIFICATION OF: } & 17. LIMITATION OF & 18. NUMBER & 19a. NAME OF RESPONSIBLE PERSON \\
\hline a. REPORT & b. ABSTRACT & c. THIS PAGE & & & 19b. TELEPHONE NUMBER (include area code) \\
\hline $\mathrm{U}$ & $\mathrm{U}$ & $\mathrm{U}$ & $\mathrm{U}$ & 66 & \\
\hline
\end{tabular}




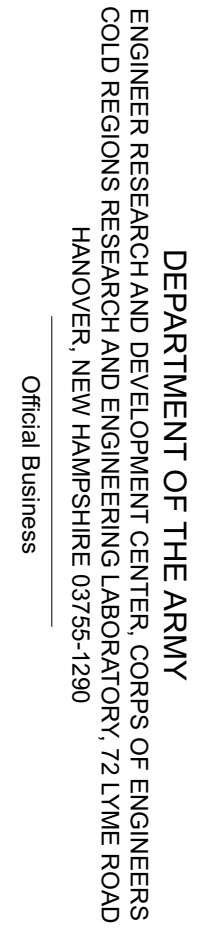

